Issued by Sandia National Laboratories, operated for the United States Department of Energy by Sandia Corporation.

NOTICE: This report was prepared as an account of work sponsored by an agency of the United States Government. Neither the United States Government, nor any agency thereof, nor any of their employees, nor any of their contractors, subcontractors, or their employees, make any warranty, express or implied, or assume any legal liability or responsibility for the accuracy, completeness, or usefulness of any information, apparatus, product, or process disclosed, or represent that its use would not infringe privately owned rights. Reference herein to any specific commercial product, process, or service by trade name, trademark, manufacturer, or otherwise, does not necessarily constitute or imply its endorsement, recommendation, or favoring by the United States Government, any agency thereof, or any of their contractors or subcontractors. The views and opinions expressed herein do not necessarily state or reflect those of the United States Government, any agency thereof, or any of their contractors.

Printed in the United States of America. This report has been reproduced directly from the best available copy.

Available to DOE and DOE contractors from

U.S. Department of Energy

Office of Scientific and Technical Information

P.O. Box 62

Oak Ridge, TN 37831

Telephone: (865)576-8401

Facsimile: (865)576-5728

E-Mail: reports@adonis.osti.gov

Online ordering: http://www.doe.gov/bridge

Available to the public from

U.S. Department of Commerce

National Technical Information Service

5285 Port Royal Rd

Springfield, VA 22161

Telephone: (800)553-6847

Facsimile: (703)605-6900

E-Mail: orders@ntis.fedworld.gov

Online order: http://www.ntis.gov/ordering.htm

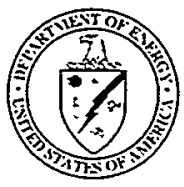




\section{DISCLAIMER}

Portions of this document may be illegible in electronic image products. Images are produced from the best available original document. 
SAND2000-2094

Unlimited Release

Printed August 2000

\title{
Application of the SmartSampling ${ }^{\mathrm{TM}}$ Methodology to the Evaluation of Contaminated Landscape Soils at Brookhaven National Laboratory
}

\author{
Christopher A. Rautman \\ Underground Storage Technology Department \\ Sandia National Laboratories \\ P. O. Box 5800 \\ Albuquerque, New Mexico 87185-0706
}

\begin{abstract}
Portions of the SmartSampling ${ }^{\mathrm{TM}}$ analysis methodology have been applied to the evaluation of radioactive contaminated landscape soils at Brookhaven National Laboratory. Specifically, the spatial, volumetric distribution of cesium-137 $\left({ }^{137} \mathrm{Cs}\right)$ contamination within Area of Concern $16 \mathrm{E}-1$ has been modeled probabilistically using a geostatistical methodology, with the purpose of identifying the likelihood of successfully reducing, with respect to a pre-existing, baseline remediation plan, the volume of soil that must be disposed of offsite during clean-up. The principal objective of the analysis was to evaluate the likelihood of successful deployment of the Segmented Gate System (SGS), a novel remediation approach that emphasizes real-time separation of clean from contaminated materials during remediation operations. One primary requirement for successful application of the segmented gate technology investigated is that a variety of contaminant levels exist at the deployment site, which would enable to the SGS to discriminate material above and below a specified remediation threshold value.

The results of this analysis indicate that there is potential for significant volume reduction with respect to the baseline remediation plan at a threshold excavation level of $23 \mathrm{pCi} / \mathrm{g}{ }^{137} \mathrm{Cs}$. A reduction of approximately 50 percent, from a baseline volume of approximately $1,064.7 \mathrm{yd}^{3}$ to less than $550 \mathrm{yd}^{3}$, is possible with acceptance of only a very small level of engineering risk. The vast majority of this volume reduction is obtained by not excavating almost all of levels 3 and 4 (from 12 to 24 inches in depth), which appear to be virtually uncontaminated, based on the available data. Additional volume reductions related to soil materials on levels 1 (depths of $0-6$ inches) and 2 (6-12 inches) may be possible, specifically through use of the SGS technology. Level-bylevel evaluation of simulation results suggests that as much as 26 percent of level 1 and as much as 65 percent of level 2 soils may actually be uncontaminated. Additionally, numerical experiments have been conducted to investigate the effects of selective excavation on the volume and average activity of the remediated materials. These numerical experiments indicate that nonselective excavation may result in mixing of contaminated and uncontaminated materials such that the total volume of material above the threshold excavation level of $23 \mathrm{pCi} / \mathrm{g}$ may exceed the baseline volume, thus defeating volume-reduction efforts.
\end{abstract}


This page intentionally left blank 


\section{Table of Contents}

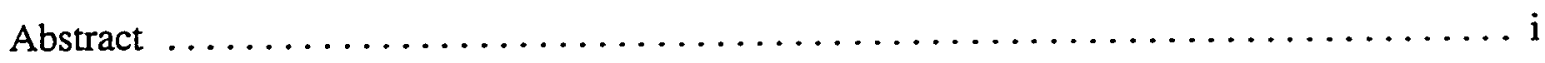

Table of Contents $\ldots \ldots \ldots \ldots \ldots \ldots \ldots \ldots \ldots \ldots \ldots \ldots \ldots \ldots \ldots \ldots \ldots \ldots \ldots \ldots \ldots$

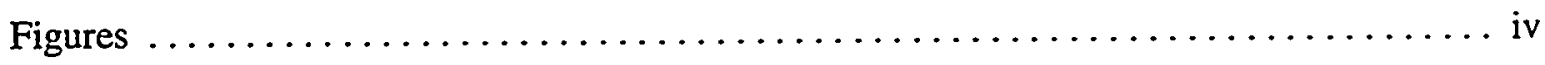

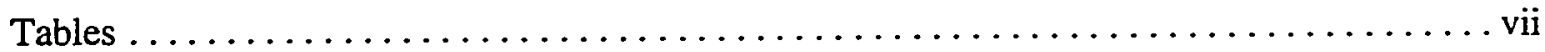

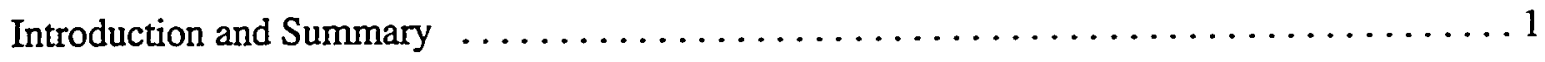

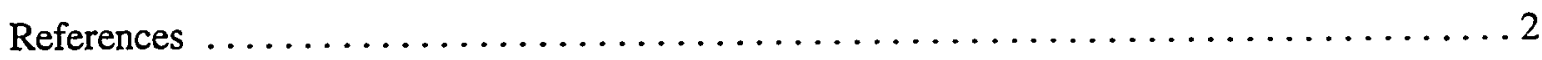

Report 1: Application of SmartSampling ${ }^{\mathrm{TM}}$ Methodology to the Evaluation of Contaminated Landscape Soils

at Brookhaven National Laboratory

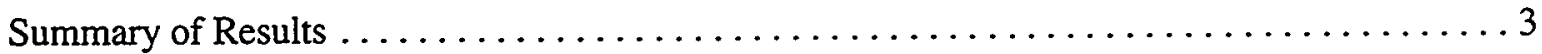

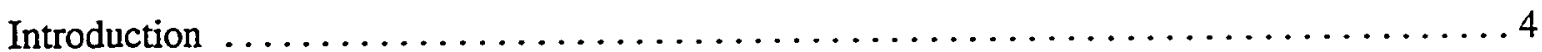

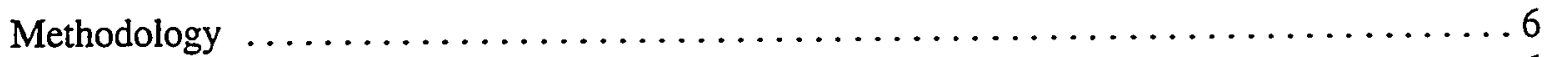

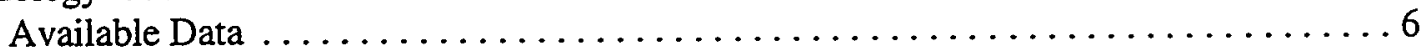

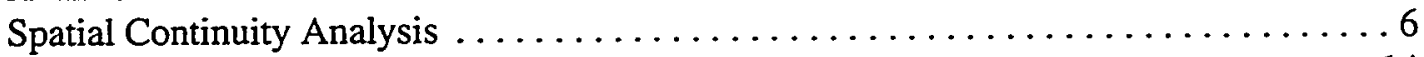

Conversion of the Mower Measurements to Secondary Data $\ldots \ldots \ldots \ldots \ldots \ldots 14$

Simulated Models of Contaminant Distribution $\ldots \ldots \ldots \ldots \ldots \ldots \ldots \ldots \ldots \ldots \ldots \ldots \ldots \ldots$

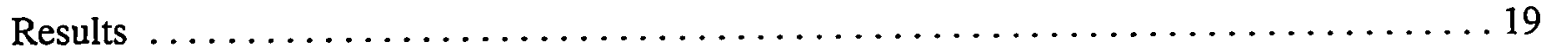

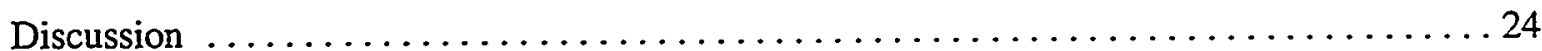

Remarks Emphasizing the Segmented Gate Technology $\ldots \ldots \ldots \ldots \ldots \ldots \ldots 28$

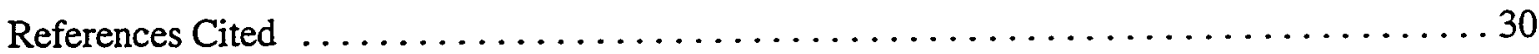

Report 2: Influence of Selective Excavation

on Contaminated Soil Volumes at Area 16E-1,

Brookhaven National Laboratory

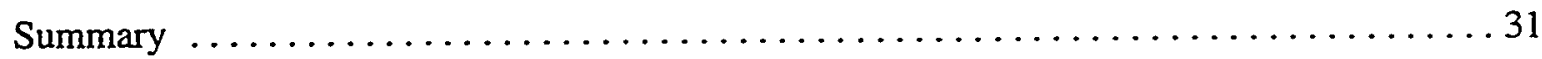

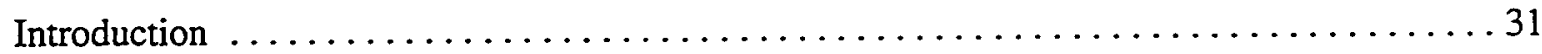

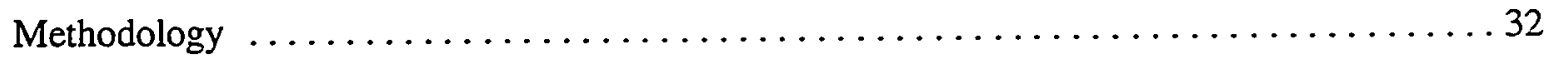

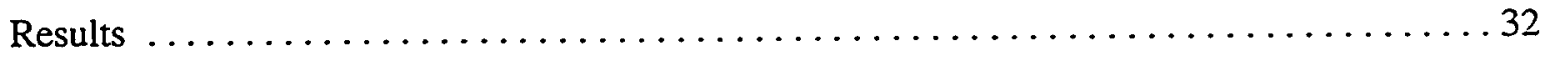

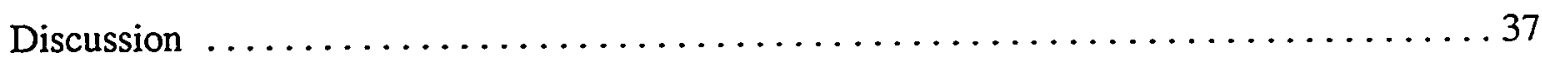

August $2000 \quad$ iii 


\section{Figures}

Report 1: Application of SmartSampling ${ }^{\mathrm{TM}}$ Methodology

to the Evaluation of Contaminated Landscape Soils

at Brookhaven National Laboratory

Figure 1. Field photographs of (a) collecting soil profiles for laboratory measurement of ${ }^{137} \mathrm{Cs}$ activity (with detail showing size of the refilled hole) and (b) collecting "mower" radiometric measurements of ${ }^{137} \mathrm{Cs}$ contamination in situ (with detail showing calibration pan of roughly equivalent size to soil sample) $\ldots \ldots \ldots \ldots \ldots \ldots \ldots \ldots \ldots$

Figure 2. Location maps showing locations of 17 soil samples on depth levels 1 [images (a), (b)] and 2 [image (c)]. . . . . . . . . . . . . . 7

Figure 3. Location maps showing locations of 17 soil samples on depth levels 3 [image (a)] and 4 [image (b)]. .8

Figure 4. Vertical profiles of 68 soil sample values (symbols). . . . . . . . . . 9

Figure 5. Histogram and descriptive statistics of the 68 soil sample measurements. . . . 10

Figure 6. Location map showing 5,527 "mower" radiometric measurements of ${ }^{137} \mathrm{Cs}$ activity in BNL Area $16 \mathrm{E}-1$.

Figure 7. Histogram and statistical summary of the mower radiometric data.

Figure 8. Normal-scores variograms computed using the 68 soil measurements

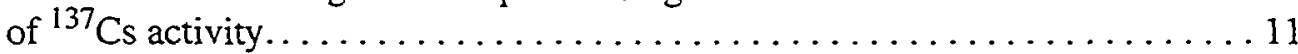

Figure 9. Activity variograms computed using the 5,527 mower radiometric measurements of ${ }^{137} \mathrm{Cs}$ activity in $\mathrm{pCi} / \mathrm{g}$ in the directions of maximum and minimum spatial correlation.

Figure 10. Omnidirectional variogram computed for the 5,527 mower measurements of ${ }^{137} \mathrm{Cs}$ activity.

Figure 11. Estimated mower value kriged onto a regular grid prior to simulation.

Figure 12. Kriged map of the mower data masked by the baseline excavation boundary.

Figure 13. (a) Nonlinear regression of soil ${ }^{137} \mathrm{Cs}$ activity vs. depth for the soil profile data set. (b) Residuals from the profile-specific predictions of soil sample values in figure 4 . 
Figure 14. Vertical profiles of the 68 soil sample values, fitted by the nonlinear regression relationship of equation (1).

Figure 15. Correlation of collocated (nearest-neighbor) mower measurements and soil activity values.

Figure 16. Views of a representative simulation of ${ }^{137} \mathrm{Cs}$ activity at Area $16 \mathrm{E}-1$ at three of the four depth levels considered in this analysis. ........... 20

Figure 17. Probability maps showing the likelihood of exceeding (a) $23 \mathrm{pCi} / \mathrm{g}$ and (b) $200 \mathrm{pCi} / \mathrm{g}$ for each $0.5-\mathrm{m} \times 0.5-\mathrm{m}$ remediation panel on level 1 (0-6 inches depth).

Figure 18. Probability maps showing the likelihood of exceeding (a) $23 \mathrm{pCi} / \mathrm{g}$ and (b) $200 \mathrm{pCi} / \mathrm{g}$ at each $0.5-\mathrm{m} \times 0.5-\mathrm{m}$ remediation panel on level 2

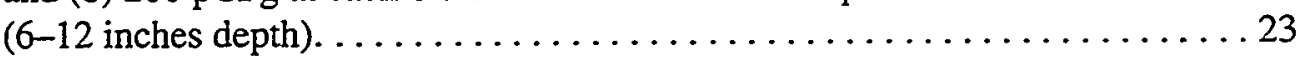

Figure 19. Probability maps showing the likelihood of exceeding (a) $23 \mathrm{pCi} / \mathrm{g}$ at each $0.5-\mathrm{m} \times$ 0.5-m remediation panel on level 3 (12-18 inches depth). . . . . 24

Figure 20. Estimates of the volume of contaminated soil at BNL Area 16E-1 as a function of the acceptable reliability level, compared with the baseline estimate of contaminated volume, for two different modeling

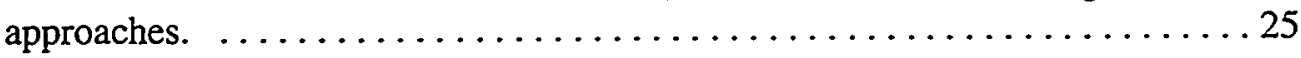

Figure 21 . Estimates of total ${ }^{137} \mathrm{Cs}$ Inventory at the BNL Area $16 \mathrm{E}-1$ site. . . . . . 26

Figure 22. Excavation maps for BNL Area 16E-1, levels 1 (a), 2 (b), and 3 (c), generated using a reliability level of 0.95 .

Figure 23. Histograms of simulated contaminant activities on levels 1 [(a), (b)

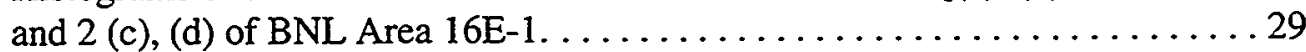

Figure 24. Excavation map for BNL Area 16E-1, level 2, generated using an acceptable reliability level of 0.75 (probability of failure $=0.25$ ).

\section{Report 2: Influence of Selective Excavation on Contaminated Soil Volumes at Area 16E-1, Brookhaven National Laboratory}

Figure 1. Excavation maps (red = dig) for levels 1 [image (a)], 2 [image (b)], and 3 [image (c)], for the $1 \times 1 \times 1$ non-upscaled models, 95 -percent reliability level. 
Figure 2. Excavation maps ( $\mathrm{red}=\mathrm{dig}$ ) for levels 1 [image (a)], 2 [image (b)], and 3 [image (c)], for the $4 \times 4 \times 1$ upscaled models, 95-percent reliability level. . 35

Figure 3. Excavation maps (red $=\mathrm{dig}$ ) for levels $1-2$ [image (a)] and 3-4 [image (b)] for the $4 \times 4 \times 2$ upscaled models, 95-percent reliability level. 36

Figure 4. Excavation map (red $=$ dig) for levels $1-4$ for the $4 \times 4 \times 4$ upscaled models, 95-percent reliability level.

Figure 5. Excavation maps (red = dig) for levels 1-2 [image (a)], and 3-4 [image (b)] for the $8 \times 8 \times 2$ upscaled models, 95-percent reliability level.

Figure 6. Excavation map (red $=$ dig) for levels $1-4$ for the $8 \times 8 \times 4$ upscaled models, 95-percent reliability level.

Figure 7. Contaminant volumes at different levels of selective excavation (degrees of upscaling), computed at a threshold ${ }^{137} \mathrm{Cs}$ activity of $23 \mathrm{pCi} / \mathrm{g}$ and at 95-percent reliability. 


\section{Tables}

Report 1: Application of SmartSampling ${ }^{\mathrm{TM}}$ Methodology to the Evaluation of Contaminated Landscape Soils at Brookhaven National Laboratory

Table 1: Summary of Variogram Ranges for Soil and Mower Data $\ldots \ldots \ldots \ldots \ldots 12$

Report 2: Influence of Selective Excavation on Contaminated Soil Volumes at Area 16E-1, Brookhaven National Laboratory

Table 1: Summary of Results for Numerical Upscaling Experiments . . . . . . . . 40 
This page intentionally left blank. 


\title{
Application of the SmartSampling ${ }^{\mathrm{TM}}$ Methodology to the Evaluation of Contaminated Landscape Soils at Brookhaven National Laboratory
}

\author{
INTRODUCTION AND SUMMARY
}

This Sandia report contains the very slightly revised and expanded text of two informal reports that were written in very late 1999 to support a decision to apply the Segmented Gate System (SGS) technology to the remediation of contaminated landscape soils at Brookhaven National Laboratory as part of Sandia's participation in the Accelerated Site Technology Deployment (ASTD) Program initiative. The reports are being collected and published in this format to archive the work that was done at that time. The Segmented Gate System is a novel remediation technology that allows real-time physical separation of radioactively contaminated soil materials from those which are below a specified activity threshold. Successful application of the SGS technology is predicated, in part, on there being a variety of levels of radioactivity spatially distributed throughout a contaminated site. Essentially homogeneous contaminated materials cannot be processed effectively using the Segmented Gate.

The approach used to support this decision regarding deployment of the SGS is to apply selected portions of the SmartSampling ${ }^{\mathrm{TM}}$ modeling methodology to make probabilistic predictions of the magnitude and spatial variability of contaminants at the Brookhaven site. Relatively rigorously measured values of cesium-137 $\left({ }^{137} \mathrm{Cs}\right)$ contamination obtained from a small number of shallow soil profiles were combined with a much larger number of surficial radiometric measurements of ${ }^{137} \mathrm{Cs}$ of lower reliability to produce a suite of geostatistically simulated models of the nature and extent of contamination. This suite of simulated models, all of which are geologically plausible and consistent with the measured information, were then postprocessed to make probabilistic statements concerning the heterogeneity and absolute magnitudes of contaminated soils for relatively small ( $1-\mathrm{m} \times 1-\mathrm{m} \times 6$-inch) soil volumes in three dimensions. The results of this portion of the analysis were twofold: (1) The probability of contamination throughout the deeper portions of the evaluated site is so low that significant volumes of soils (with respect to the predefined baseline excavation plan) almost certainly need not be excavated. (2) There are relatively large portions of the shallower portions of the evaluated site that are likely to be below the proposed excavation threshold, but for which the locations cannot be predicted confidently using the existing data sets. These volumes of effectively uncontaminated material are ideal candidates for real-time separation from contaminated material using the SGS.

Because the mechanized equipment likely to be used for actual excavation of the contaminated landscape soils is anticipated to deal with much larger physical volumes than the resolution of the geostatistical modeling grid, initial work was expanded to consider the potential impacts of more-or-less selective excavation practices on the volume-reduction estimates. This analysis consists of a number of relatively simplistic numerical upscaling experiments using the suite of geostatistical simulations generated for the first part of the analysis. The results of this portion of the analysis indicated that a certain degree of selective excavation is, indeed, necessary to achieve the volume reductions identified in the first part of the analysis. Selectivity in the depth dimension appears to be particularly critical to successful deployment of the SGS processing technology. 


\section{REFERENCES}

The reports contained within this Sandia document were written with a minimum of scholarly trappings, which includes references and citations of one form or another. The following are several references that will provide the interested reader with background material on the Brookhaven landscape-soil problem, the Segmented Gate System technology, SmartSampling ${ }^{\mathrm{TM}}$, and some general textbooks on geostatistical modeling in general. Note that the content of pages on the world-wide web are subject to change without notice; however, the listed sites were current as of the date of publication of this report.

CDM Federal Programs Corp. Final Remedial Action Work Plan, Area of Concern16, Landscape Soil. Brookhaven National Laboratory. April 13, 2000.

CDM Federal Programs Corp. Final Remedial Action Field Sampling Plan, Area of Concern 16, Landscape Soil. Brookhaven National Laboratory. April 13,2000.

Deutsch, C.V., and Journel, A.G., 1998, GSLIB geostatistical software library and user's guide, New York: Oxford University Press, 369 p.

Goovaerts, P., Geostatistics for natural resources evaluation, New York: Oxford University Press, $483 \mathrm{p}$.

Segmented Gate System - http://www.csu821.sandia.gov/organization/div6000/ctr6100/ 6131SGS/organization/div6000/ctr6100/6131SGS/snlweb3.htm

SmartSampling ${ }^{\mathrm{TM}}$ - http://www.nwer.sandia.gov/sample/index.html 


\title{
Application of SmartSampling ${ }^{\mathrm{TM}}$ Methodology to the Evaluation of Contaminated Landscape Soils at Brookhaven National Laboratory
}

\author{
Christopher A. Rautman \\ Sandia National Laboratories \\ Albuquerque, New Mexico 87185
}

\section{Summary of Results}

Portions of the SmartSampling TM analysis methodology have been applied to the evaluation of radioactive contaminated landscape soils at Brookhaven National Laboratory. Specifically, the spatial, volumetric distribution of cesium- $137\left({ }^{137} \mathrm{Cs}\right)$ contamination within Area of Concern $16 \mathrm{E}-1$ has been modeled probabilistically using a geostatistical methodology, with the purpose of identifying the likelihood of successful reducing, with respect to a pre-existing, baseline remediation plan, the volume of soil that must be disposed of offsite during clean-up. The analysis is not a complete application of SmartSampling ${ }^{\mathrm{TM}}$, in that costs of characterization, remediation, and potential failure were not considered. Rather, the principal objective of the analysis was to evaluate the likelihood of successful deployment of the Segmented Gate System (SGS), a novel remediation approach that emphasizes real-time separation of clean from contaminated materials during remediation operations. One primary requirement for successful application of the segmented gate technology investigated is that a variety of contaminant levels exist at the deployment site. This range and distribution of values would enable to the SGS to discriminate material above and below a specified remediation threshold value.

The results of this analysis indicate that there is potential for significant volume reduction with respect to the baseline remediation plan at a threshold excavation level of $23 \mathrm{pCi} / \mathrm{g}{ }^{137} \mathrm{Cs}$. A reduction of approximately 50 percent, from a baseline volume of approximately $1,064.7 \mathrm{yd}^{3}$ to less than $550 \mathrm{yd}^{3}$, is possible with acceptance of only a very small level of engineering risk. The vast majority of this volume reduction is obtained by not excavating almost all of levels 3 and 4 (from 12 to 24 inches in depth), which appear to be virtually uncontaminated, based on the available data.

Additional volume reductions related to soil materials on levels 1 (depths of $0-6$ inches) and 2 (6-12 inches) may be possible, specifically through use of the SGS technology. Although probabilistic modeling of contamination on these two levels indicates virtually certain contamination throughout level 1 and only small regions of likely uncontaminated soil on level 2 at generally acceptable reliability levels, more detailed analysis of potential contaminant distributions on these two levels suggests that the usual probabilistic risk constraints might be relaxed markedly if the additional soil volume thus identified as "less-likely to be contaminated" is processed through the SGS for real-time determination of the true contamination level. Level-by-level evaluation of simulation results suggests that as much as 26 percent of level 1 and as much as 65 percent of level 2 soils may actually be uncontaminated.

Combining these two volume-reduction scenarios results in a volume reduction of approximately 70 percent, from $1,074.7 \mathrm{yd}^{3}$ to approximately $290 \mathrm{yd}^{3}$. Note that this reduction may be accomplished without the additional costs of treating the entire baseline volume with the SGS. 


\section{Introduction}

Contaminated landscape soils containing the radioactive isotope, cesium-137 $\left({ }^{137} \mathrm{Cs}\right)$, have been identified at several locations at Brookhaven National Laboratory (BNL) on Long Island, New York. Excavation of these contaminated soils, followed by off-site disposal of the contaminated material has been proposed as the remedial option. A baseline excavation plan has been developed, based on a remedial action level of $23 \mathrm{pCi} / \mathrm{g}$.

It has been proposed to reduce the volume of soil required to be shipped for offsite disposal through use of the Segmented Gate System (SGS), a novel remediation technology that allows rapid, real-time analysis of excavated materials, with soil that exceeds a specified activity level being physically separated from other materials that do not exceed this level. Separation occurs as the material is processed along a conveyor-belt system. Remediation costs for transportation and offsite disposal would thus be reduced over the baseline cost estimate, albeit at the additional costs involved in the SGS processing.

One requirement for successful deployment of the SGS at any site is that there must be a certain degree of variation in the contaminant levels of relatively small volumes of soil material. If the contamination is completely homogeneous, no volume reduction would be possible, as the entire mass of material would assay (presumably) above the action level. However, if some volumes are markedly above threshold whereas other volumes are below, the SGS technology may allow cost-efficient separation of these two types of material during excavation without greatly increased costs for prior characterization of the exact locations of the different classes of materials.

In order to assess the likelihood of a successful deployment of the segmented gate system at Brookhaven, certain probabilistic modeling analyses normally considered part of the SmartSampling ${ }^{\mathrm{TM}}$ methodology were conducted for BNL Area of Concern 16E-1, one of the largest and presumably most contaminated of the various landscape-soil sites. These analyses considered a limited number of soil-profile samples taken to a depth of 2 feet ( 24 inches), which were analyzed in a small-scale mock-up of the actual SGS scintillation-counter configuration. These data are considered quite reliable with respect to the actual magnitude of ${ }^{137} \mathrm{Cs}$ activity present in the soil, and they are referred to as the "primary" data in this report. Additionally, a very large number of surface radiometric measurements of ${ }^{137} \mathrm{Cs}$ activity were made in the field. Because the counting configuration of these radiometric measurements, referred to as the "mower" data, is not as carefully controlled as the measurement set-up for the soil-profile samples, these values are judged less reliable and are treated as "secondary" data in this analysis.

Figure 1 presents field photographs of sampling activities at BNL area 16E-1. Figure 1(a) shows collection of one of the soil-profile samples using a posthole digger. The completed hole is roughly one-foot "square," and samples were collected in 6-inch increments. Figure 1(b) is a photograph of the so-called mower detector in operation. Radiometric measurements are collected over two-second intervals as the "mower" moves at a ground speed of 30 feet per minute The "area" represented by each measurement is thus approximately one foot square. The "support volume" associated with each type of measurement is thus approximately equivalent. 
(a)
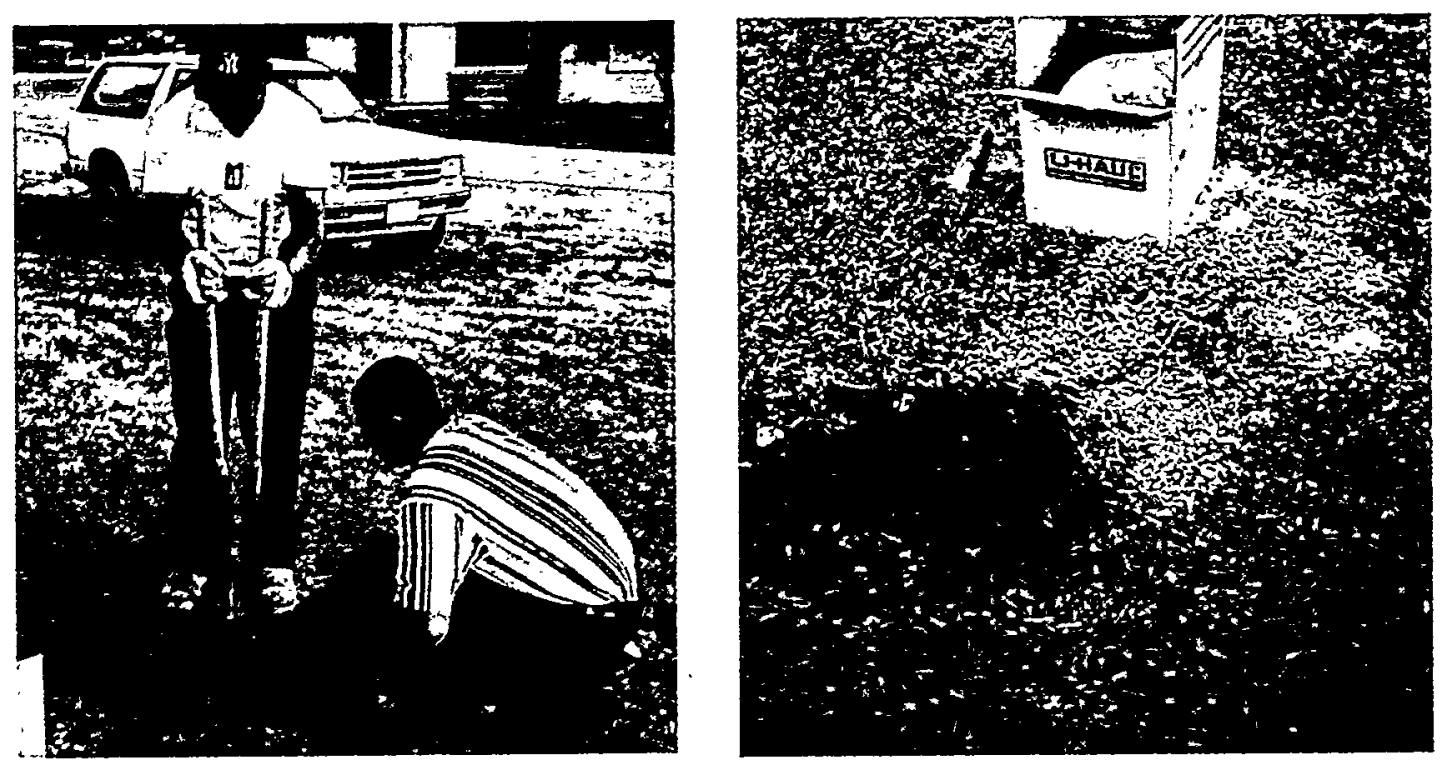

(b)
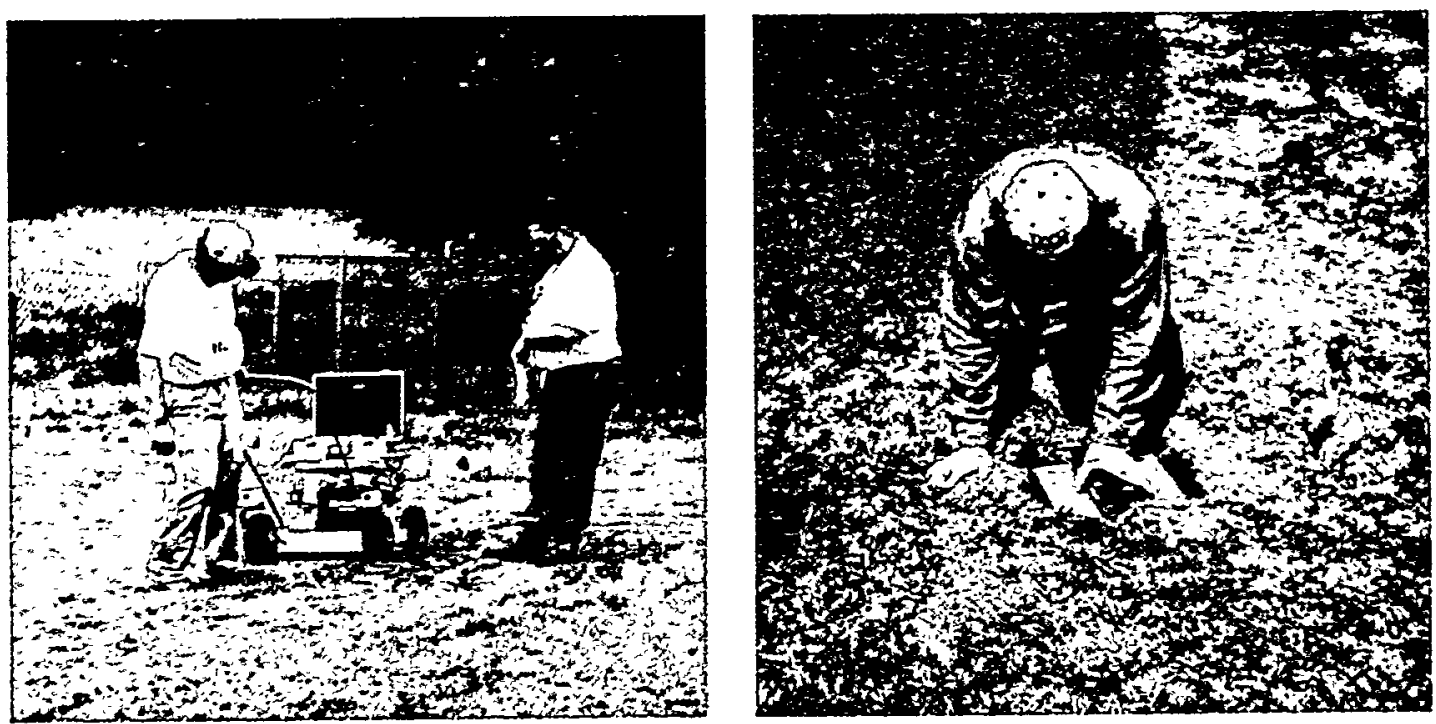

Figure 1. Field photographs of (a) collecting soil profiles for laboratory measurement of ${ }^{137} \mathrm{Cs}$ activity (with detail showing size of the refilled hole) and (b) collecting "mower" radiometric measurements of ${ }^{137} \mathrm{Cs}$ contamination in situ (with detail showing calibration pan of roughly equivalent size to soil sample) 


\section{Methodology}

\section{Available Data}

Figures 2 and 3 show the spatial locations and activity values of the 17 sets of soil-profile samples obtained from Area 16E-1. Each soil profile consists of four individual samples representing a 6-inch $(0.1524-\mathrm{m})$ increment of soil approximately 1 -foot square down to a depth of 24 inches $(0.61 \mathrm{~m})$. The successively deeper soil samples are referred to as representing levels 1 (near surface) to 4 (deepest), and the samples are assigned a depth location corresponding to the midpoint of each 6 -inch increment. Figure 4 shows the $68(=17 \times 4)$ soil samples in profile view. Figure 5 presents a histogram of the 68 soil measurements.

Figure 6 shows the location and final, calibrated activity values of the 5,527 mower radiometric measurements on the ground surface. A histogram of these values is presented in figure 7. There are actually several other items of note concerning the mower data (fig. 6). First, the outline of the maximum extent of the mower measurements does not precisely reflect the baseline excavation boundary. Our understanding is that small-scale local topography is responsible to some extent for this difference in outline. Second, we note that there are several instances of elevated ${ }^{137} \mathrm{Cs}$ readings in the mower data set that occur outside the limits of the baseline excavation boundary. These extra-boundary regions of contamination have not been modeled as part of this exercise. And third, we note that the mower measurements underwent three different calibration attempts. This accounts for the indication of "Rev.3," or similar notations on some figures, and indicates that the most recent version of the mower data was used in this modeling.

\section{Spatial Continuity Analysis}

Standard variograms were computed for both the soil profile values (in transformed normal-score space; Deutsch and Journel, 1998) and the mower data (in cesium-activity space). Only an omnidirectional variogram could be obtained for the soil data because the small number of samples limits the number of data pairs available for the calculation. However, the large number of mower radiometric values available allows a relatively thorough assessment of horizontal anisotropy, at least as it exists on the ground surface. Figure 8 presents the resulting variograms for the soil data; the omnidirectional variogram in the horizontal plane is presented in part (a) and for the vertical profiles in part (b). Figure 9 presents the horizontal variograms for the surficial mower data. There is a moderate degree of anisotropy apparent in the full set of directional variograms. The maximum direction of continuity is at an azimuth of approximately 120 degrees or at $\mathrm{S} 60^{\circ} \mathrm{E}$, with a minimum direction of continuity at $90^{\circ}$ to that, or at $\mathrm{N} 30^{\circ} \mathrm{E}$. This anisotropy may be observed in the data location map of figure 6. Nested spherical variogram models have been fitted to each of these experimental variograms, and the parameters of these models are shown on the figures: the variogram parameters are repeated in table 1.

The spatial modeling process requires a single input model of spatial continuity in three dimensions, yet we have two different variograms that are incomplete (for the mower data, two dimensions only; fig. 9) or only imperfectly defined (for the soil data, based on only 68 samples; fig. 8). We need to reconcile these two similar-yet-different-in-detail spatial models in a manner that captures relevant spatial features of the single variable of interest, namely ${ }^{137} \mathrm{Cs}$ activity. 

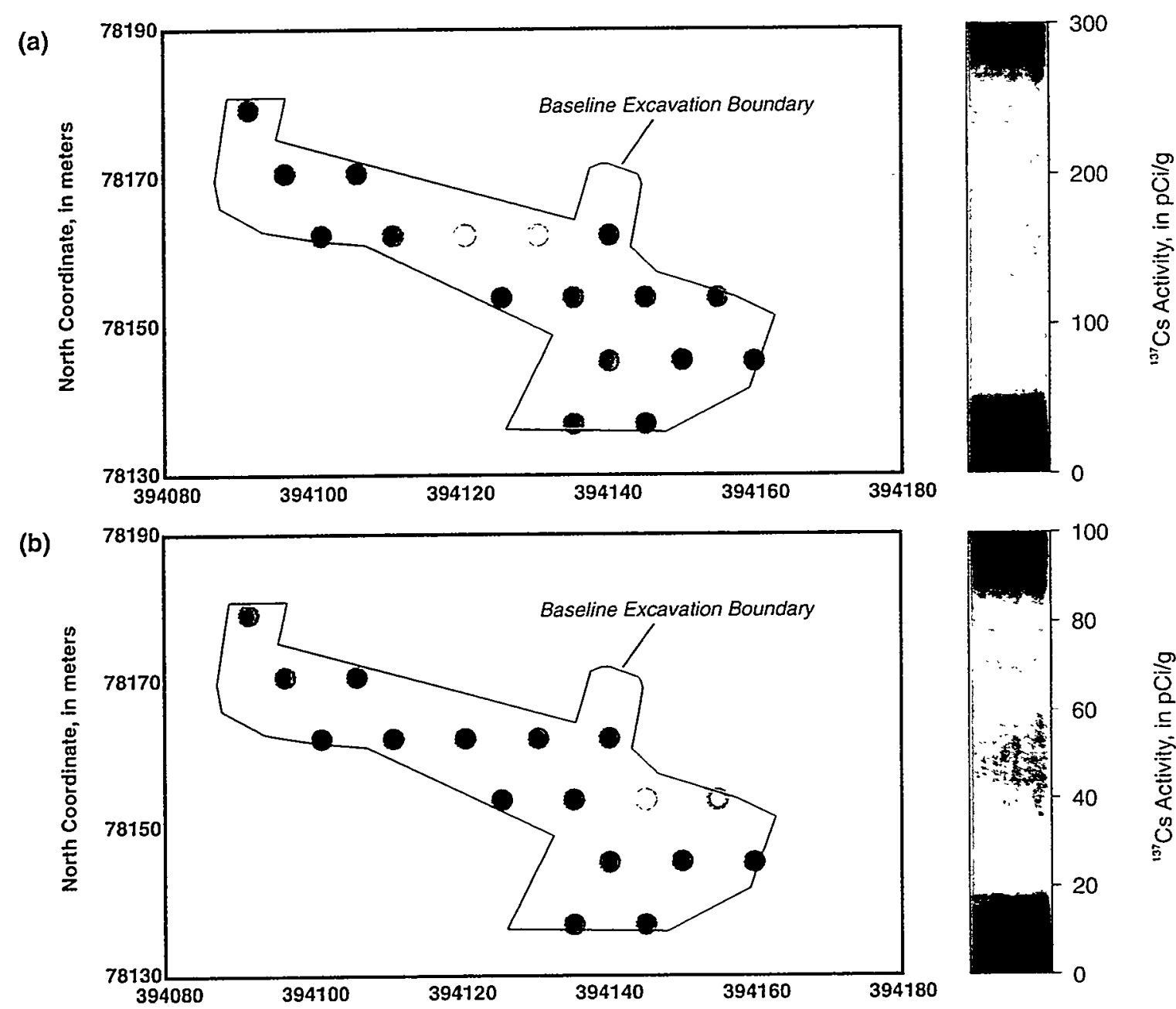

(c)

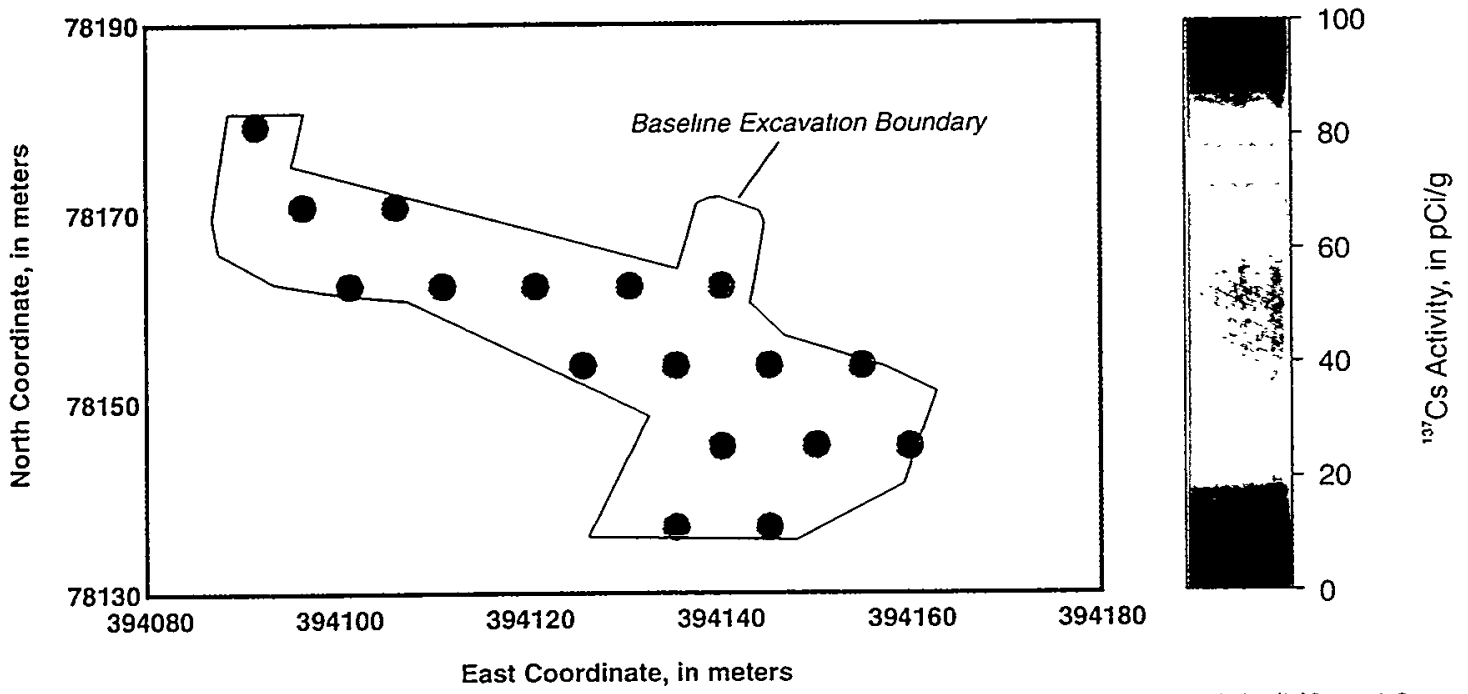

Figure 2. Location maps showing locations of 17 soil samples on depth levels 1 [images (a), (b)] and 2 [image (c)]. Samples are color coded according to activity level in pCi/g. Coordinates are in meters. Note change of color scales for level 1 [images (a), (b)]; image (b) uses the color scale common to levels $2-4$. 
(a)

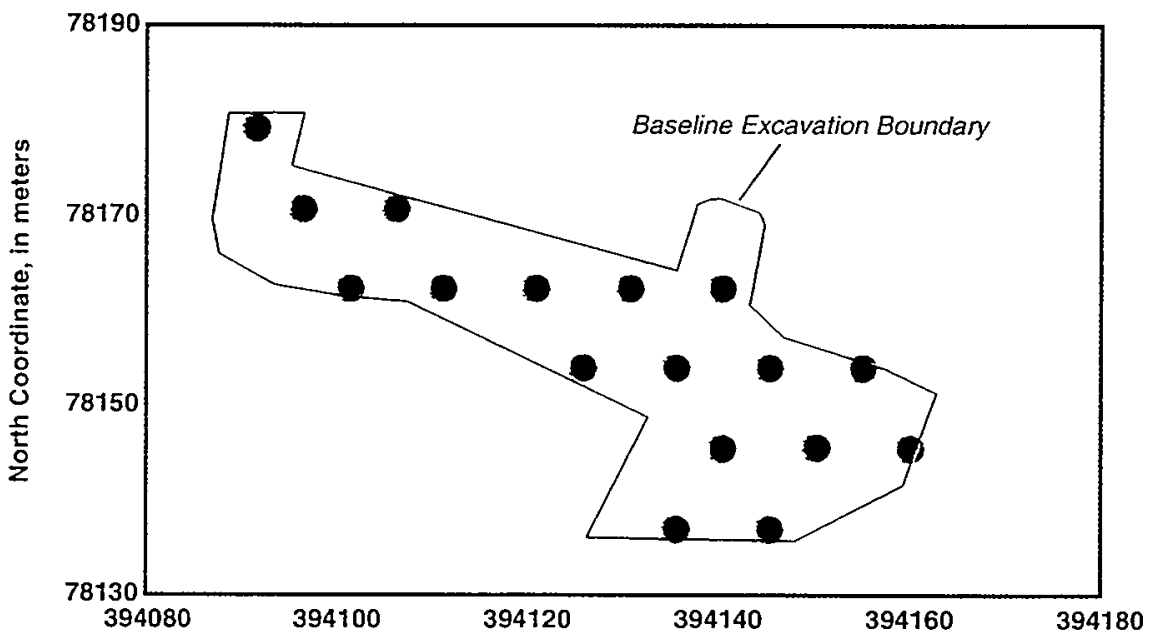

(b)

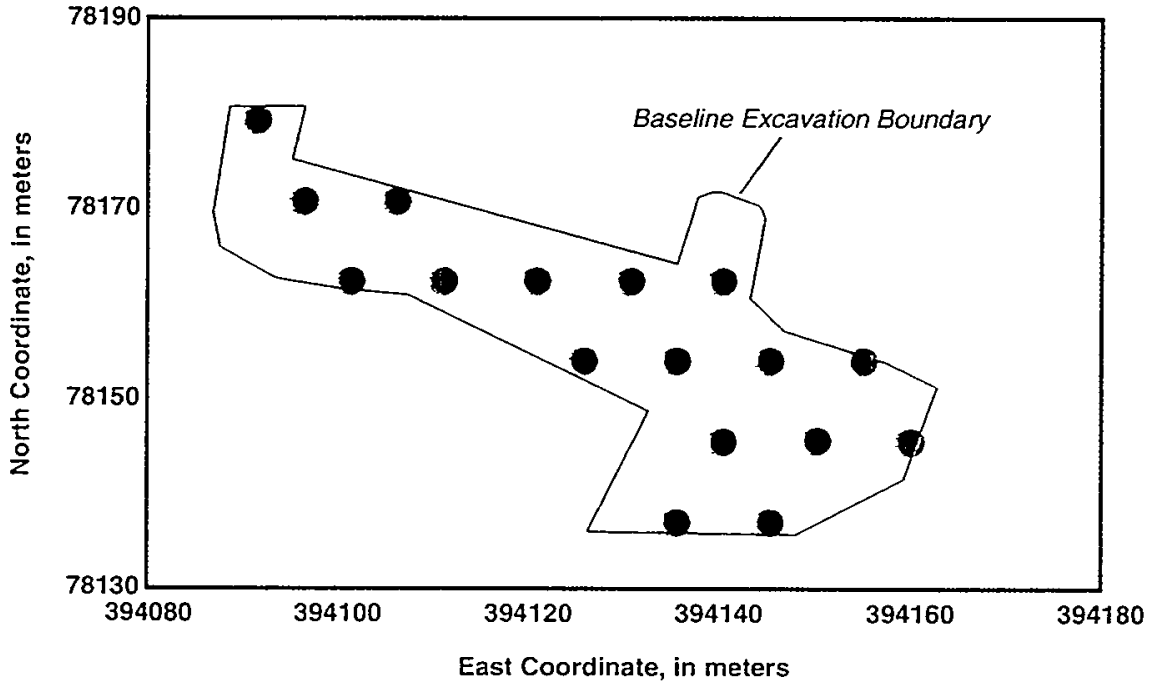

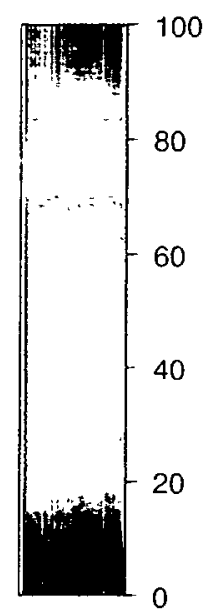

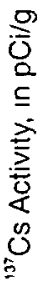

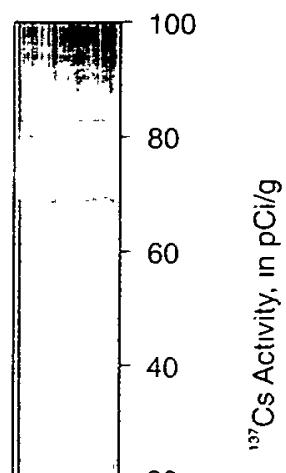

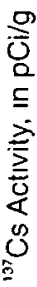

Figure 3. Location maps showing locations of 17 soil samples on depth levels 3 [image (a)] and 4 [image (b)]. See figure 2 for explanation. 

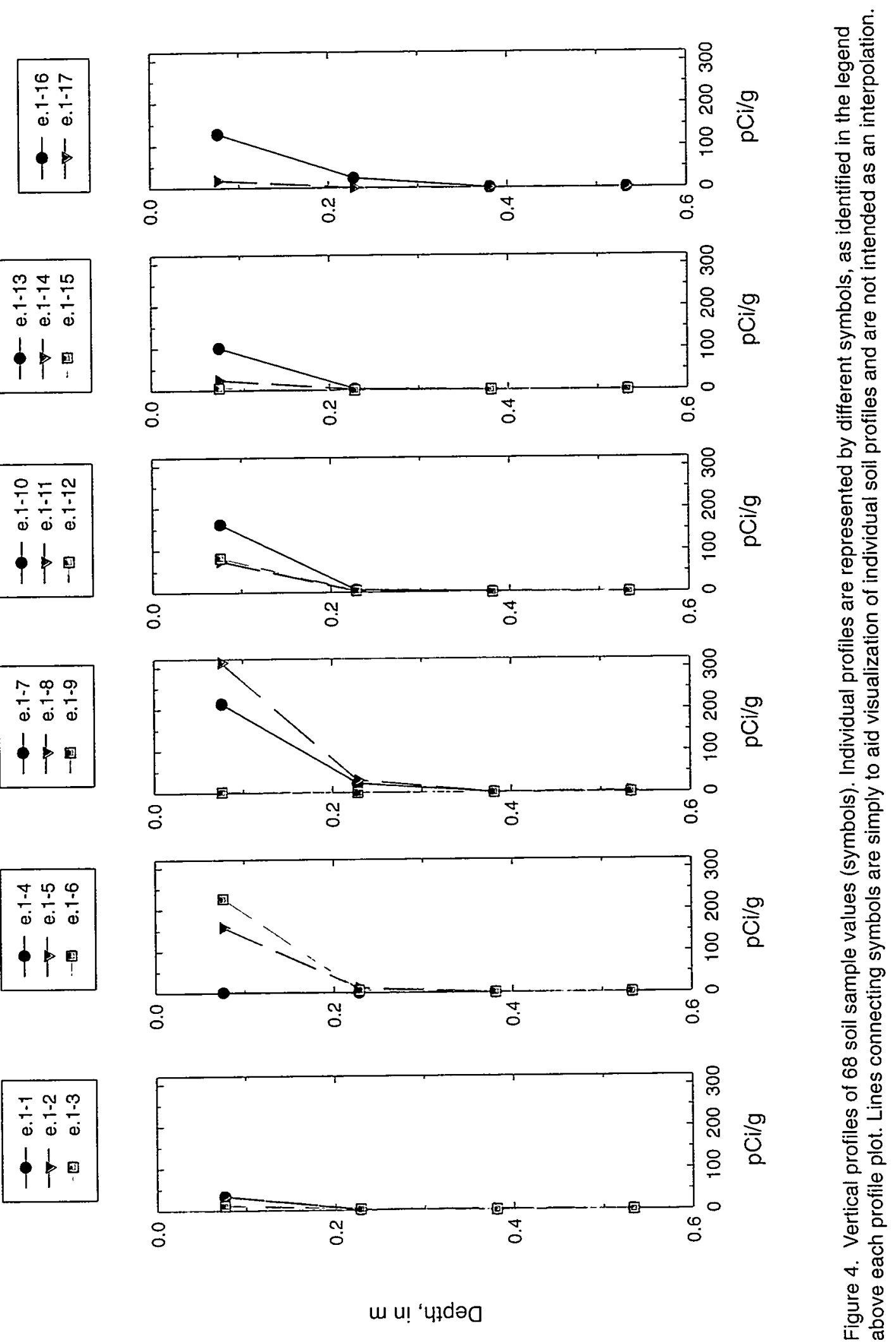

w u! ' uzdaO
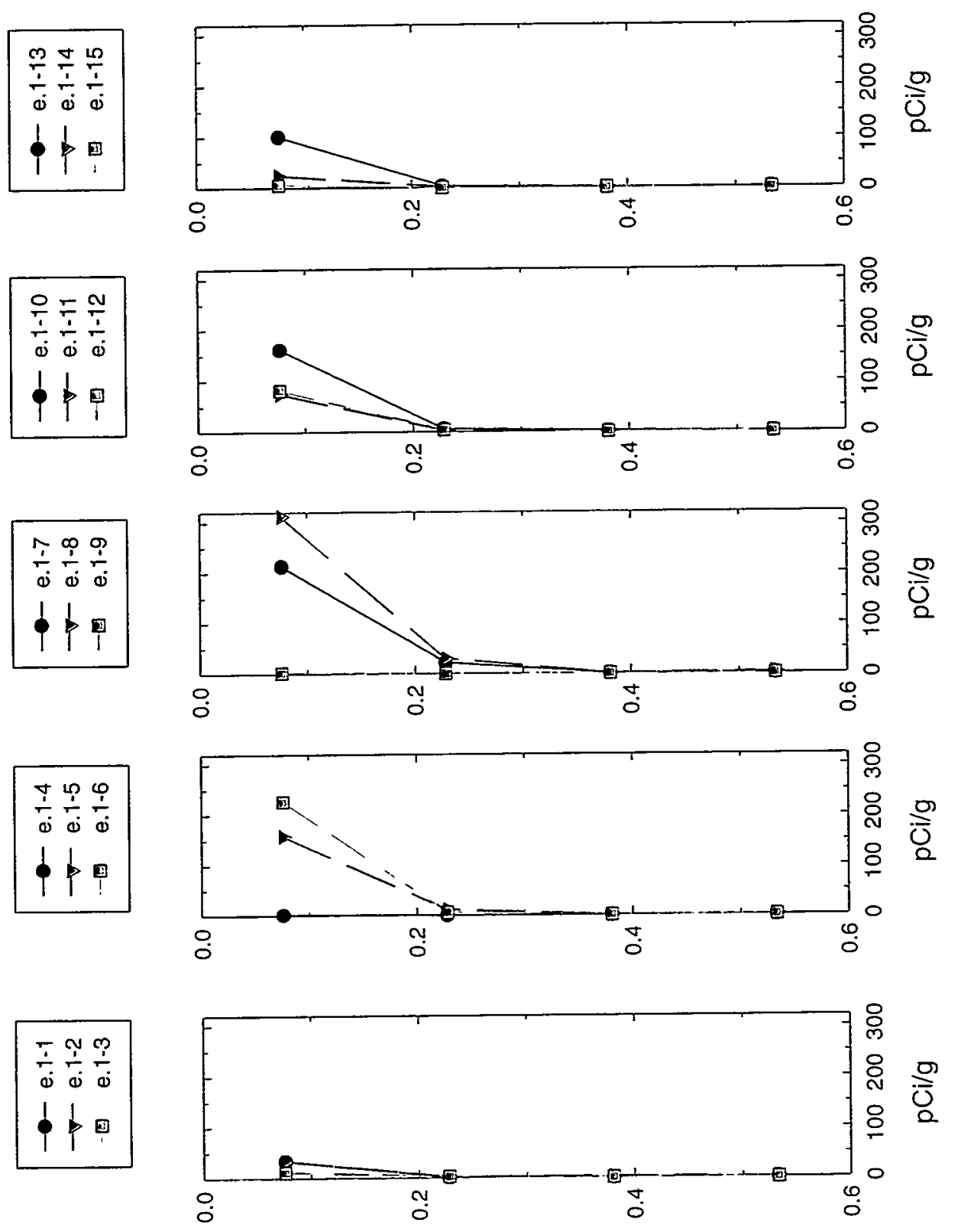


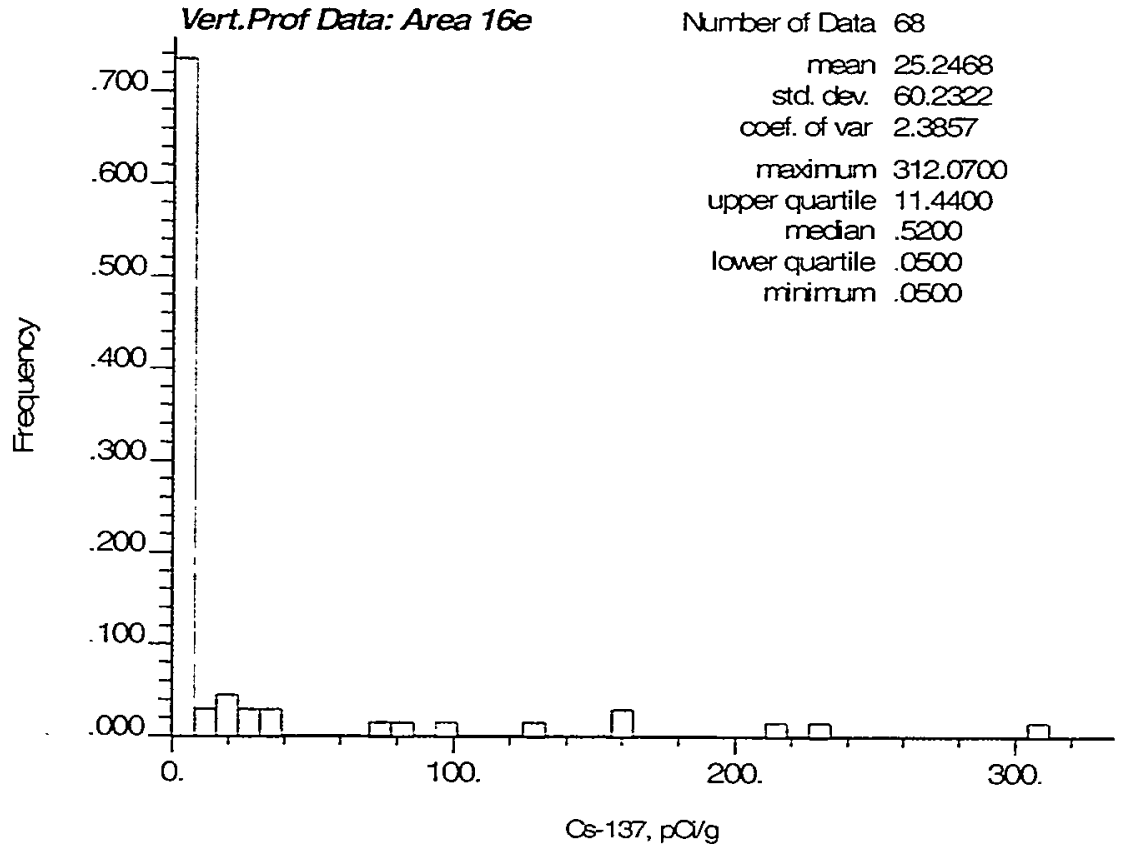

Figure 5. Histogram and descriptive statistics of the 68 soil sample measurements.

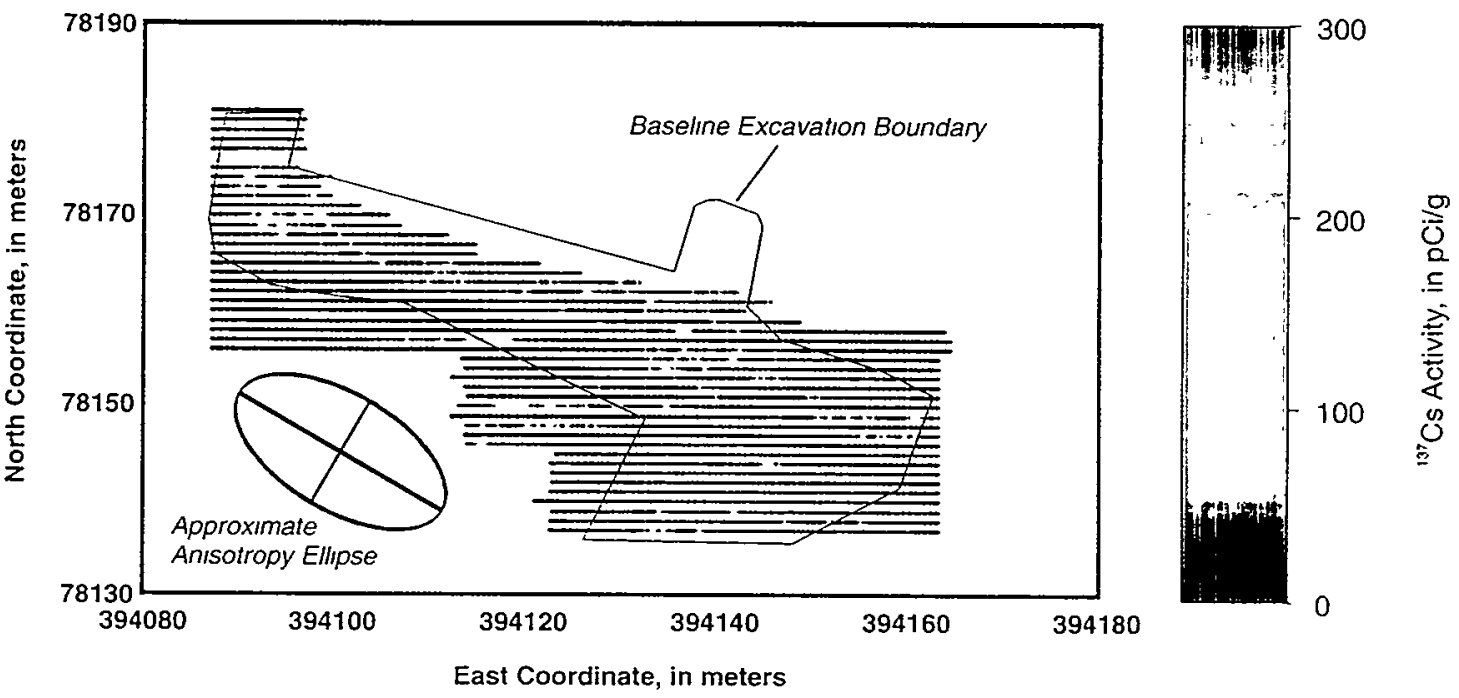

Figure 6. Location map showing 5,527 "mower" radiometric measurements of ${ }^{137}$ Cs activity in BNL Area $16 \mathrm{E}-1$. Note mismatch between spatial extent of mower coverage and the baseline excavation boundary. Note presence of elevated activities outside the limits of the baseline excavation boundary (see text). 


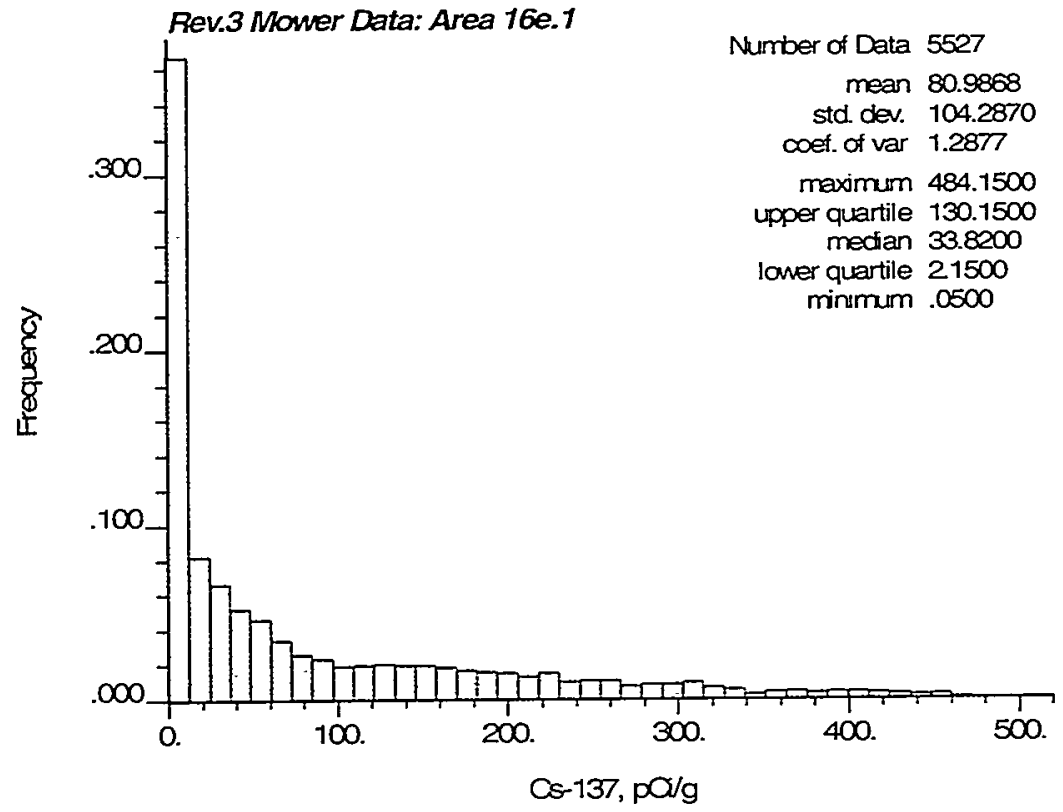

Figure 7. Histogram and statistical summary of the mower radiometric data.
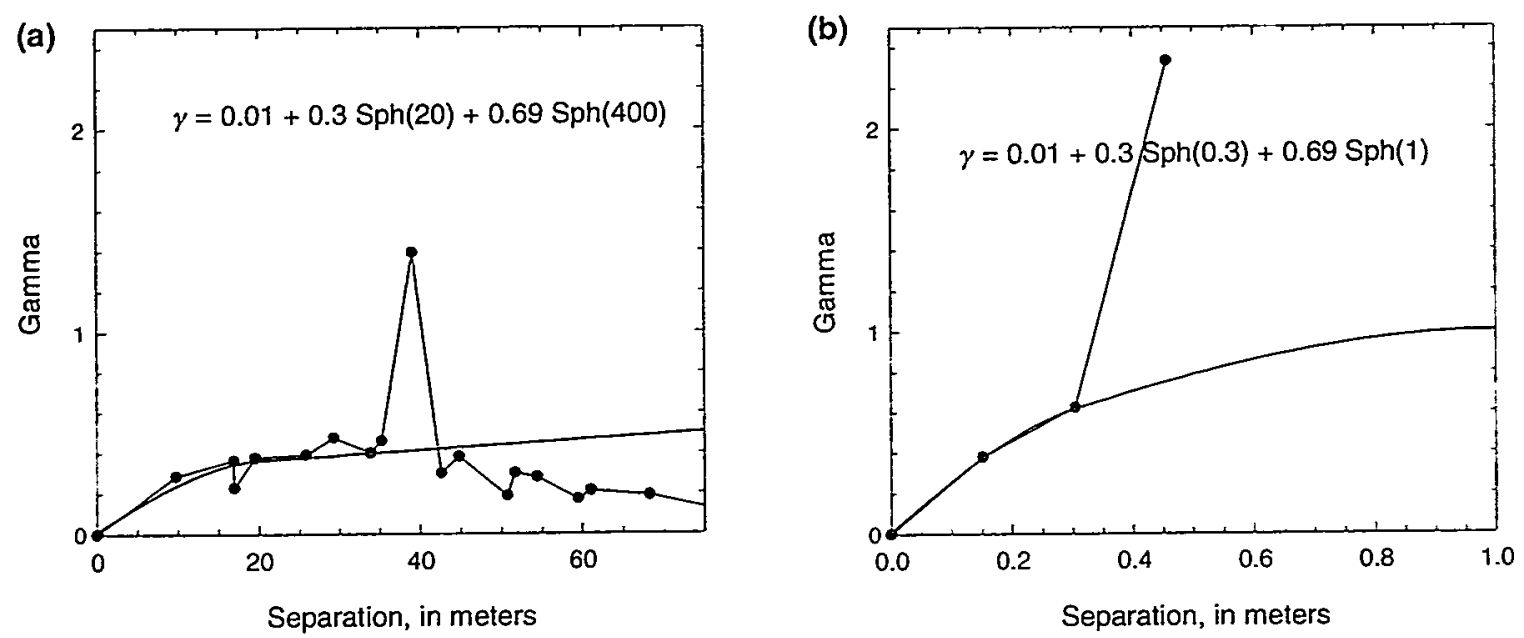

Figure 8. Normal-scores variograms computed using the 68 soil measurements of ${ }^{137} \mathrm{Cs}$ activity. (a) omnidirectional horizontal; (b) vertical. 


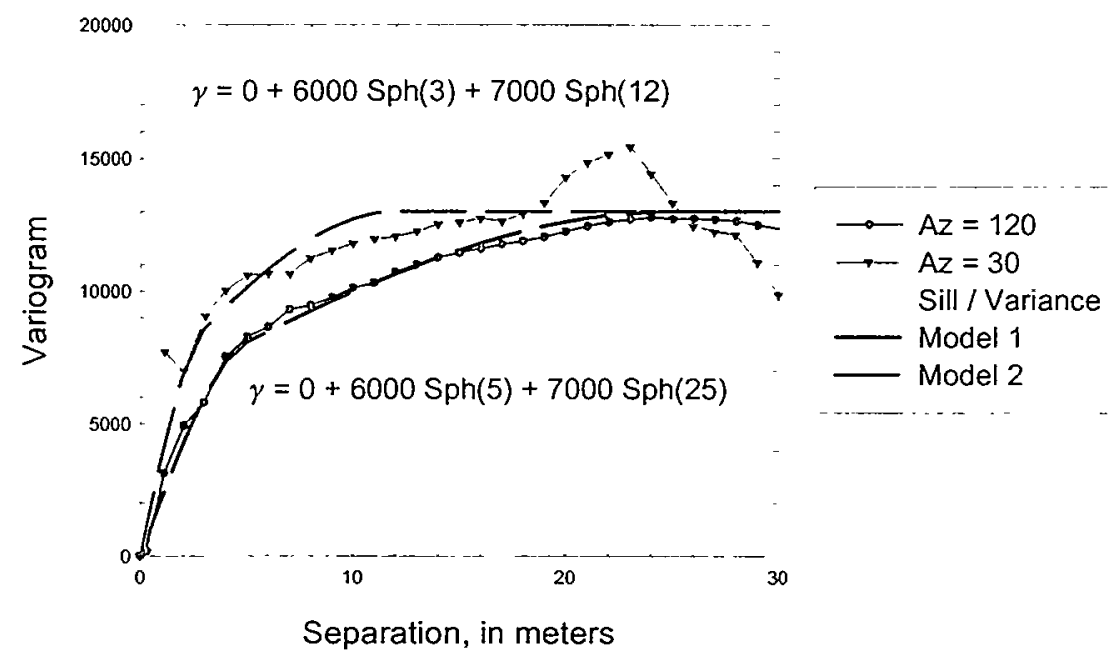

Figure 9. Activity variograms computed using the 5,527 mower radiometric measurements of ${ }^{137} \mathrm{Cs}$ activity in $\mathrm{pCi} / \mathrm{g}$ in the directions of maximum and minimum spatial correlation. See figure 6 for a graphical representation of the inferred anisotropy ellipse.

Table 1: Summary of Variogram Ranges for Soil and Mower Data

\begin{tabular}{lccccccc}
\hline & Nugget, & & \multicolumn{2}{c}{ Structure 1 } & \multicolumn{2}{c}{ Structure 2 } & \multicolumn{2}{c}{ Structure 3 } \\
\cline { 3 - 8 } & $\mathrm{C}_{0}$ & Sill & $\begin{array}{c}\text { Range, } \\
\mathrm{m}\end{array}$ & Sill & $\begin{array}{c}\text { Range, } \\
\mathrm{m}\end{array}$ & Sill & $\begin{array}{c}\text { Range, } \\
\mathrm{m}\end{array}$ \\
\hline Soil Data, Horizontal & 0.01 & 1 & 1 & 0.30 & 20.0 & 0.69 & 400 \\
\hline Soil Data, Vertical & 0.01 & 1 & 1 & 0.30 & 0.3 & 0.69 & 1.0 \\
\hline Mower Data, $\mathrm{Az}=30^{\circ}$ & 0.00 & 6000 & 5.0 & 7000 & 25.0 & 2 & 2 \\
\hline Mower Data, Az. $=120^{\circ}$ & 0.00 & 6000 & 3.0 & 7000 & 12.0 & 2 & 2 \\
\hline Mower Data, Omnidirectional & 0.00 & 6000 & 3.0 & 7000 & 20.0 & 2 & 2 \\
\hline
\end{tabular}

1. This structure not visible in the soil data because sample spacing exceeds range of correlation.

2. This structure is a "dummy" structure required to make the normal-score variogram have a total sill of 1.0

Because there is, in fact, a single, underlying variable of interest, although measured through two different means, one might logically expect (a) that the soil data should exhibit similar horizontal anisotropy to that of the mower values, and (b) that our inability to identify this anisotropy using the soil data alone is due solely to the small number of soil sample measure- 
ments (only 17 horizontal locations). We may therefore assume with some justification that such anisotropy does exist, and we will attempt to model it quantitatively as follows.

Aggregation of data pairs in all directions (an omnidirectional variogram) in the presence of actual anisotropy has the effect of producing an apparent range of spatial correlation intermediate between those of the directional variograms in the true maximum and minimum directions (which examine only those data pairs whose separation vector match, with some tolerance, the directions of interest). Therefore, we compute an omnidirectional variogram for the mower data geometrically equivalent to the omnidirectional variogram of figure 8 . This spatial correlation measure is presented in figure 10 , together with its fitted model (see also table 1). Note that the ranges of each nested structure are, indeed, intermediate to those of the directional variograms in figure 9 (table 1). This behavior is as expected from theory, and it lends strength to our argument that anisotropic spatial continuity patterns exist for the soil measurements but that our sampling pattern is too coarse to reveal that anisotropy.

Because both the soil values and the mower data are measuring the same underlying physical attribute, cesium radioactivity, there is a relatively strong presumption that both the actual directions of maximum ( $\mathrm{S} 60^{\circ} \mathrm{E}$ ) and minimum ( $\mathrm{N} \mathrm{30}$ $\mathrm{E}$ ) spatial correlation, and the anisotropy ratio between those directions, are essentially the same for both the soil and the mower values. Therefore, we can apply the ratios of the directional variogram ranges to the omnidirectional range for the mower data (for the longer structure: $25 / 20$ at $\mathrm{S} 60^{\circ} \mathrm{E} ; 12 / 20$ at $\mathrm{N} 30^{\circ} \mathrm{E}$ ) and multiply by the omnidirectional range for the soil data in order to determine the actual anisotropic ranges that should exist for the soil measurements, were sufficient samples available. Determining those anisotropic ranges of the single, three-dimensional variogram model will be described in the final paragraph of this section.

Examining the average horizontal sample spacing (compare figs. 2, 3 and 6) for both the soil measurements and the mower data, it is immediately apparent that the shorter-range structure visible in the mower data (with anisotropic ranges of 5 and $3 \mathrm{~m}$ ) simply cannot be observed in the soil variogram because the much wider horizontal spacing of the soil profiles $(\sim 10 \mathrm{~m})$ exceeds the maximum range of this nested structure; see the explicit "correlation" of the different variogram structures in table 1). Furthermore, the longer-range structure modeled for the soil variogram is a "dummy" structure required to make the normal-score variogram have a total sill of one (as required by the simulation program; Deutsch and Journel, 1998). The reason the apparent variance of the soil variogram is less than the actual variance of the normal-score data $(=1.0)$ is that the soil variogram is computed "looking" horizontally only along a very thin vertical window or "bandwidth." This search strategy effectively limits the data pairs being considered only to those within each 6-inch vertical level. Because the contaminant activity decreases systematically with depth (fig. 4), consideration of only sample pairs within a single depth increment at a time results in an apparent variance smaller than that of the data set taken as a whole.

Selecting the $20-\mathrm{m}$ structure from the soil data variogram as the relevant correlation pattern common to the two data sets, the divisors in the above ratios cancel, leaving us with inferred anisotropic ranges for the soil measurements of contamination of 25 and 12 meters, respectively. This result is intuitively satisfying as well, because both data sets are measuring the same underly- 


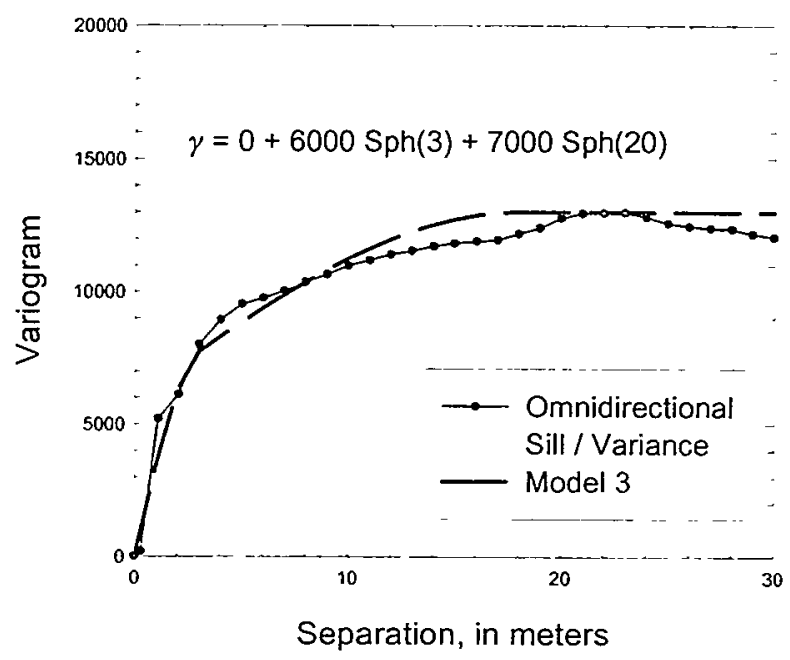

Figure 10. Omnidirectional variogram computed for the 5,527 mower measurements of ${ }^{137} \mathrm{Cs}$ activity.

ing physical quantity, as noted previously. That two closely related measures of a single phenomenon should yield essentially a single spatial continuity pattern is to be expected.

\section{Conversion of the Mower Measurements to Secondary Data}

Because the mower data are deemed of a somewhat lower order of reliability than the more rigorously tested soil profile samples, we decided to model those values as "secondary" data in contrast to the "primary" soil values. The sequential simulation algorithm (program SGSIM; Deutsch and Journel, 1998) selected for use requires that the secondary data exist at every grid location to be modeled. This requirement poses an immediate problem, as the mower values are surface measurements and there are no corresponding values available to represent depth levels 2 through 4. Additionally, the measured values, although closely spaced, are not located precisely on a regular grid, such as is required and generated by the simulation program.

The non-regular spacing issue was dealt with by interpolating the measured activity values onto a regular grid measuring $0.5-\mathrm{m}$ by $0.5-\mathrm{m}$ in both north and east directions using the BNL metric coordinate grid. Interpolation is by ordinary kriging (program KT3D; Deutsch and Journel, 1998), although the close spacing and large number of input values (near-exhaustive coverage) result in very minimal changes in data values by the interpolation process. The variogram used in the interpolation is the full anisotropic variogram given in table 1 . The kriged map of the mower data is presented in figure 11, and the same map, masked by the baseline excavation plan boundary is presented in figure 12. Note the "wild" artifacts that appear in figure 11 outside of the baseline excavation boundary, which result solely from attempting to model in regions unconstrained by measured data (compare with figure 6 ). 


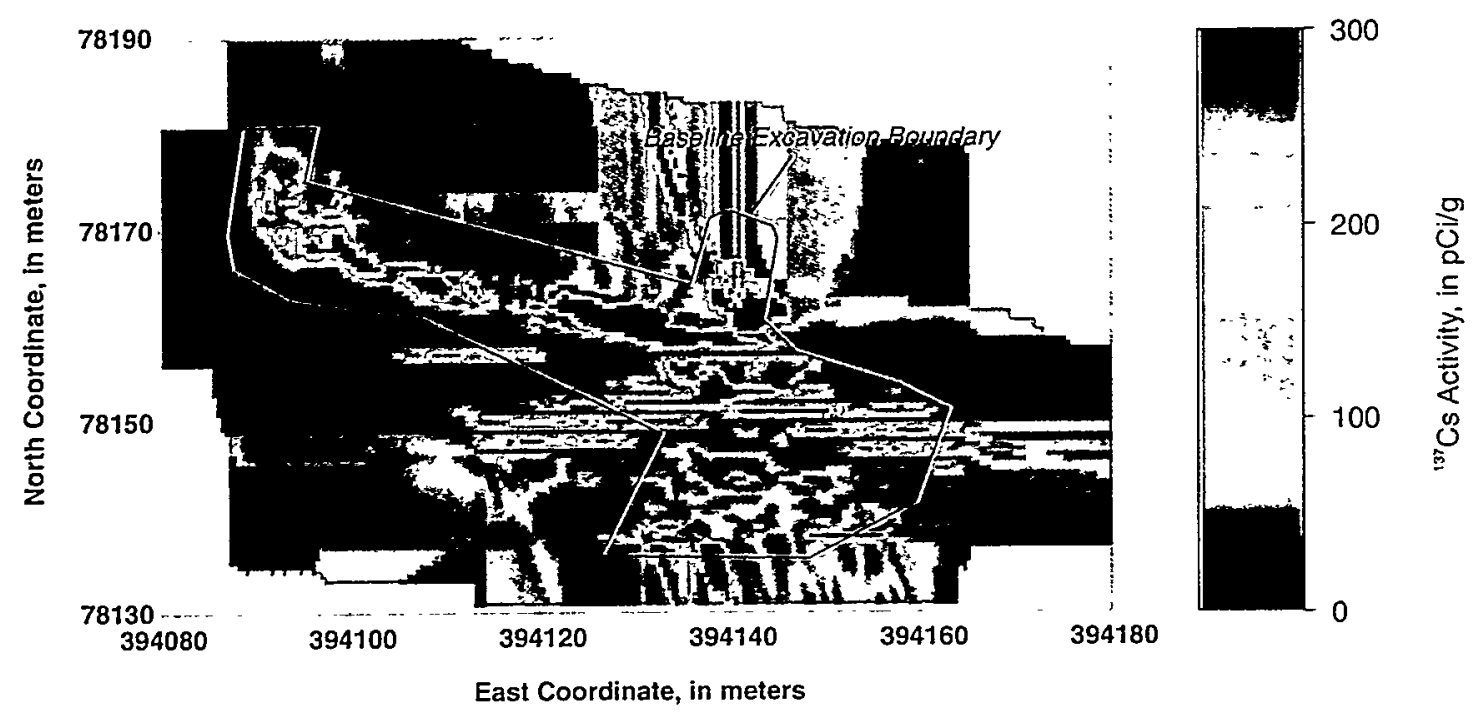

Figure 11. Estimated mower value kriged onto a regular grid prior to simulation.

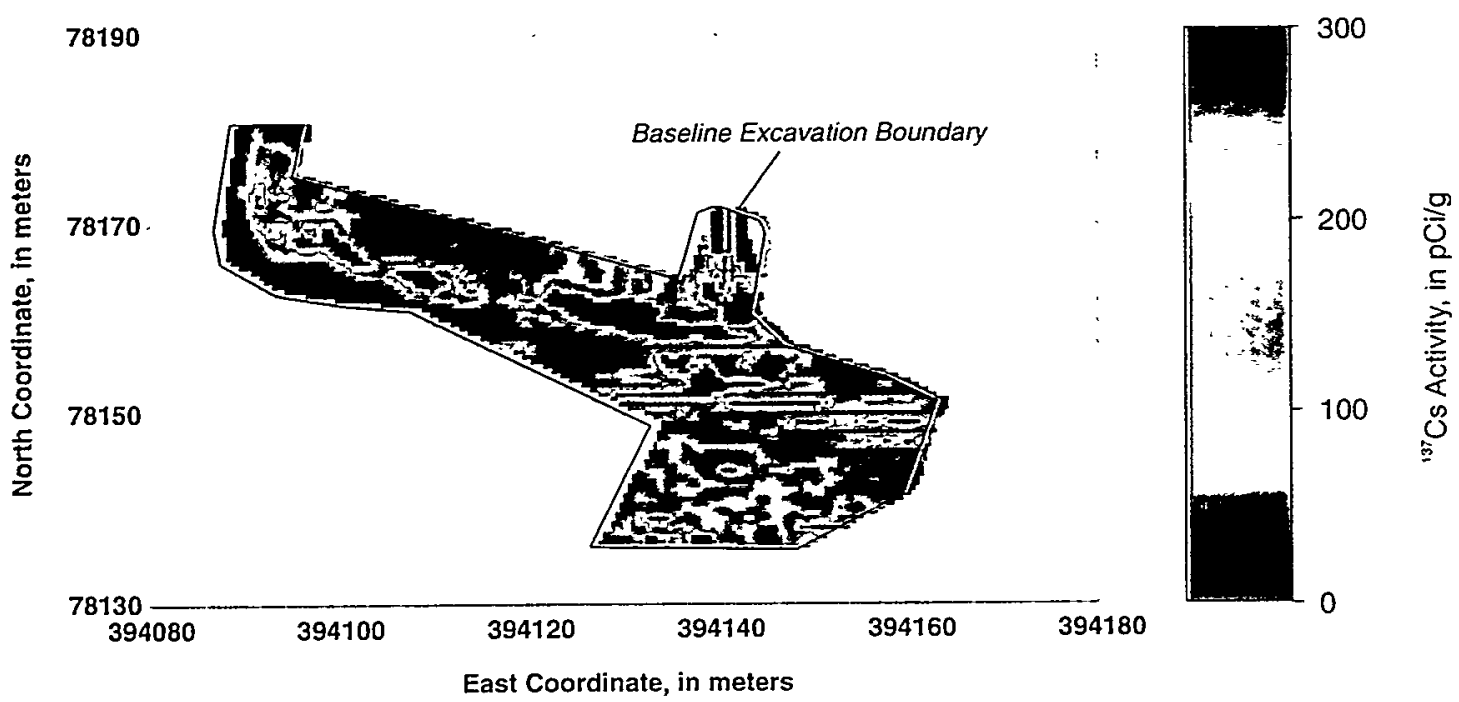

Figure 12. Kriged map of the mower data masked by the baseline excavation boundary. Regions outside this boundary are not. simulated in the next portion of this modeling exercise. 
To allow estimation of what the equivalent mower "measurements" would be at each successive depth increment, we have made use of the consistent and systematic decrease in contaminant magnitude with depth observed in the 17 soil profiles (figure 4). Figure 13(a) presents these 68 data in another form: as measured activity as a function of depth. A negative-exponential decay function in the form of

$$
y=y_{0}+a e^{-b x}
$$

has been fitted to the data, where $y$ is the measured activity, $x$ is depth (in meters, for compatibility with the easting and northing coordinates), and $y_{0}, a$, and $b$ are fitting constants. This nonlinear regression curve is also shown on the figure as the heavy partial line.

(a)

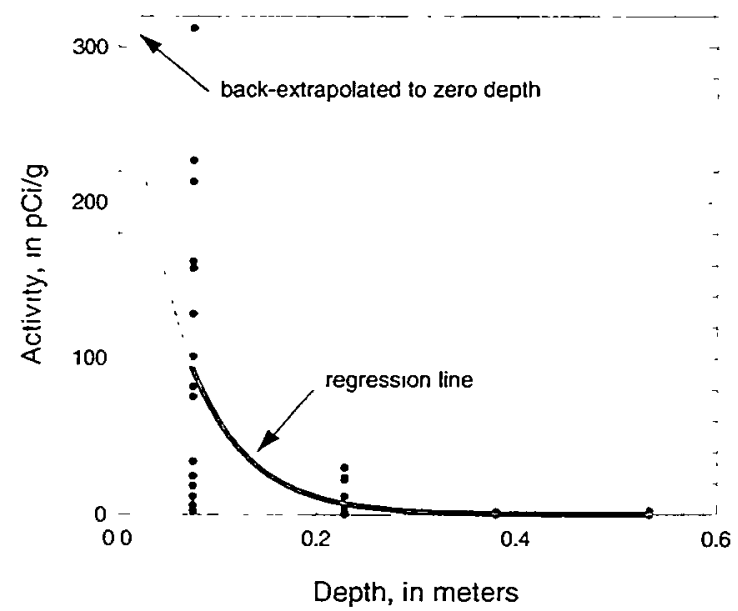

(b)

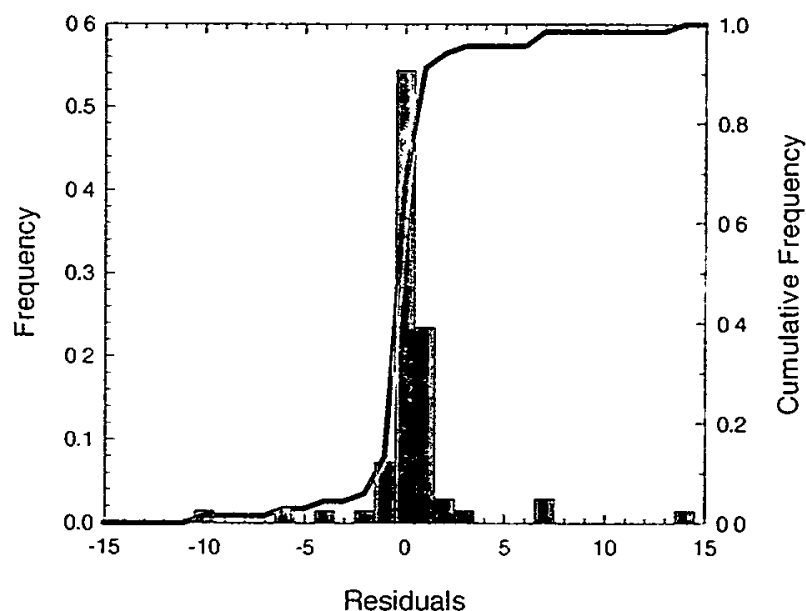

Figure 13. (a) Nonlinear regression of soil ${ }^{137}$ Cs activity vs. depth for the soil profile data set. (b) Residuals from the profile-specific predictions of soil sample values in figure 4 using the average regression relationship (heavy partial line) of (a) where the a parameter of equation (1) is the topmost soil sample value back-extrapolated to zero depth (see thinner line). Note that many data points in (a) plot on top of one another (especially at the deeper levels).

Although the wide variation in level 1 soil sample activities is not particularly well fitted by this "average" regression, it is possible to apply the regression coefficients, $y_{0}$ and $b$, to each individual soil sample value (which is assumed to represent a composite contamination value averaged from 0 to 6 inches) extrapolated to zero depth [thinner line in figure 13(a)] using the regression and then taking that zero-depth value as the $a$ coefficient. Using the customized version of the average regression applied to each soil profile separately, it is then possible to make very accurate predictions of the soil measurements for levels 2,3 and 4 knowing the uppermost value. Recall that the topmost soil sample is assigned a depth corresponding to the midpoint of the $0-6$-inch depth increment $(0.0762 \mathrm{~m})$. The resulting continuous activity predictions are plotted as a function of depth as the curved lines on figure 14. Residuals from the individually customized prediction exercise are presented in figure 13(b). The residuals are mean-zero, small with respect 

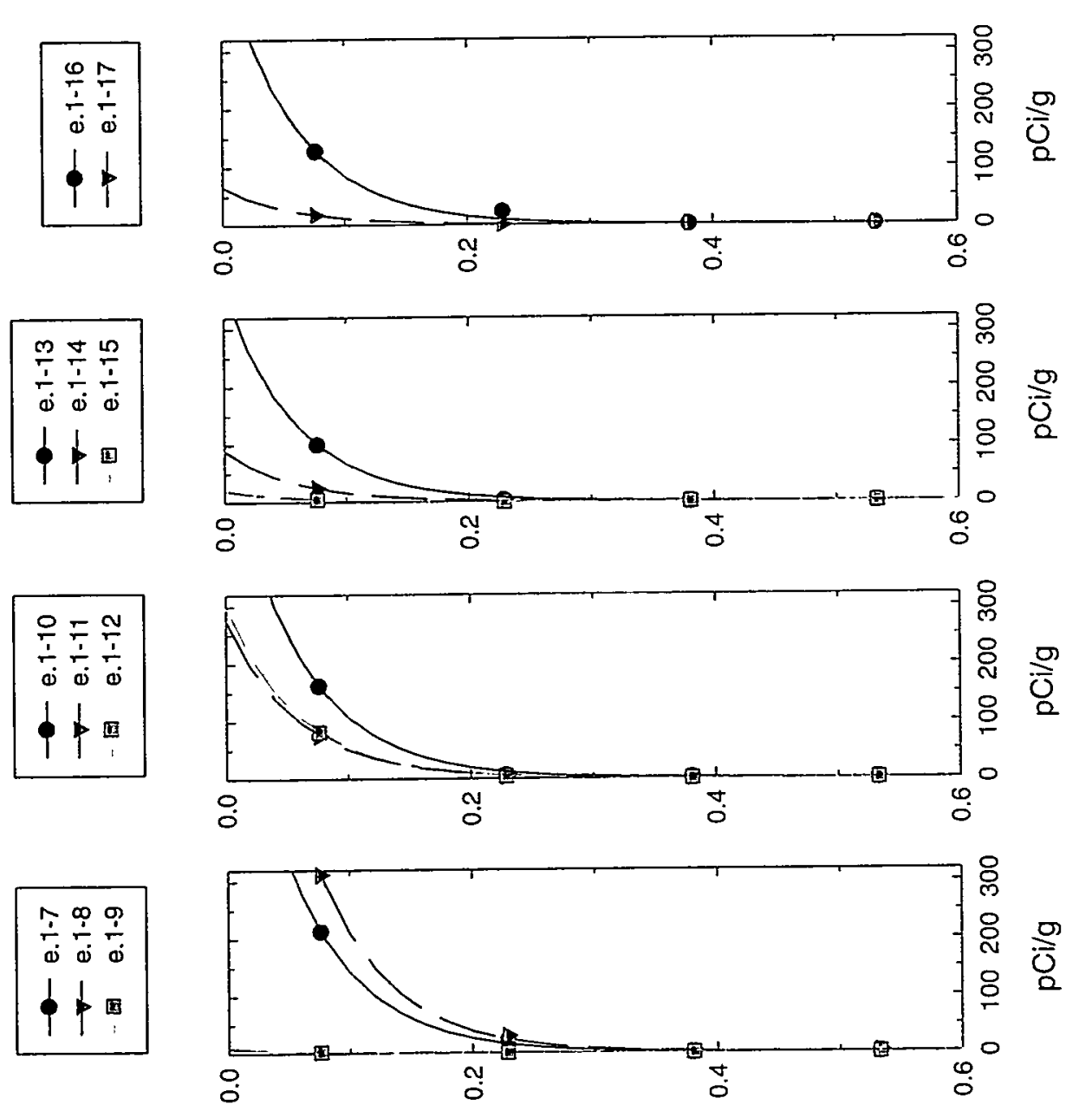

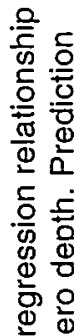

ธั

๙

듣 몽

응

各赤

웡

守交

뭉

믐

임

这

के

is

잉

它

o 09

竞

裙

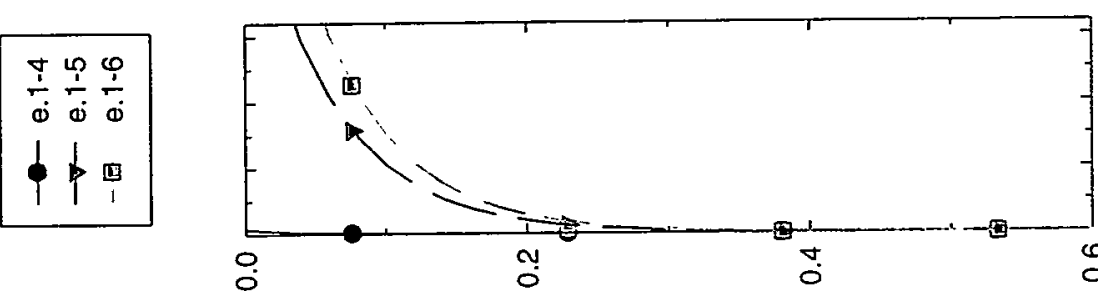

8

泠

$\frac{0}{0}$

름

刃

$\overline{\bar{O}} \stackrel{\Phi}{=} \frac{3}{\mathrm{~N}}$

œ 잉

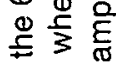

两

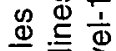

흥

흥

즌 등

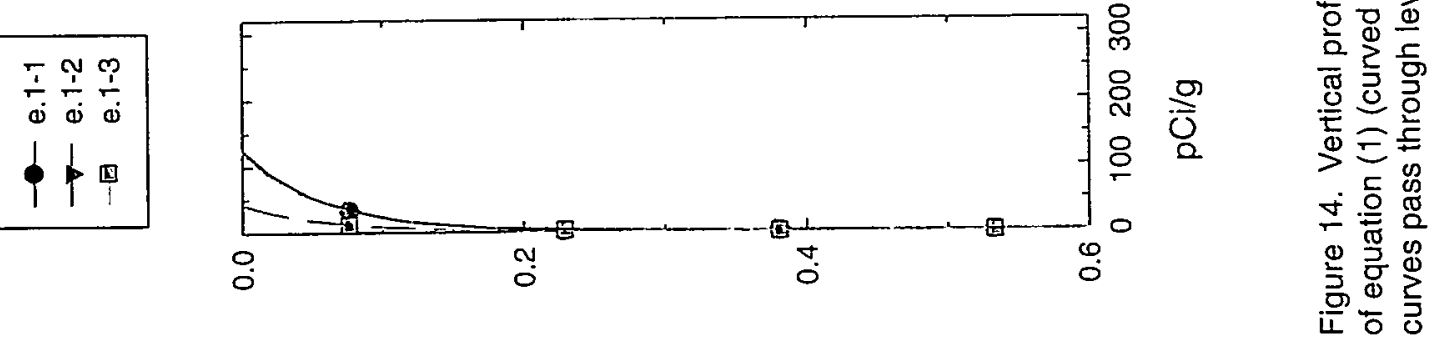

u u! 'ułdeg 
to the magnitude of the activity values (which range from 0.05 to $312 \mathrm{pCi} / \mathrm{g}$ ), and approximately normally distributed. This type of error distribution suggests that the customized nonlinear regression is a reasonably accurate and overall unbiased predictor of the ${ }^{137} \mathrm{Cs}$ activities anticipated at depth.

The regression coefficients from equation (1) were then applied to each of the gridded mower values obtained from the kriging exercise (figure 11), taken as measured at zero depth, and "depth-decayed" secondary values were generated at each discretizing node of the desired output grid using the customized nonlinear regression. The third dimension of this grid consists of values at the midpoints of each 6 -inch $(0.1524-\mathrm{m})$ depth increment or level. Grid nodes outside the baseline excavation boundary (figure 12) were set to a missing-value flag (-999), and these nodes were not modeled in the simulation exercise that follows.

\section{Simulated Models of Contaminant Distribution}

The modified, three-dimensional, anisotropic soil variogram described above, the depth-decayed secondary mower data values, and the 68 primary soil measurements of ${ }^{137} \mathrm{Cs}$ activity were provided as input to the sequential gaussian simulation algorithm, SGSIM (Deutsch and Journel, 1998). Simulation as a modeling methodology attempts to generate an arbitrary number of equally likely "realizations" of the modeled property. Conditionally simulated models (1) reproduce the input data (primary only) at those data locations, (2) reproduce the overall statistical character of the input data (histogram, mean, standard deviation, etc.), and (3) reproduce the observed spatial character (variogram) of the input values. Effectively, each realization is distinguishable from others of the same suite only by the random-number "seed" value that initiates the simulation process. In the present instance, 100 such statistically indistinguishable, "exhaustive" models of ${ }^{137} \mathrm{Cs}$ contamination for Area $16 \mathrm{E}-1$ were generated. Because of the three characteristics of the simulations just described, the presumption is that variability among the different realizations represents constrained uncertainty related to lack of specific knowledge at each individual grid node.

The secondary data derived from the mower measurements were incorporated into the simulations using a process known as collocated cokriging (Deutsch and Journel, 1998). At each simulation node, the collocated secondary datum (from the kriging of the mower values) is entered into the estimation of the locally conditioned probability density function, from which the individual simulated values are then drawn, weighted by the correlation coefficient ( $r$-value) between the primary and secondary data populations. This correlation coefficient was determined by cross-plotting (figure 15) each level-1 soil sample value and its nearest-neighbor mower value. The correlation analysis indicates that $r=0.817$. Program SGSIM was modified to ignore grid nodes located outside the baseline excavation boundary.

Figure 16 presents color-coded views of ${ }^{137} \mathrm{Cs}$ activities for one arbitrarily selected simulation. The views are level-by-level, and they confirm the expected overall decrease in contaminant magnitude with depth. Additional processing can demonstrate that, in fact, the three characteristics of conditional simulations are reproduced. 


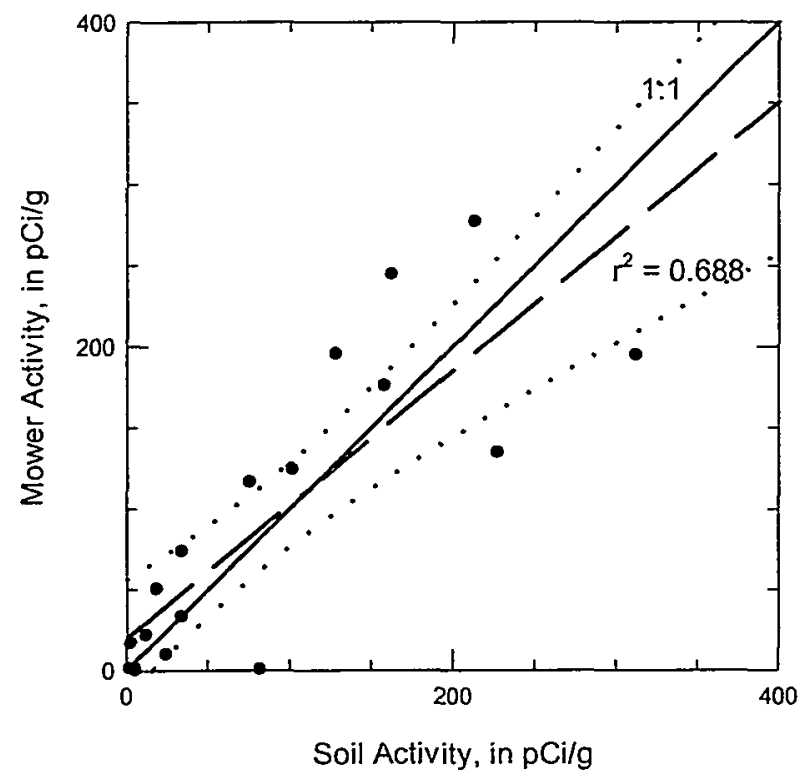

Figure 15. Correlation of collocated (nearest-neighbor) mower measurements and soil activity values. Only one data pair is separated by more than $0.7 \mathrm{~m}$, and that pair is separated by approximately $1.25 \mathrm{~m}$. Dashed line is the regression fit with 95-percent confidence interval (dotted).

A separate suite of simulations of ${ }^{137} \mathrm{Cs}$ activity was generated using only the soil data as input, although the anisotropic variogram developed using the mower radiometric data was retained. On a visual comparison level, the models of contamination generated in this manner are very similar to the results presented in figure 16 . However, as will be demonstrated below in the results section, the quantitative results are somewhat more conservative (indicating slightly larger volumes of contaminated soil).

\section{Results}

The SmartSampling ${ }^{\mathrm{TM}}$ methodology involves postprocessing a (large) suite of the statistically indistinguishable, equally plausible, conditional simulations to make probabilistic statements about where contamination is "likely" to be present, and where it is likely to be absent. A fundamental tenet of the methodology is that if the acceptable risk of making a classification error - stating that some region is "clean" when it is, in fact, "dirty" - is precisely zero, then the only possible remediation alternative is to clean "everything." It is only through accepting a reliability of less than 100 percent (i.e., associated with a finite risk of failure), that it is possible to reduce the area/volume of material to be remediated from the universe of everwhere that might possibly be contaminated. Thus, a determination of "how likely is likely" is required. This determination is outside the scope of this report. As prescribed in the SmartSampling ${ }^{\mathrm{TM}}$ process, this decision must be made, jointly, by all parties with a stake in the decision. 


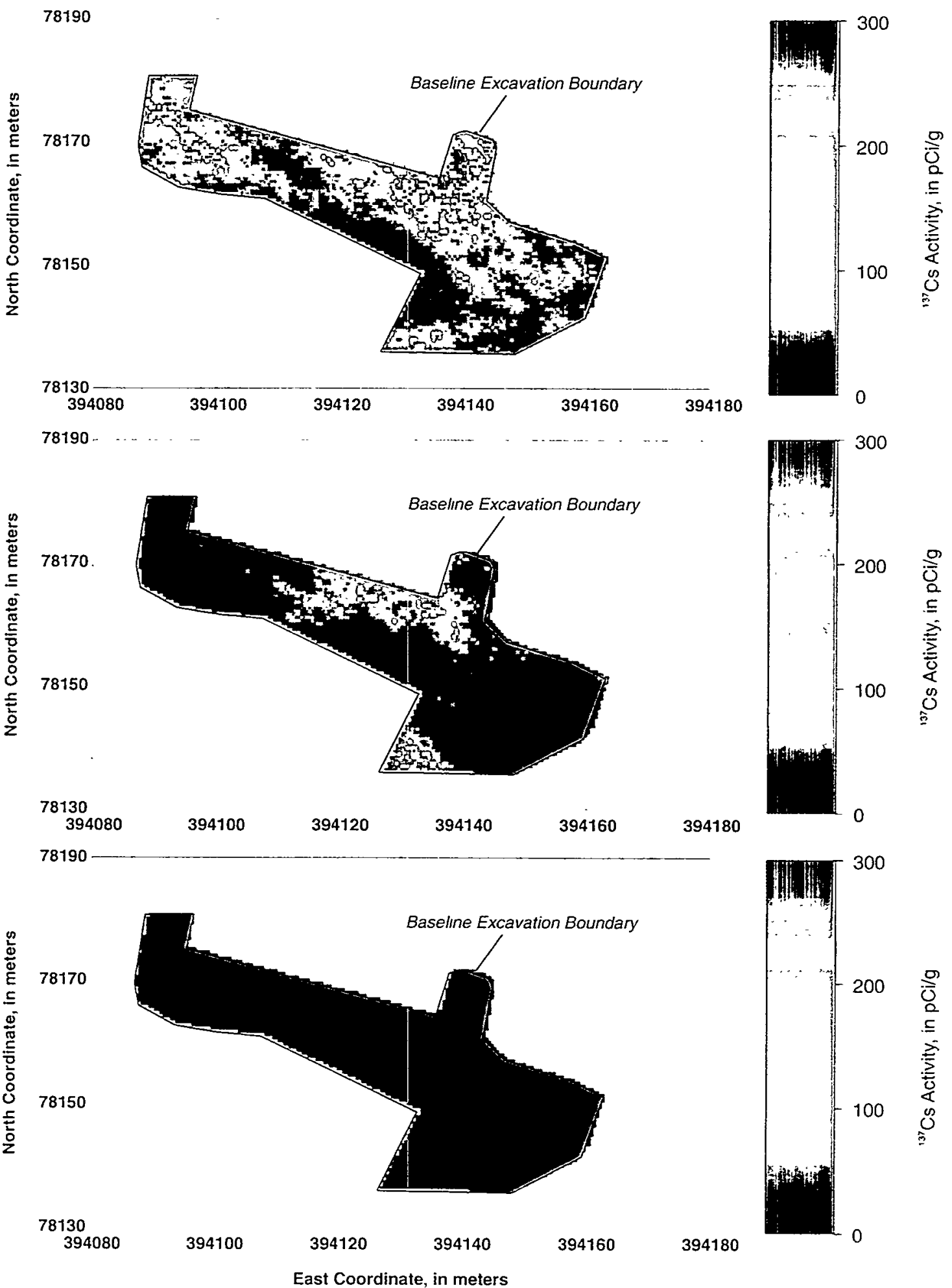

Figure 16. Views of a representative simulation of ${ }^{137} \mathrm{Cs}$ activity at Area $16 \mathrm{E}-1$ at three of the four depth levels considered in this analysis. Level 4 is not presented, as the image is essentially identical to that for level 3. An individual simulation panel is $0.5-\mathrm{m} \times 0.5-\mathrm{m} \times 6$-inches deep. 
However, a suite of computer simulations can be processed many different ways, and thus provide information about a multitude of different potential remediation options. For example, figure 17 presents a set of probability maps showing the quantitative likelihood of exceeding two alternative action levels of $23 \mathrm{pCi} / \mathrm{g}$ and $200 \mathrm{pCi} / \mathrm{g}$ at each $0.5-\mathrm{m} \times 0.5-\mathrm{m}$ remediation panel on level 1 . The color scale is in probability units, scaled between zero and one. Evidently, the region likely to be contaminated at very high activities [fig. 17(b)] is markedly smaller than that likely to be contaminated at the lower activity level [fig 17(a)] at the same level of reliability. Also, it is virtually certain (probability near 1) that certain specific regions [shown in red on 17(a)] exceed the lower action level of $23 \mathrm{pCi} / \mathrm{g}$. A similar set of figures showing probability of contamination at 23 and $200 \mathrm{pCi} / \mathrm{g}$ for level 2 is presented in figure 18 . The map for the probability of exceeding $23 \mathrm{pCi} / \mathrm{g}$ on level 3 is presented in figure 19. The corresponding map for $200 \mathrm{pCi} / \mathrm{g}$ on level 3 is not shown, as the probability is virtually zero everywhere.

It is also possible to process the suite of simulations in another manner, this time iterating through all possible probability levels from zero to one and counting the number of contaminated panels that exist at each probability level for a given action level for Area $16 \mathrm{E}-1$. The number of contaminated panels varies from a maximum of 21,364 for a reliability level of 1.00 (no failures allowed) to a minimum of zero panels for a reliability level of zero. Knowing the definition of the simulation grid $\left(0.5-\mathrm{m} \mathrm{x} 0.5-\mathrm{m} \times 6\right.$-inches $\left.=0.498 \mathrm{yd}^{3}\right)$ allows the number of contaminated panels to be converted into an estimate of the volume of contaminated soil. Figure 20 presents the results of this calculation. Note that the steep decrease in the "contaminated" volume between reliability levels of approximately 99 and 96 percent will correspond to equally sharp decreases in potential remediation cost, as remediation cost is simply a rescaling of volume by the per-unit excavation and treatment-or-disposal cost.

If the bulk density of the soil material is known or can be reasonably estimated, it is possible to convert the volume of material along with its modeled specific activity to an actual estimate of the total radioactive inventory (in curies) above any particular threshold activity, using the simple relationship:

$$
\text { Total Activity }=\text { Specific Activity } \rho_{b} \text { Panel Volume Conversion Factors }
$$

where the total activity is expressed in curies (Ci), the specific activity of a given modeling panel is in picocuries per gram ( $\mathrm{pCi} / \mathrm{g}$ ), bulk density $\left(\rho_{b}\right)$ is in $\mathrm{g} / \mathrm{cm}^{3}$, and the panel volume is in $\mathrm{cm}^{3}$. The "conversion factors" are those constants necessary to convert the relevant length measurements to centimeters, and the definitional conversion that one Curie $=10^{12}$ picocuries.

Bulk density measurements were obtained as part of the soil-profile data collection effort, and although the densities vary somewhat from less than 1.0 to as much as $2.0 \mathrm{~g} / \mathrm{cm}^{3}$, the mean bulk density is approximately $1.5 \mathrm{~g} / \mathrm{cm}^{3}$. Densities of soil samples near the surface are somewhat lower than those of samples obtained from the deeper levels. The estimated spatial distribution of bulk density at Area 16E-1 could be modeled explicitly for each grid panel, if necessary.

Assuming a mean bulk density of approximately $1.5 \mathrm{~g} / \mathrm{cm}^{3}$ (density was measured for each of the 68 soil profile samples), it is possible to compute that the total amount of ${ }^{137} \mathrm{Cs}$ con- 
(a)
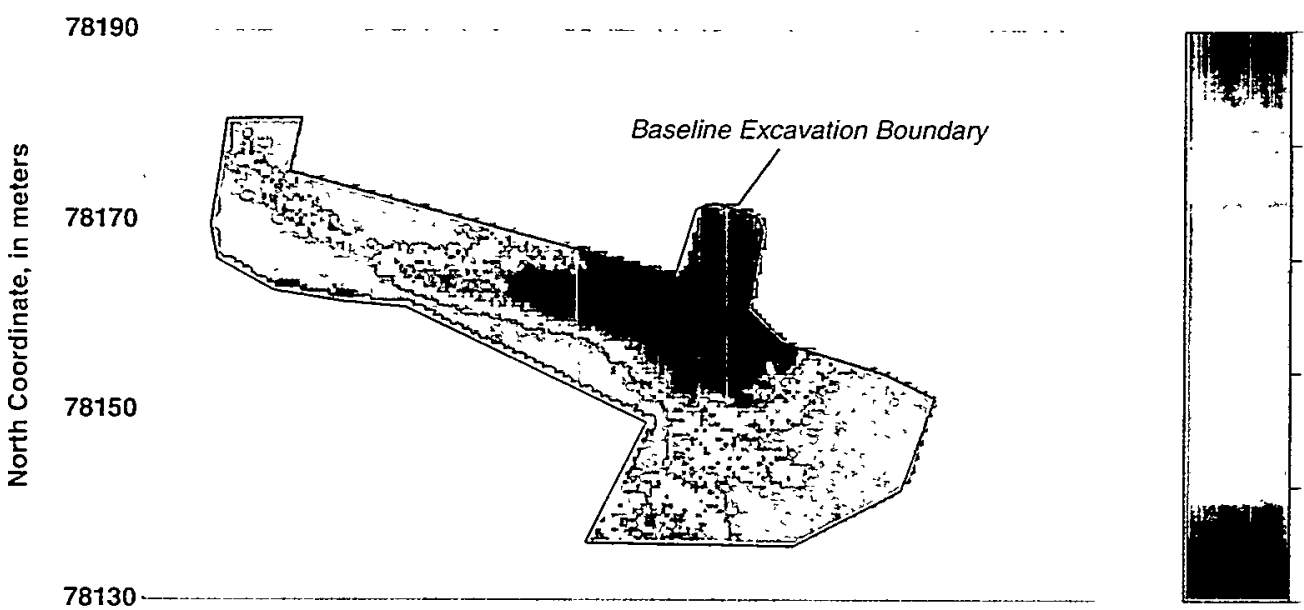

1.0

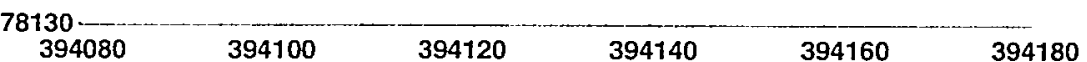

394180

(b)
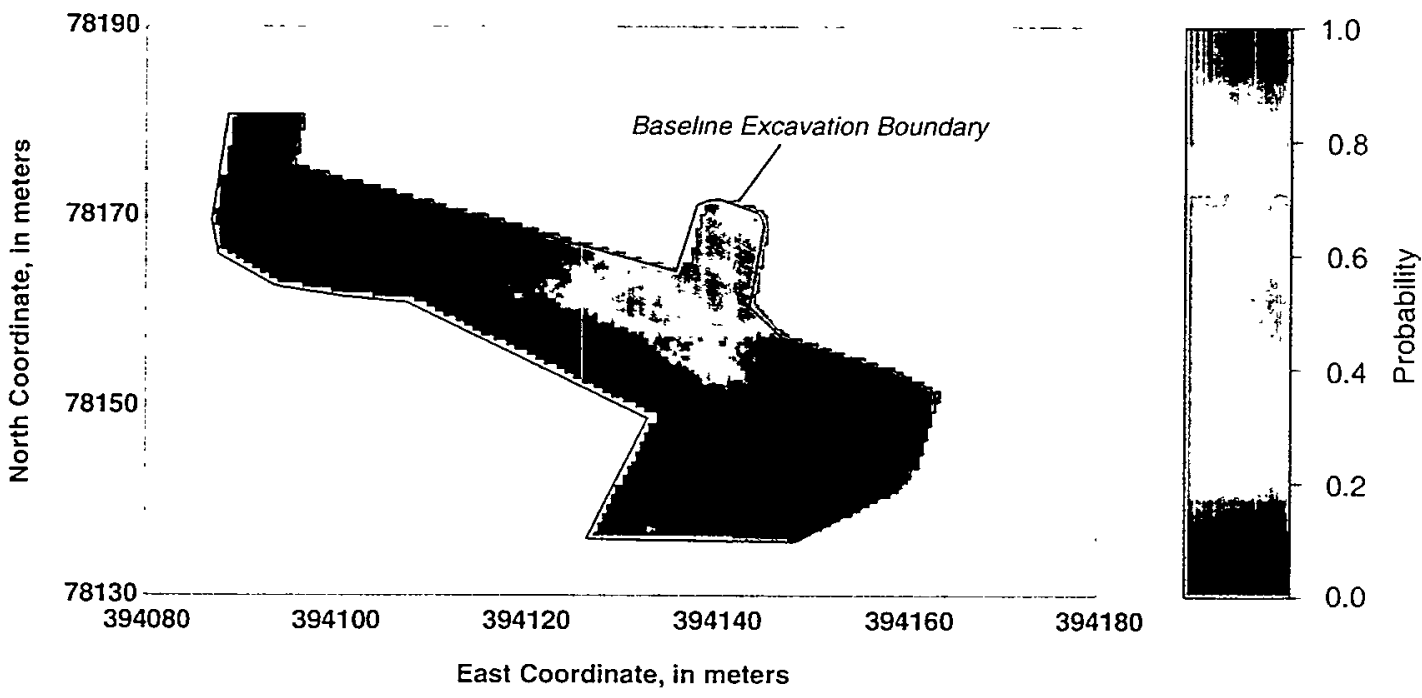

Figure 17. Probability maps showing the likelihood of exceeding (a) $23 \mathrm{pCi} / \mathrm{g}$ and (b) $200 \mathrm{pCi} / \mathrm{g}$ for each 0.5-m $\times$ 0.5-m remediation panel on level 1 (0-6 inches depth). 
(a)
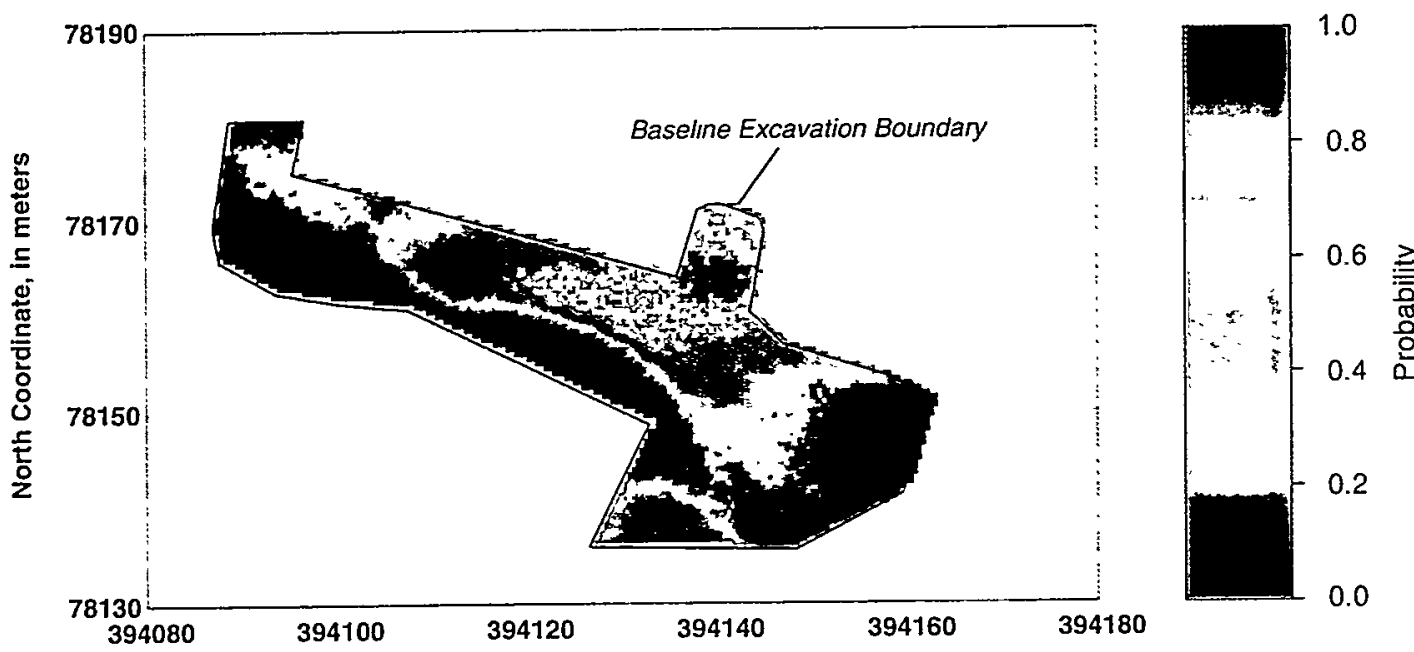

(b)
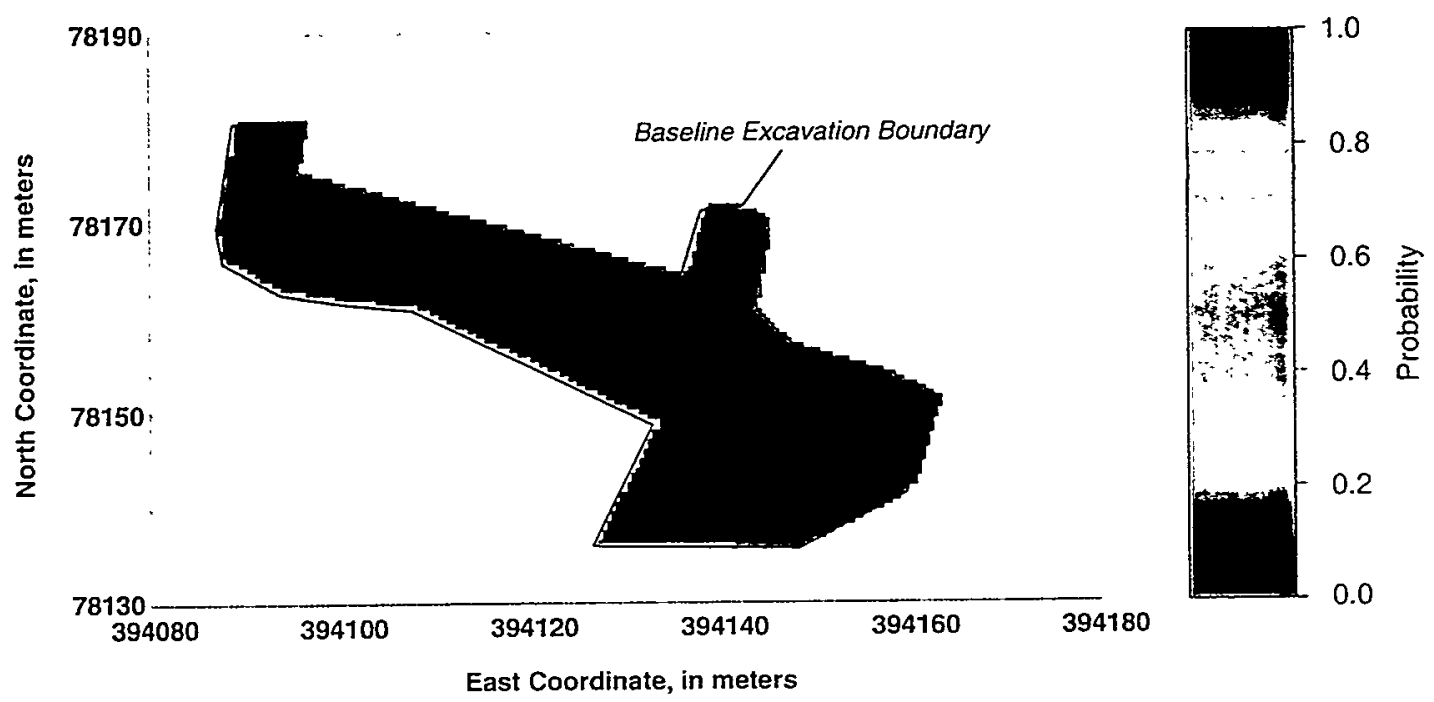

Figure 18. Probability maps showing the likelihood of exceeding (a) $23 \mathrm{pCi} / \mathrm{g}$ and (b) $200 \mathrm{pCi} / \mathrm{g}$ at each $0.5-\mathrm{m} \times 0.5-\mathrm{m}$ remediation panel on level 2 (6-12 inches depth). 


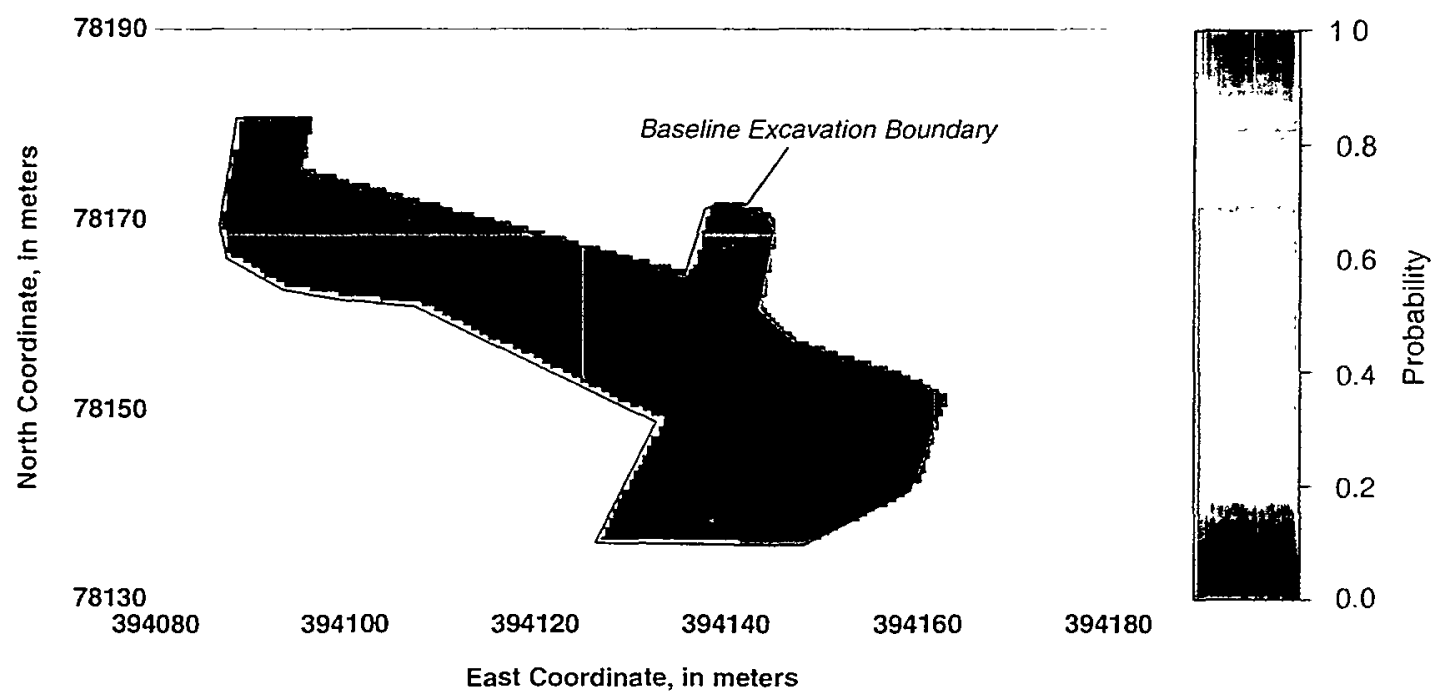

Figure 19. Probability maps showing the likelihood of exceeding (a) $23 \mathrm{pCi} / \mathrm{g}$ at each $0.5-\mathrm{m} \times 0.5-\mathrm{m}$ remediation panel on level 3 (12-18 inches depth).

tamination in place at Area $16 \mathrm{E}-1$ is $0.0314 \mathrm{Ci}$. Figure 21 summarizes the total radioactivity at the site as a function of activity level.

\section{Discussion}

Examination of the probability map of figure 19 suggests that there is very little reason to undertake significant excavation of materials on levels 3 or 4 , as the probability of encountering contamination in excess of $23 \mathrm{pCi} / \mathrm{g}$ is exceedingly low (level 3) to nonexistent (level 4). Most of this potential volume reduction is immediately apparent on figure 20 as the sharp drop in the volume of contaminated material from the baseline volume of $1,064.7 \mathrm{yd}^{3}$ (converted from metric units) to a volume of about $550 \mathrm{yd}^{3}$ at reliability levels of 98 or 99 percent. Additional examination of figure 20 indicates that additional potential reductions in volume are possible, although at progressively increasing levels of risk of making an incorrect determination.

Note that the prominent drop in estimated volume is essentially independent of whether or not the mower/secondary data (and the implicit negative-exponential decay trend with depth involved in the secondary data) are used; compare figure 20 , the red dashed line (soil data only) vs. the solid black line (soil plus mower data). The soil-data-only modeling did, however, retain use of the anisotropic, composite variogram developed using both the soil and the mower data. Accordingly, we conclude that the lower two levels (from 12 to 24 inches in depth) are, in fact, essentially uncontaminated, and that the external assumption of the negative-exponential decay trend (for the secondary data only) has not imposed an unintended consequence on the quantitative results. 


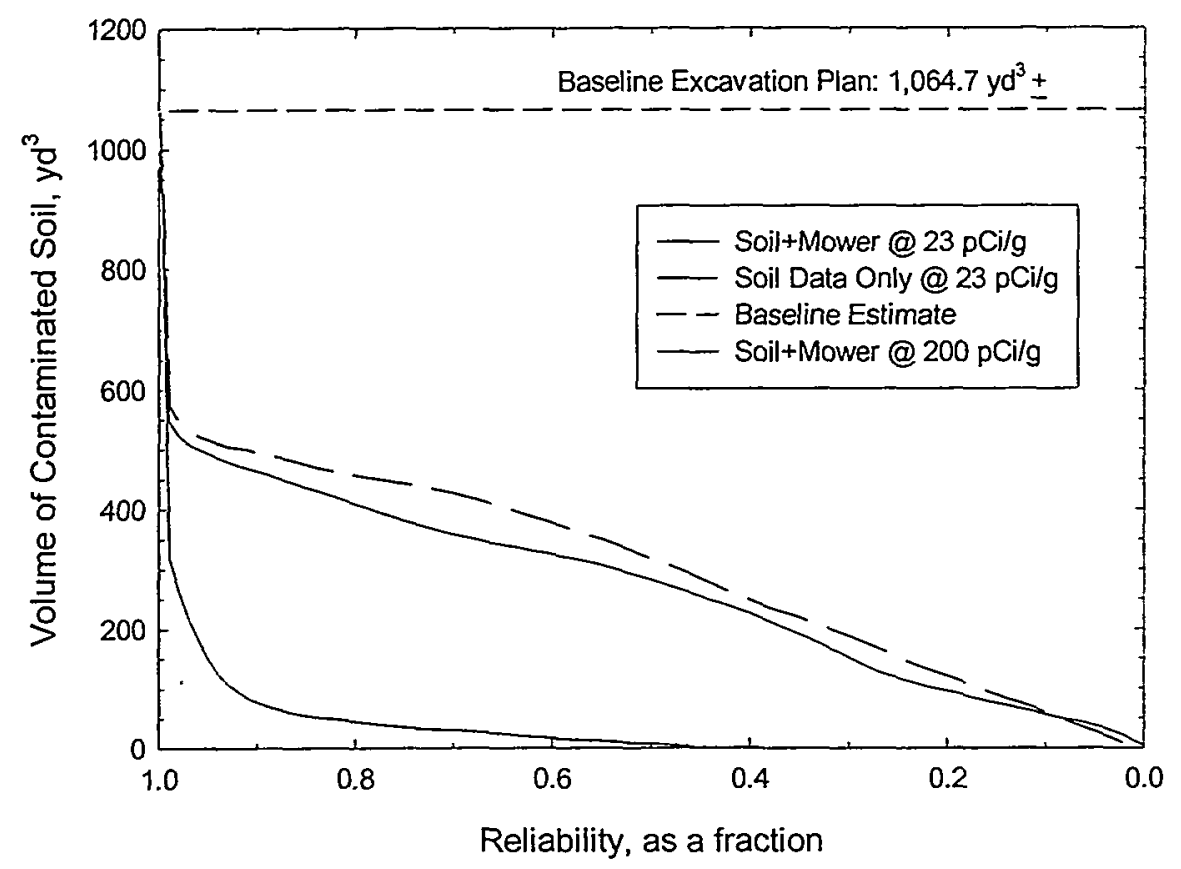

Figure 20. Estimates of the volume of contaminated soil at BNL Area 16E-1 as a function of the acceptable reliability level, compared with the baseline estimate of contaminated volume, for two different modeling approaches. Estimates are provided for material exceeding $23 \mathrm{pCi} / \mathrm{g}$ and exceeding $200 \mathrm{pCi} / \mathrm{g}$.

Examination of the final curve in figure 20 indicates that there is a non-trivial volume of material that is very likely to exceed $200 \mathrm{pCi} / \mathrm{g}$. The total volume of this highly radioactive soil appears to exceed $100-200 \mathrm{yd}^{3}$ at reasonably high reliability levels, and a reasonable maximum-volume estimate of this "hot" material is approximately $300 \mathrm{yd}^{3}$. Whether it is cost effective to process this material with the Segmented Gate System, as opposed to directly disposing of the material, is beyond the scope of this report. Examination of the higher-probability values in figure 17(b) suggests that the majority of this potential direct-disposal contaminated soil is located in the northeast-trending "thumb" that extends away from the main northwest-southeast-trending baseline excavation boundary.

For the sake of discussion, the probability maps of figures 17 through 19 have been turned into "excavation maps" at a reliability level of 0.95 . No representation is made that a 5-percent probability of failure is the optimal decision. Rather, these illustrations are presented in figure 22 as an example of converting probabilistic statements into a concrete plan of action at any required level of reliability. Regions that are likely to exceed $23 \mathrm{pCi} / \mathrm{g}$ at a probability level in excess of 0.05 are colored red on the maps, whereas regions that are less than 5-percent likely to exceed 23 $\mathrm{pCi} / \mathrm{g}$ are shown in blue. All of level 1 [fig. 22(a)] would be marked for excavation under this presumption that 95 percent is the proper reliability level, whereas only a very small portion of depth level 3 [fig. 22(c)] would be so marked. 
(a)

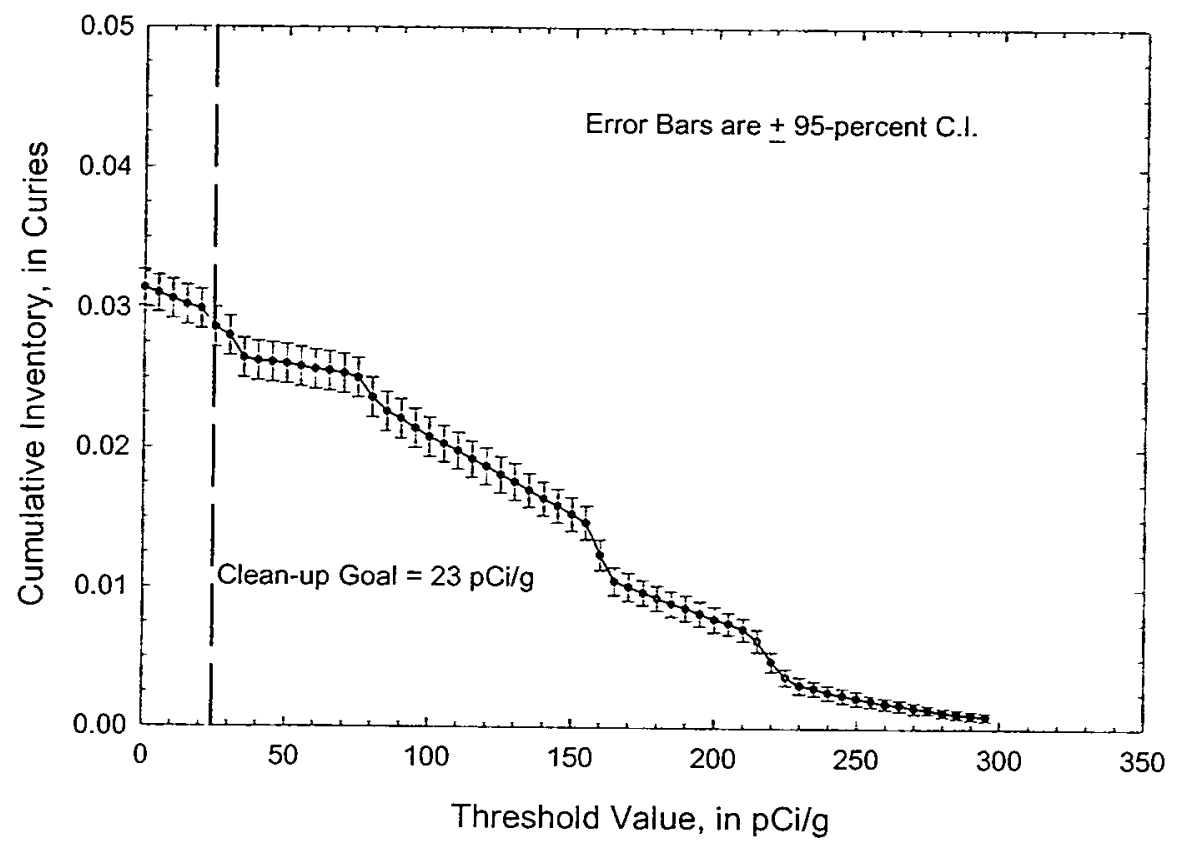

(b)

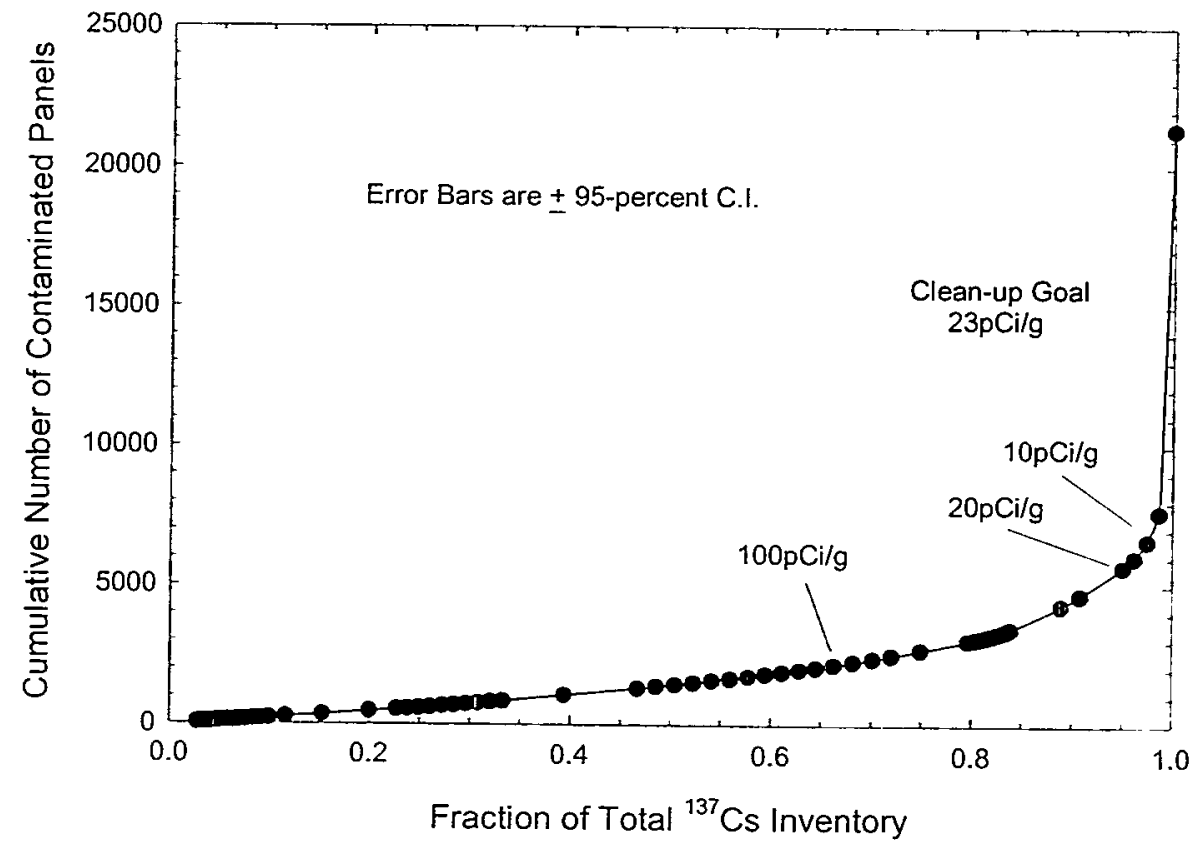

Figure 21. Estimates of total ${ }^{137} \mathrm{Cs}$ Inventory at the BNL Area $16 \mathrm{E}-1$ site. (a) Cumulative inventory as a function of threshold activity level. (b) Relationship between fractional inventory and number of contaminated $0.5-\mathrm{m} \times 0.5-\mathrm{m} \times 0.1524-\mathrm{m}$ panels as a function of threshold activity level. 
(a)
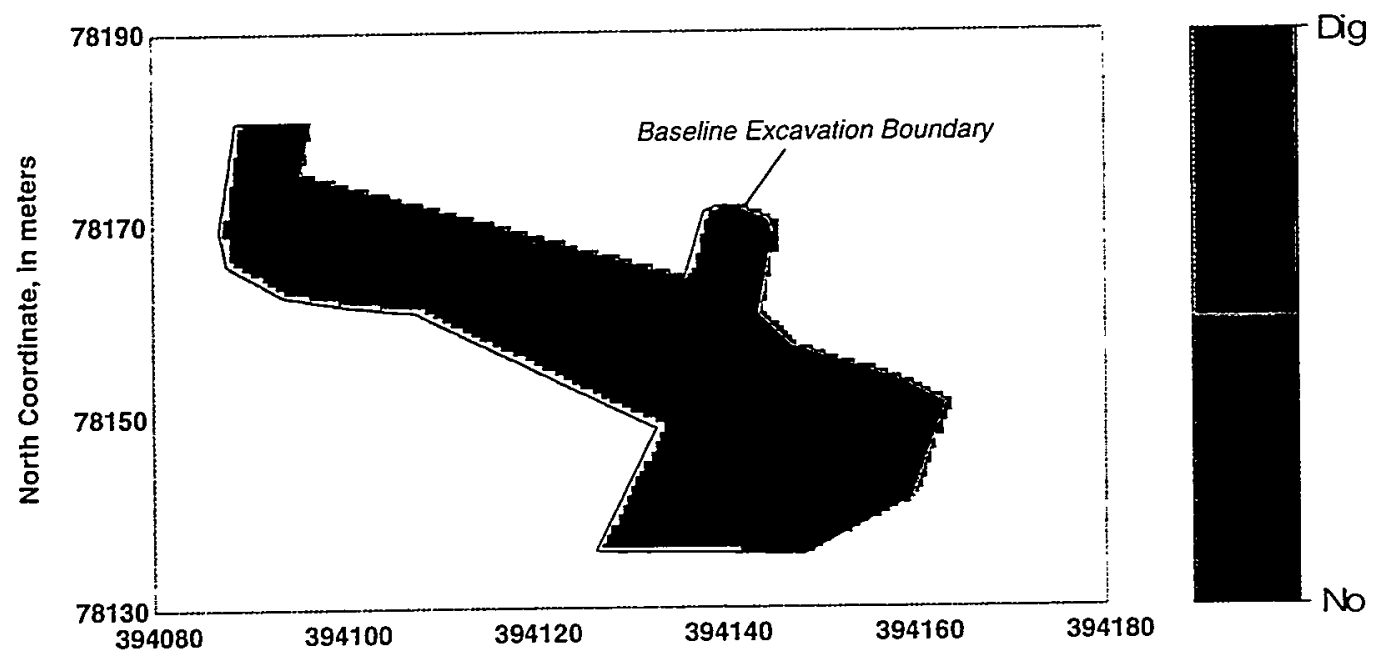

(b)
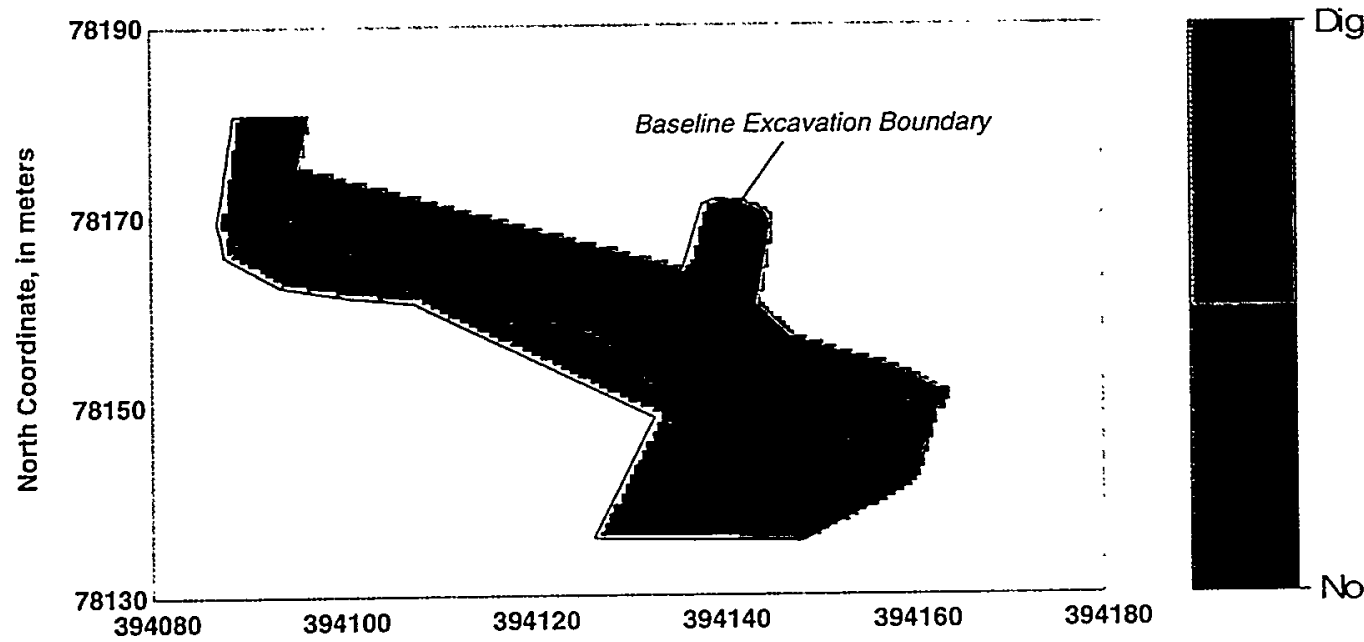

(c)
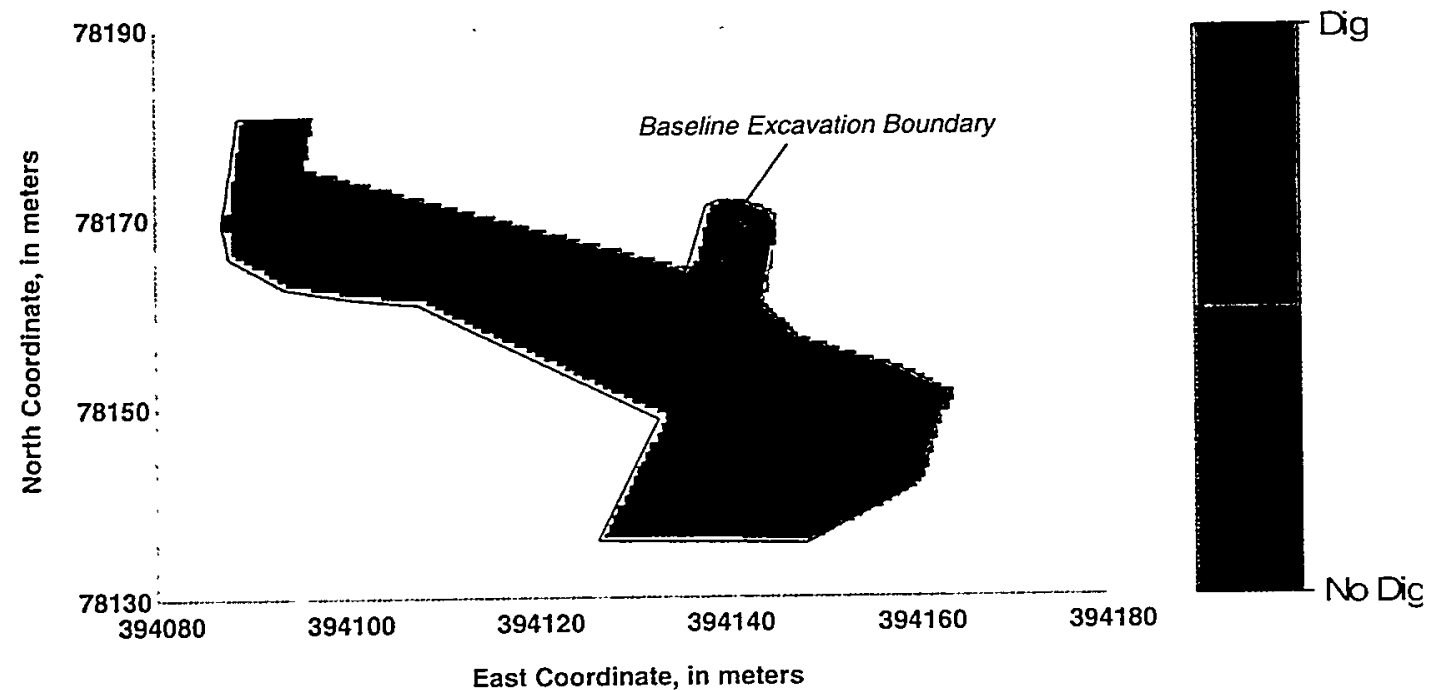

Figure 22. Excavation maps for BNL Area 16E-1, levels 1 (a), 2 (b), and 3 (c), generated using a reliability level of 0.95 . The map for level 4 is not presented; it is entirely blue. 


\section{Remarks Emphasizing the Segmented Gate Technology}

One of the objectives of this modeling exercise was to provide information relevant to determining whether the SGS technology could likely be deployed successfully at BNL. Examination simply of the measured data, specifically in histogram format (figs. 5 and 7), suggests that there is, in fact, a wide range of contaminant levels at the site that should be amenable to physical separation by the SGS system. This inference is supported by the results of the SmartSampling TM evaluation, particularly as represented in the probability map of figures 17(b) and 18(b) (likelihood of material in excess of $200 \mathrm{pCi} / \mathrm{g}$ ). Additional support is found in the total inventory data of figure 21(a) and (b). A large fraction of the total estimated inventory (perhaps 50 percent or more) is associated with modeling panels of high activity in excess of $150 \mathrm{pCi} / \mathrm{g}$ [fig. 21(a)]. Additionally, more than 2,000 of the $0.5-\mathrm{m} \times 0.5-\mathrm{m}$ by 6 -inch modeling panels can be identified as exhibiting activities exceeding $100 \mathrm{pCi} / \mathrm{g}$ [fig. 21(b)]. This diversity of contamination levels strongly suggests that separation of materials with differing activities should be possible with the SGS.

Additional insight into the likely successful deployment of the SGS at BNL may be obtained by examining the behavior of the modeled contamination on levels 1 and 2 . SmartSampling $^{\mathrm{TM}}$ is a probabilistic methodology. Although the available data indicate a strong probability of contamination throughout level 1 and for almost all of level 2 [figures 17(a) and 18(a)], it is instructive to examine the actual simulated distribution of contaminants on each of these levels.

We have extracted the grid nodes from levels 1 and 2 for a single simulation and for a composite of 20 different simulations. These results are presented in figure 23 . These histograms indicate that there is a nontrivial fraction of modeling panels on each of these levels that would appear to be below the action level of $23 \mathrm{pCi} / \mathrm{g}$. It is not possible to resolve precisely where these panels occur, because the activity of unsampled panels is uncertain, given the current extent of physical sampling. However, the SGS provides a means of determining the activity of specific lots of excavated soil materials in essentially real time during the excavation and shipping process. Thus it would appear that application of the SGS during excavation of materials on levels 1 and 2 of BNL Area 16E-1 would allow "live" determination of actual contaminant status, and thus enable additional volume reductions beyond that associated with the limited excavation of level 3 and non-excavation of level 4.

If we use the 20-simulation composite histograms of figure 23 (b) and (d) as a reasonable expectation of actual in-situ conditions and a more robust statistical estimate than that obtainable from a single simulation, it would appear that as much as approximately 25 -percent of level 1 soil and 60-percent of level 2 soils may, in fact, be below the action level of $23 \mathrm{pCi} / \mathrm{g}{ }^{137} \mathrm{Cs}$. These histograms also suggest the wide variety of contaminant magnitudes discussed above as a requirement for successful deployment of the SGS.

An approximation of where material that might benefit from this real-time characterization of contaminant magnitude is located may be obtained by "relaxing" the acceptable reliability level, and by comparing the additional area (volume) thus marked as likely to be "uncontaminated" with an excavation map generated for a more reasonable probability of failure. For example. figure 24 presents a potential "excavation map" for level 2 at a markedly higher lower reliability level -0.75 or 75 percent (corresponding to a probability of failure of 0.25 ). Compar- 

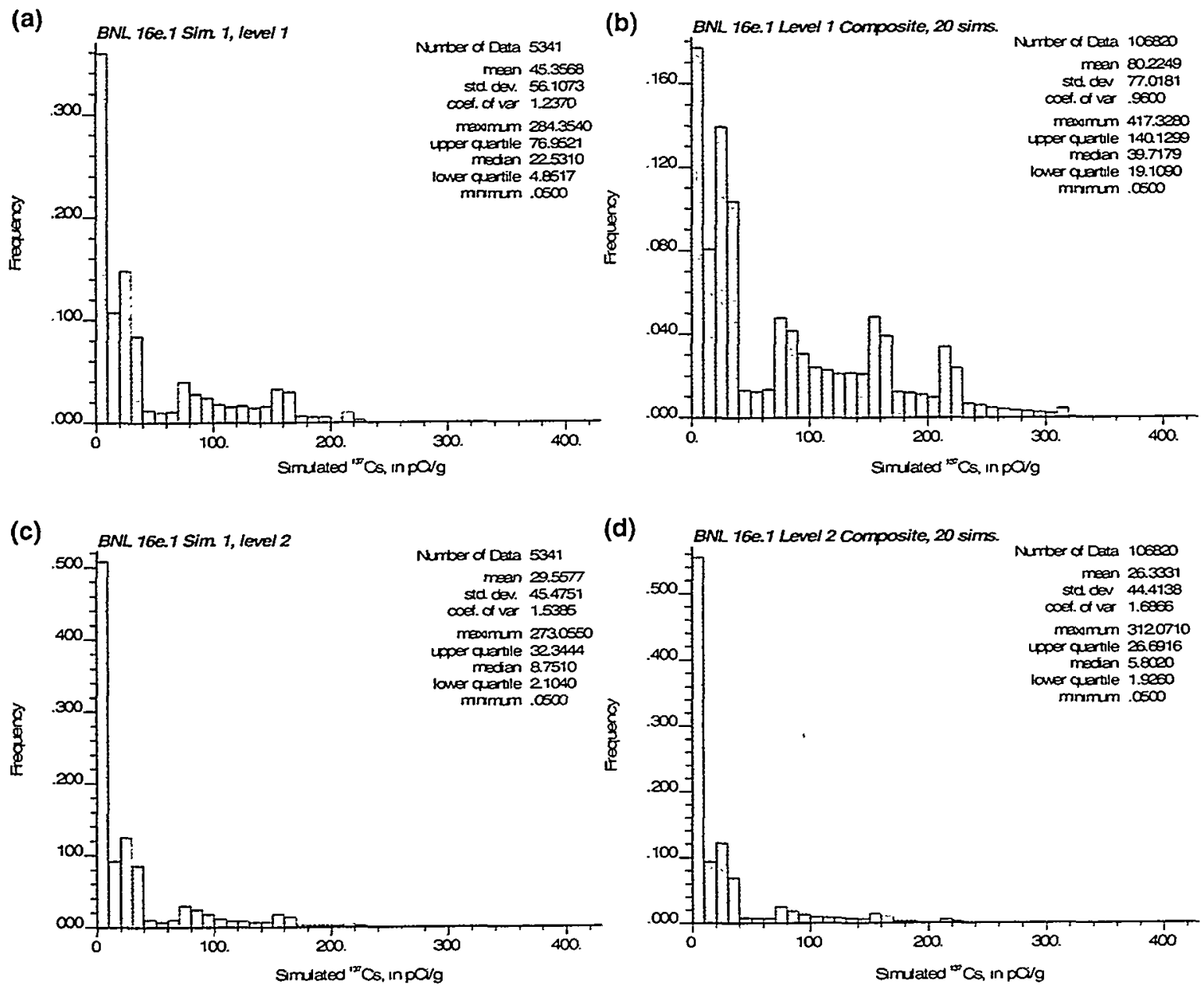

Figure 23. Histograms of simulated contaminant activities on levels 1 [(a), (b) and 2 (c), (d) of BNL Area $16 \mathrm{E}-1$ for both a single simulation (a), (c) and a composite of 20 simulations (b), (d).

ison of the blue ("do not excavate") region of figure 24 with the blue region on the corresponding excavation map of figure 22 (b), generated with a reliability level equal to 0.95 , indicates the material in question.

One important caveat, however, applies to this discussion of application of the SGS technology at BNL. Modeling of contaminant distributions has been conducted using relatively small volume elements: $0.5-\mathrm{m}$ by $0.5-\mathrm{m}$ by $0.1524-\mathrm{m}$, or approximately $0.05 \mathrm{yd}^{3}$. Although it might be possible to excavate soils at BNL in units of this size (the horizontal dimensions are approximately those of a backhoe bucket), it seems unlikely that the excavated material can be transported and processed in such small increments. It does seem important, particularly in light of the modest proportion of material that may be below threshold even on the "highly contaminated" levels 1 and 2, to practice selective excavation and processing, to the extent possible, and to avoid wholesale mixing of materials, especially during transport and stockpiling prior to processing by the SGS equipment. Whether such a selective approach is cost effective, of course, depends upon 


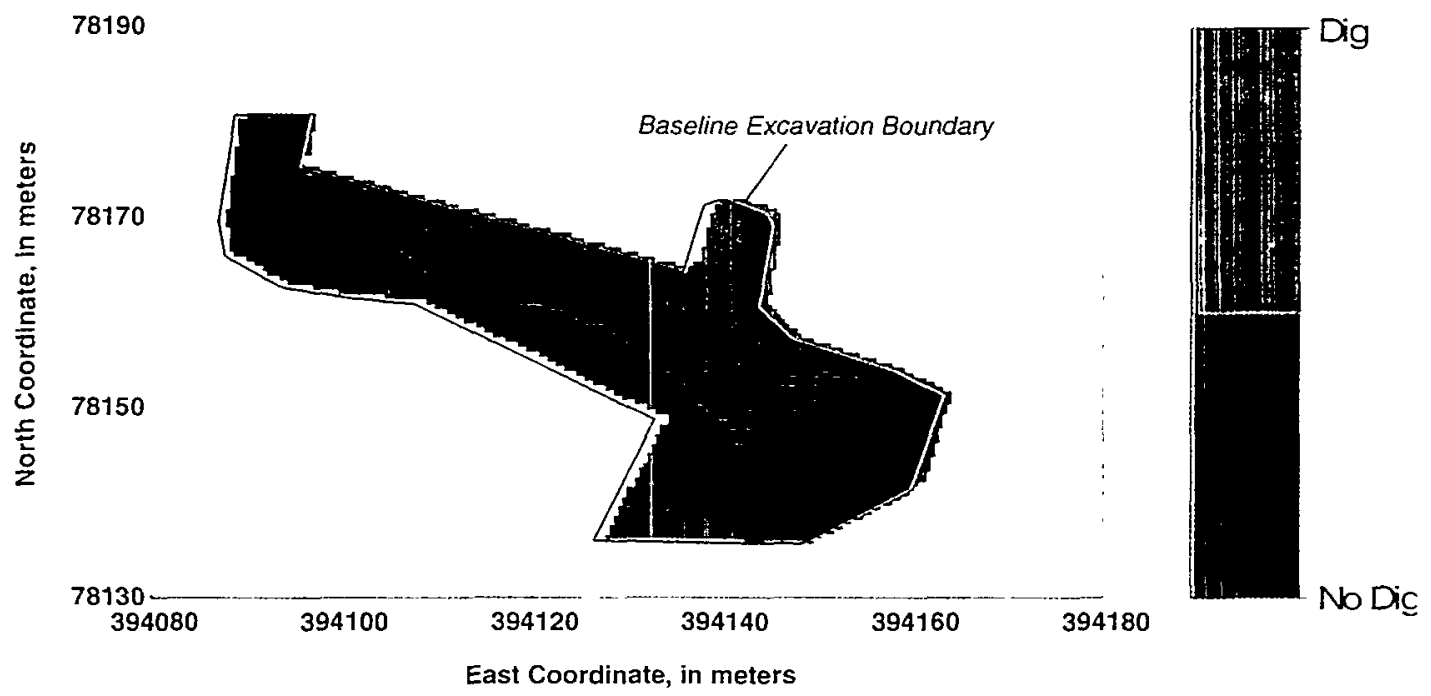

Figure 24. Excavation map for BNL Area 16E-1, level 2, generated using an acceptable reliability level of 0.75 (probability of failure $=0.25$ ). Compare to figure $22(\mathrm{~b}$ ).

the relative costs of excavating and maintaining the integrity of relatively small volumes of material vs. the cost of disposing of large volumes of mixed contaminated and uncontaminated (but collectively above threshold) contaminated soils. Such an analysis is beyond the scope of this report.

\section{References Cited}

Deutsch, C.V., and Journel, A.G., 1998, GSLIB geostatistical software library and user's guide, New York: Oxford University Press, 369 


\title{
Influence of Selective Excavation on Contaminated Soil Volumes at Area 16E-1, Brookhaven National Laboratory
}

\author{
Christopher A. Rautman \\ Sandia National Laboratories \\ Albuquerque, New Mexico 87185
}

\section{Summary}

We have conducted numerical experiments that document the importance of selective excavation to the remediation of the cesium-137 $\left({ }^{137} \mathrm{Cs}\right)$ contaminated landscape soils associated with Area of Concern 16E-1 at Brookhaven National Laboratory. These numerical experiments make use of detailed, small-scale geostatistical simulations of contaminant distributions at area $16 \mathrm{E}-1$, which show plausible spatial distributions of elevated ${ }^{137} \mathrm{Cs}$ values, consistent with characterization data consisting of 68 soil-profile samples to a depth of $2 \mathrm{ft}$ and 5,527 surficial radiometric measurements that have been obtained from the site.

The results of these numerical experiments, which involve the upscaling of the detailed geostatistical models to several, more operationally reasonable remediation panels, indicates that selective excavation of the site using either 6-inch or 1-foot depth increments results in approximately the same volume of contaminated soil above a threshold ${ }^{137} \mathrm{Cs}$ activity of $23 \mathrm{pCi} / \mathrm{g}$. This in situ volume is approximately $620-650 \mathrm{yd}^{3}$. However, excavation of the site using the full baseline depth increment of 2 feet nearly doubles the volume of contaminated soil that must be disposed of to some $1250 \mathrm{yd}^{3}$. The increased volume results from the presumed mixing with large volumes of essentially uncontaminated material from the 1- to 2 -ft depth interval where dilution by the uncontaminated material is not sufficient to lower the average activity below the relevant threshold activity.

\section{Introduction}

Previous modeling, directed toward evaluating the likelihood of successful deployment of the Segmented Gate System (SGS) at Brookhaven National Laboratory during the remediation of ${ }^{137} \mathrm{Cs}$ contaminated landscape soils using portions of the SmartSampling ${ }^{\mathrm{TM}}$ methodology, indicated a very small probability of encountering contaminated materials at depths greater than 1 foot at Area of Concern 16E-1. This supplemental analysis focuses on the consequences of moreor-less selective excavation of these contaminated soils (above $23 \mathrm{pCi} / \mathrm{g}{ }^{137} \mathrm{Cs}$ ) during remedial activities, and it emphasizes that poor selectivity during physical excavation may reduce or eliminate any potential volume reductions that might be obtained through application of the SGS technology.

The previous modeling generated 100 statistically indistinguishable geostatistical simulations of ${ }^{137} \mathrm{Cs}$ distribution at the Area $16 \mathrm{E}-1$ site, conditioned to 17 soil profiles, each consisting of samples at four discrete depths (a total of 68 measurements), and 5,527 surficial radiometric measurements. Simulated models were generated geostatistically using a $0.5-\mathrm{m} \times 0.5-\mathrm{m} \times 6$-inch grid spacing. Postprocessing of these 100 replicate stochastic realizations of contaminant distribu- 
tion indicated a very likely reduction of the contaminated volume from a baseline estimate of $1,064.7 \mathrm{yd}^{3}$ to approximately $550 \mathrm{yd}^{3}$. Most of this volume reduction would be obtained by not excavating the depth interval from 12 to 24 inches, for which the likelihood of exceeding $23 \mathrm{pCi} / \mathrm{g}$ is modeled to be generally less than 5 percent. Additional potential volume savings to be obtained largely by real-time characterization of the excavated materials using the SGS were indicated to possibly yield further volume reduction to approximately $290 \mathrm{yd}^{3}$.

\section{Methodology}

The current effort has focused on upscaling the detailed $0.5-\mathrm{m}$ by $0.5-\mathrm{m}$ by 6 -inch geostatistical models to reflect selective remediation units of more reasonable size for excavation by mechanical equipment. Accordingly, we have adopted an admittedly simplistic approach of averaging the detailed grid using first a 4-by-4 horizontal compositing scheme. which creates remediation panels $2-\mathrm{m}$ by $2-\mathrm{m}$ in size. Additionally, averaging has included several different depth increments. First, we consider retaining the 6 -inch depth discretization (yielding a $4 \times 4 \times 1$ pattern), then we consider a $1-\mathrm{ft}$ depth increment (yielding a $4 \times 4 \times 2$ pattern), and finally we consider taking the entire (baseline) 2-ft depth increment at a single pass (yielding a $4 \times 4 \times 4$ upscaling pattern). The same exercise has been repeated for an 8 -by -8 horizontal compositing scheme (remediation panels $4-\mathrm{m}$ by $4-\mathrm{m}$ in plan); both $8 \times 8 \times 2$ and $8 \times 8 \times 4$ schemes are presented. Upscaling is computed on a simulation-by-simulation basis so that the reasonably anticipated internal heterogeneity of ${ }^{137} \mathrm{Cs}$ is captured.

Note that because of a relatively simplistic implementation of the averaging process, the "excavation boundaries" provided originally by the baseline remediation plan may move outward from the original boundaries. This may include migration to include regions outside the physical limits of contamination (e.g., into a paved parking area). The initial geostatistical grid cells are simply processed four at a time (or eight at a time) in both the $\mathrm{x}$-and $\mathrm{y}$-coordinate directions (and by variable multiples in the vertical z-direction). Thus, if the original boundary fell within a new upscaled grid panel, the activities of all originally modeled cells were included in estimating the new, upscaled activity, even if some of those original cells were below the threshold value of 23 $\mathrm{pCi} / \mathrm{g}$, and even if some original cells were not modeled. This latter impact of cells not originally modeled influences the area/volume estimates; however, the average activity is based only on the values of those original cells that were modeled. Although a more sophisticated upscaling algorithm could be developed, the changes in contaminated volumes with progressive upscaling are sufficiently large that the major conclusions of this exercise are unlikely to change. "Spreading" of the excavation boundaries is even more pronounced for the $8 \times 8$ upscaling patterns than for the $4 \times 4$ patterns.

\section{Results}

Figure 1 shows excavation maps (at a 95-percent reliability level) for the top three levels of the detailed $0.5-\mathrm{m} \times 0.5-\mathrm{m} \times 6$-inch simulated models. These "excavation maps" represent the finest degree of selectivity using the current geostatistical models. Accordingly, the volume of contaminated soil represents the minimum in-situ volume marked for excavation and disposal at the 95 -percent reliability level, approximately $493 \mathrm{yd}^{3}$ at an average activity of $81.9 \mathrm{pCi} / \mathrm{g}$, for 
comparison with the less-selective, upscaled models described below. The average activity of the material not so marked for excavation is modeled as having an average activity less than $1 \mathrm{pCi} / \mathrm{g}$.

Figure 2 shows excavation maps (at the 95-percent reliability level) for the top three levels of the upscaled $4 \times 4 \times 1$ contaminant models. Each of the upscaled panels measures $2-\mathrm{m}$ by $2-\mathrm{m}$, and the panels are 6-inches thick. A total of 703 such panels, each with a volume of roughly 0.797 $\mathrm{yd}^{3}$, are modeled as containing average ${ }^{137} \mathrm{Cs}$ activities greater than $23 \mathrm{pCi} / \mathrm{g}$. The total volume of contaminated material that must be disposed of (presumably offsite) is approximately $561 \mathrm{yd}^{3}$. The excavation map for level 4 (18-24 inches) is not presented, as none of this material is indicated as more than 5 percent likely to be contaminated. The overall average activity of the 703 contaminated remediation panels is $79.2 \mathrm{pCi} / \mathrm{g}$. The average modeled activity of remediation panels not excavated under this upscaling scenario is less than $1 \mathrm{pCi} / \mathrm{g}$.

Figure 3 presents excavation maps for the two composite excavation models, where the depth-averaging is done in 12-inch increments (the $4 \times 4 \times 2$ models). This version of upscaling indicates that a total of 387 remediation panels, each measuring 2 -m by $2-\mathrm{m}$ by 12 -inch $(=1.595$ $\mathrm{yd}^{3}$ ), are above the threshold activity of $23 \mathrm{pCi} / \mathrm{g}$. The total volume of material above threshold is thus approximately $617 \mathrm{yd}^{3}$. The average activity of the 3871 - $\mathrm{ft}$ thick contaminated panels is 65.3 $\mathrm{pCi} / \mathrm{g}$. The average activity of remediation panels not excavated under this upscaling scenario is also less than $1 \mathrm{pCi} / \mathrm{g}$.

Figure 4 presents the single excavation map for the entire 2 -ft (24-inch) baseline thickness of Area $16 \mathrm{E}-1$. The averaging panels for this model are $2-\mathrm{m}$ by $2-\mathrm{m}$ by $24-\mathrm{inches}$ ( $4 \times 4 \times 4$ original grid cells). Because the 24-inch averaging thickness includes all of the material on levels 3 and 4 that is very unlikely to be contaminated, the number of contaminated panels remains roughly the same at 371 as for the $4 \times 4 \times 2$ upscaling model (each now $3.190 \mathrm{yd}^{3}$ in volume because of the increased depth increment), but the total volume represented by these panels increases markedly to roughly $1,183 \mathrm{yd}^{3}$. Dilution of material above cutoff in the upper two levels by uncontaminated material in the lower two levels is not able to reduce the number of "averagely" contaminated panels sufficiently to offset the increased total volume that results from including the deeper levels. The average activity of the 371 contaminated $2-\mathrm{ft}$ thick panels is $40.8 \mathrm{pCi} / \mathrm{g}$. The average activity of the unexcavated panels is approximately $5 \mathrm{pCi} / \mathrm{g}$.

Figure 5 presents the excavation maps for the even larger, 8 -by- 8 upscaled model $(8 \times 8 \times 2)$, where the baseline depth is taken in two separate 12 -inch increments. The total number of contaminated 4-m x 4-m x 1-ft panels (volume $=6.379 \mathrm{yd}^{3}$ each) is 117 , but these 117 panels constitute a total volume for disposal of $746 \mathrm{yd}^{3}$. Because the excavation maps appear generally very similar to those of figure 3 (the $4 \times 4 \times 2$ model), the increase in volume results essentially from spreading of the arbitrary $8 \times 8$ averaging (=excavation) boundaries. The average activity of the 117 contaminated remediation panels is $63.5 \mathrm{pCi} / \mathrm{g}$. The unexcavated panels remaining behind under this upscaling scenario exhibit an average modeled activity of just over $5 \mathrm{pCi} / \mathrm{g}$.

Finally, figure 6 presents the excavation maps for the $8 \times 8 \times 4$ upscaled model, where the thickness of excavation is taken as the full 24-inch baseline thickness. The number of contaminated panels for this scenario is 111 (each $12.758 \mathrm{yd}^{3}$ ), for a total volume of contaminated material of $1,416 \mathrm{yd}^{3}$. Again the spreading of the excavation boundaries is evident in the increased 
(a)

78190

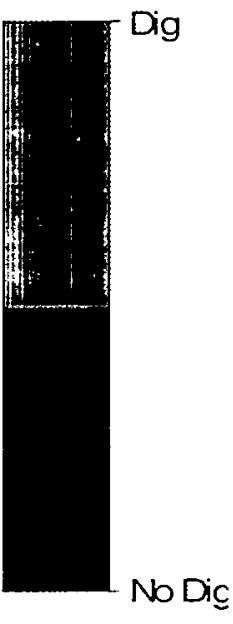

(b)
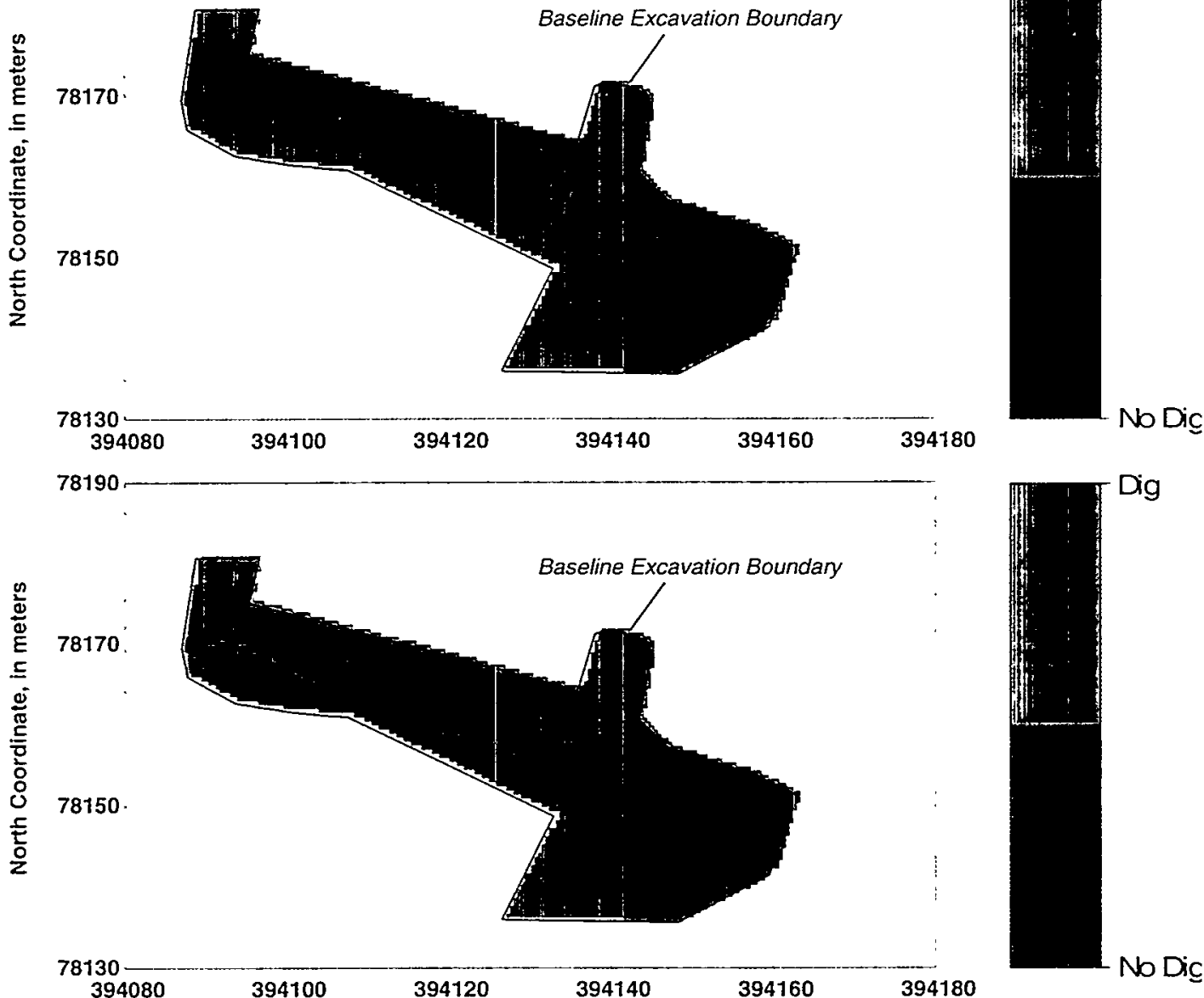

(c)

78190
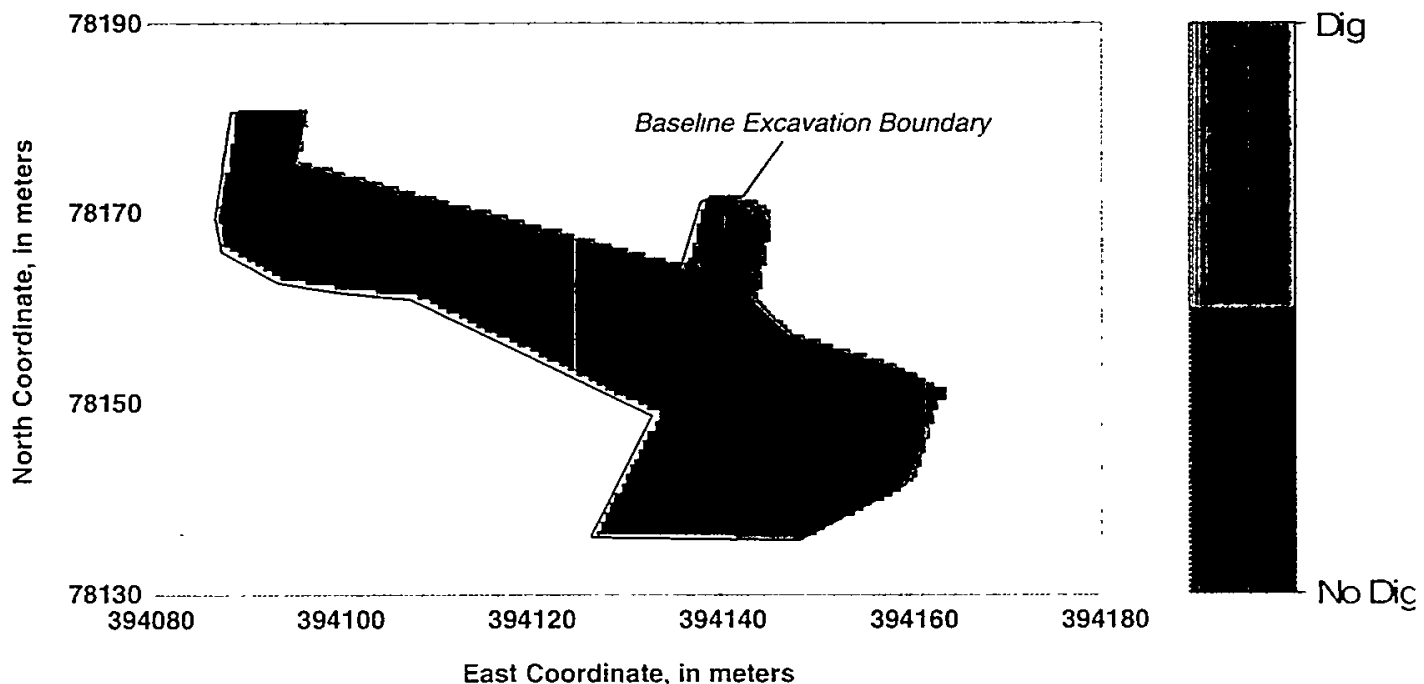

Figure 1. Excavation maps (red = dig) for levels 1 [image (a)], 2 [image (b)], and 3 [image (c)], for the $1 \times 1 \times 1$ non-upscaled models, 95 -percent reliability level. Upscaled level 4 is unexcavated in this model (entirely below $23 \mathrm{pCi} / \mathrm{g}$ ). 
(a)
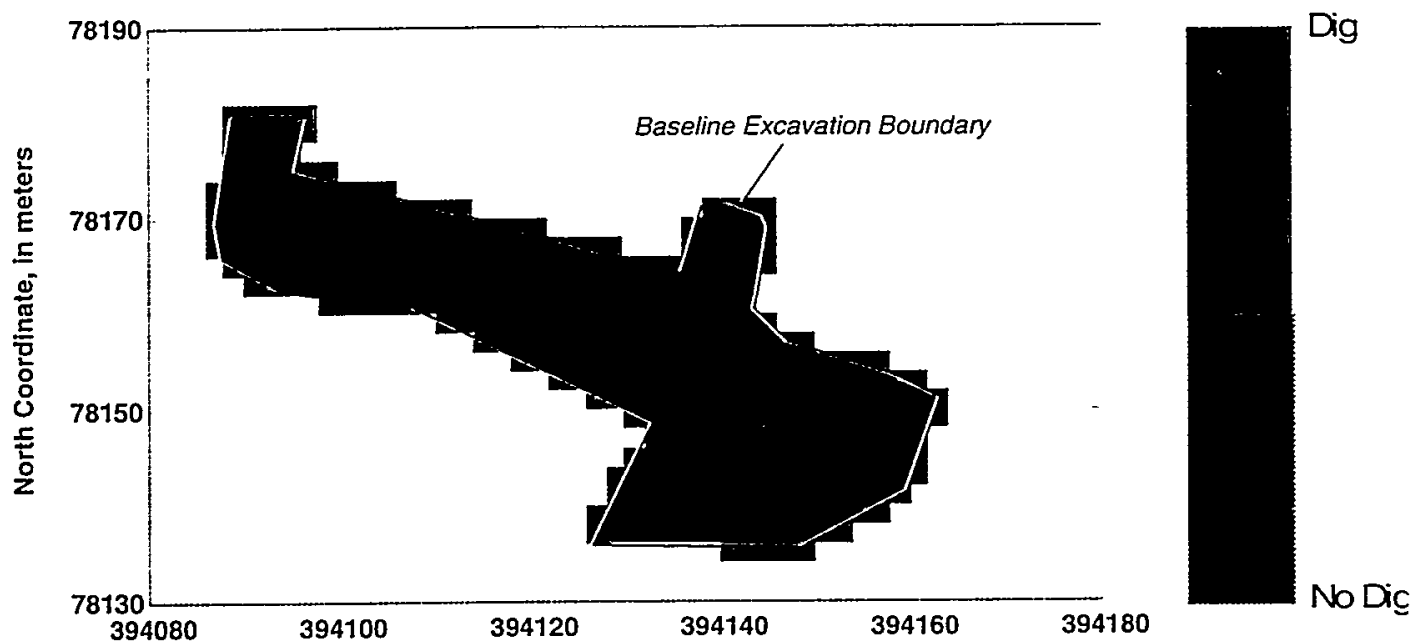

(b)

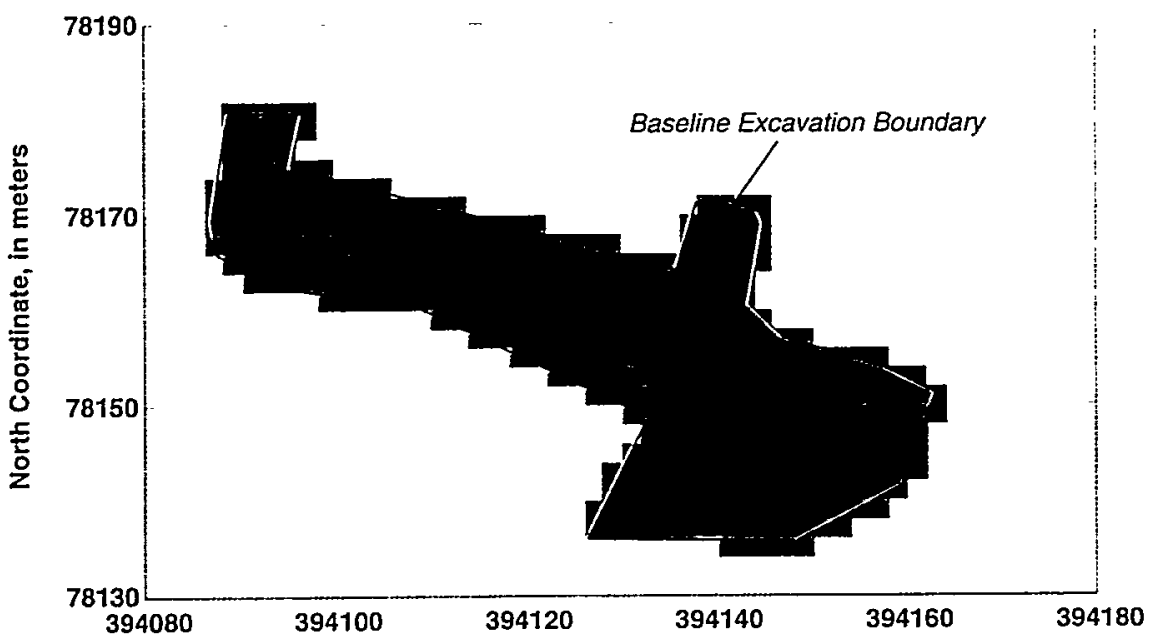

Dig

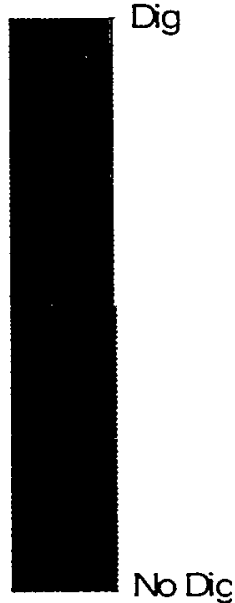

(c)
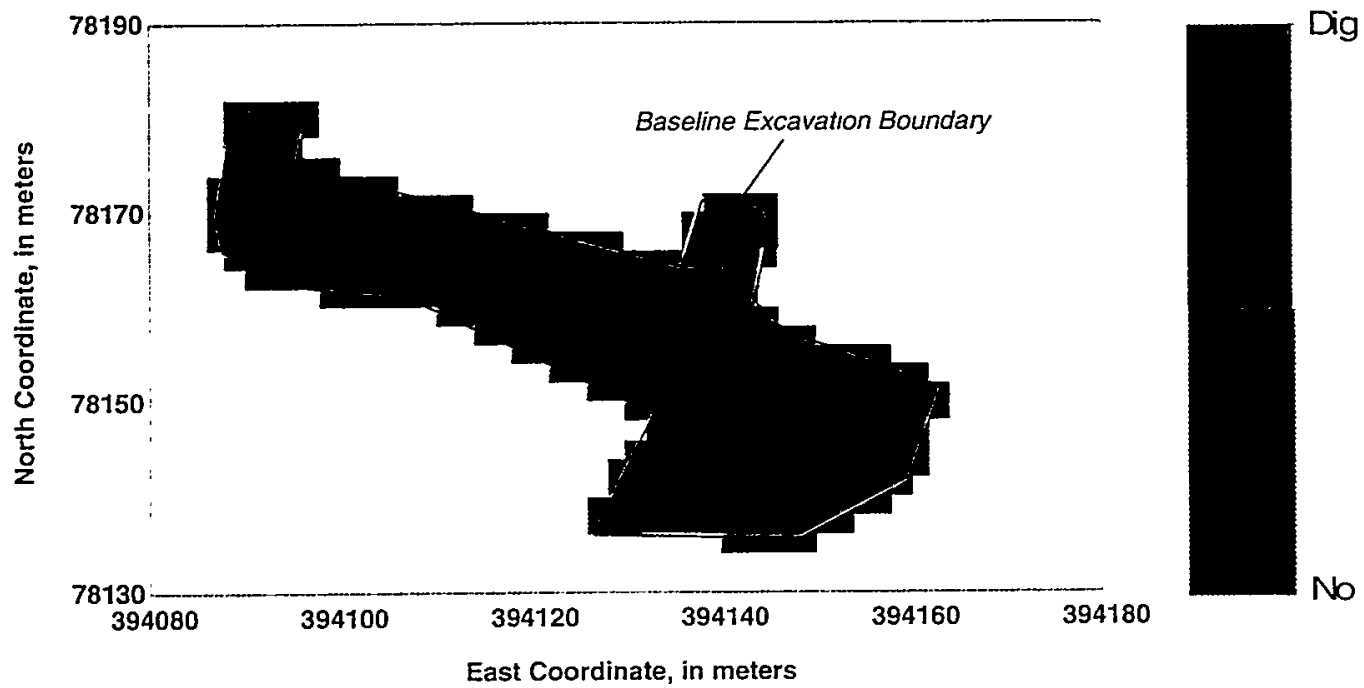

Dig

Figure 2. Excavation maps (red = dig) for levels 1 [image (a)], 2 [image (b)], and 3 [image (c)], for the $4 \times 4 \times 1$ upscaled models, 95 -percent reliability level. Upscaled level 4 is unexcavated in this model (entirely below $23 \mathrm{pCi} / \mathrm{g})$. 
(a)

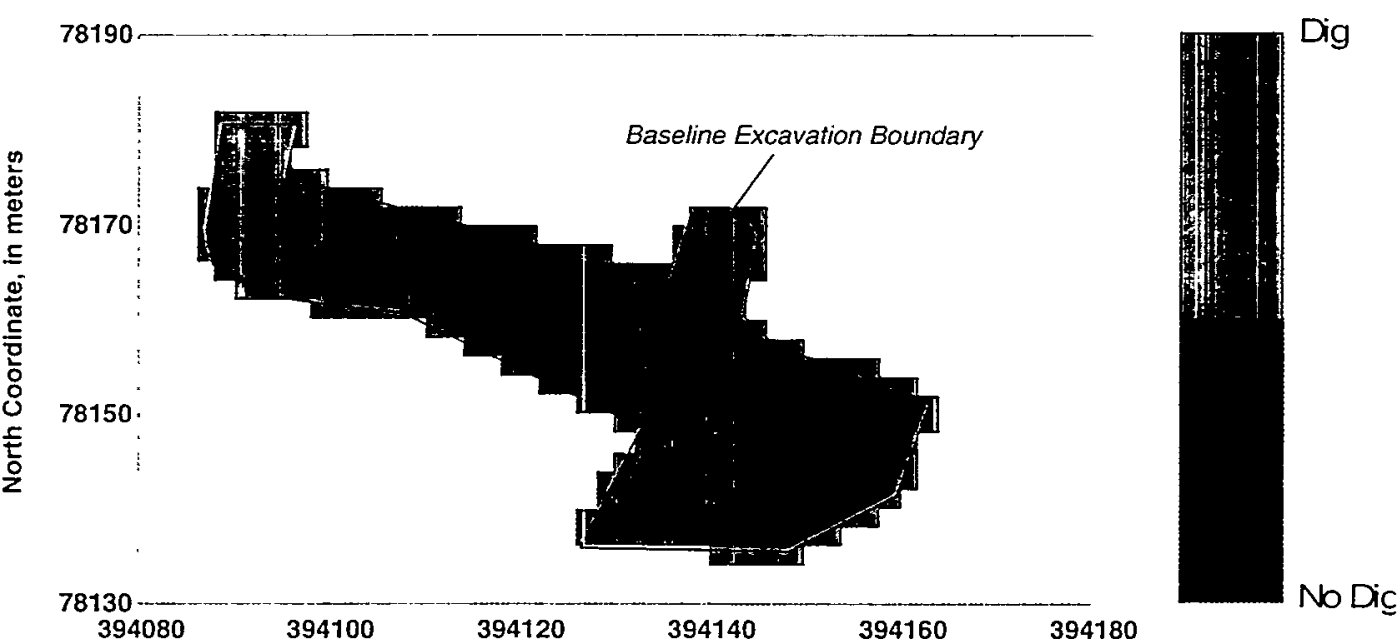

(b)

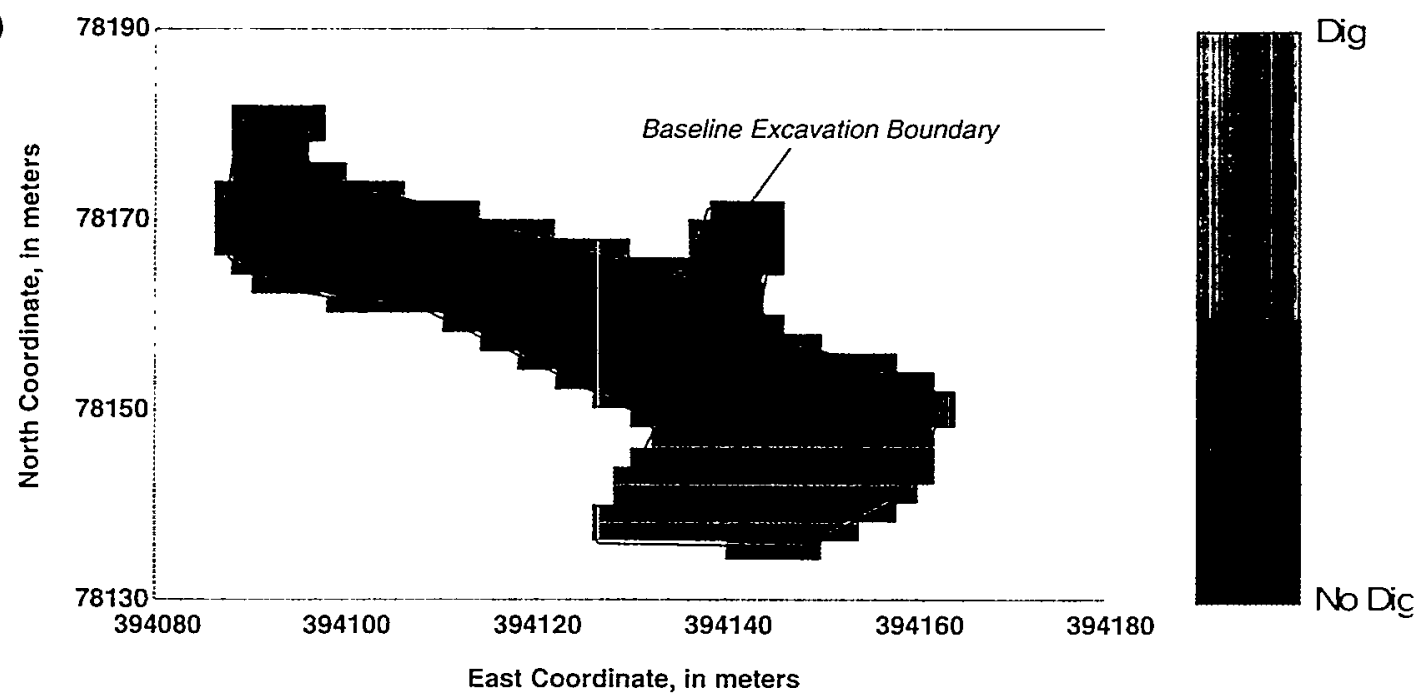

Figure 3. Excavation maps (red = dig) for levels 1-2 [image (a)] and 3-4 [image (b)] for the $4 \times 4 \times 2$ upscaled models, 95-percent reliability level. 


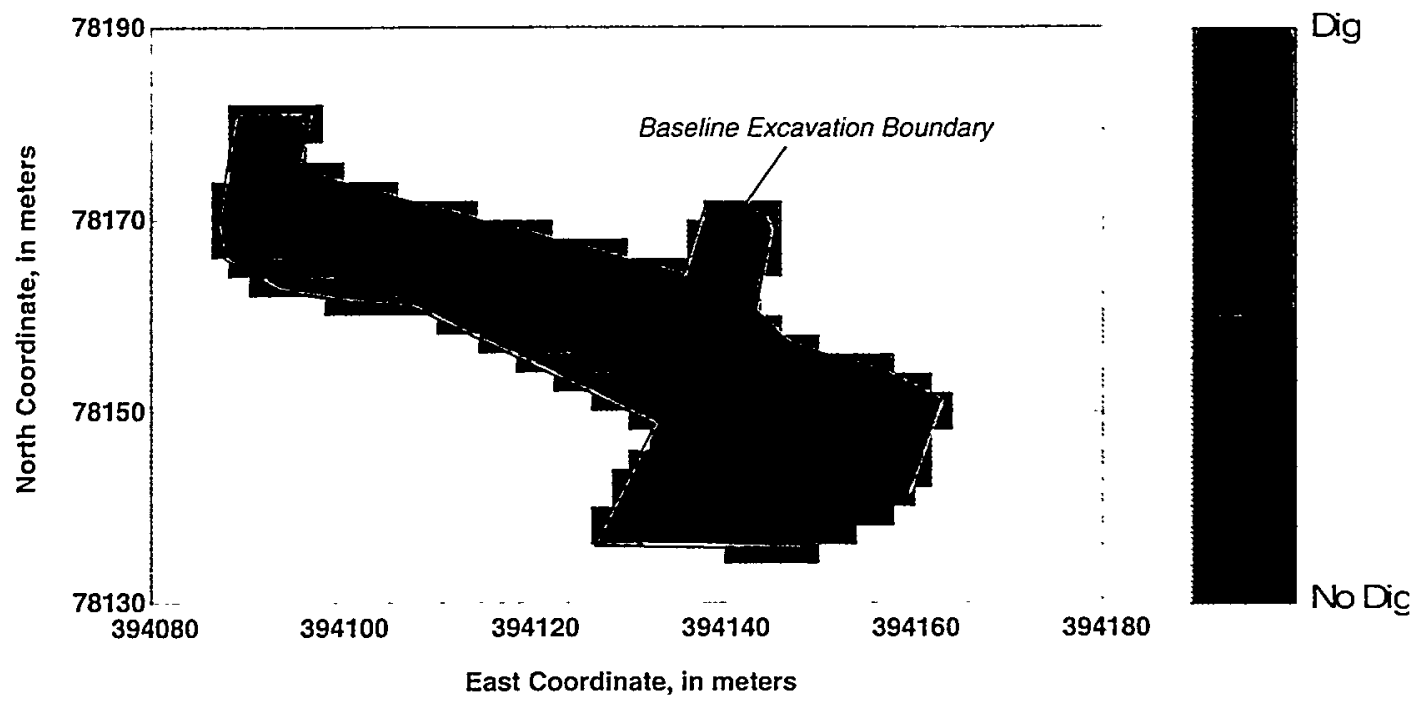

Figure 4. Excavation map (red = dig) for levels $1-4$ for the $4 \times 4 \times 4$ upscaled models, 95-percent reliability level.

volume estimate. The average activity level of the 111 panels thus marked for excavation at the 95 -percent reliability level is diluted down to $40.1 \mathrm{pCi} / \mathrm{g}$, whereas the average activity of the unexcavated panels remaining in situ is less than $6 \mathrm{pCi} / \mathrm{g}$.

\section{Discussion}

These numerical experiments clearly indicate the marked increase in volume of dilutedbut-still-contaminated material that will likely result from less-precise excavation at Brookhaven Area $16 \mathrm{E}-1$. This increase in volume is presented graphically in figure 7 , where each separate bar represents a different, progressively larger horizontal upscaling pattern and the different vertical components of each bar represent different vertical upscaling increments. The several selectiveexcavation volume estimates are compared to the baseline volume estimate, which corresponds simply to the baseline excavation boundary projected to a depth of 24 inches. A more comprehensive summary of the numerical upscaling experiments is presented in table 1.

The upscaling algorithm implemented for this analysis unquestionably represents a simplistic approach to design of an "excavation" plan. However, the conclusion is essentially inescapable that excavation -- if necessary -- of any soils in the 12-24-inch depth increment (levels 3 and 4) at this site should proceed separately from excavation of material in the 0-12-inch increment (levels 1 and 2). Some incremental volume reduction might result from excavating the very likely contaminated 0-6-inch increment separately from the underlying 6-12-inch increment, but these reductions may not be justified by the increased costs that would be associated with this finer level of selectivity. 
(a)

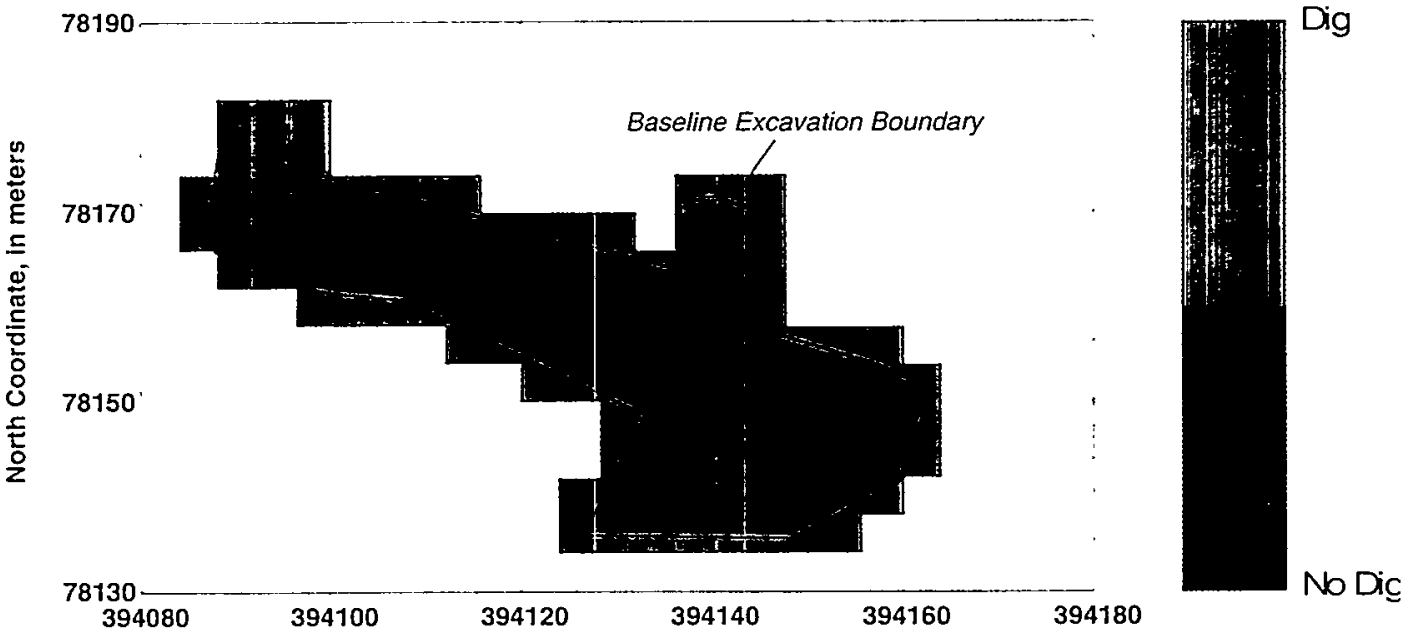

(b)
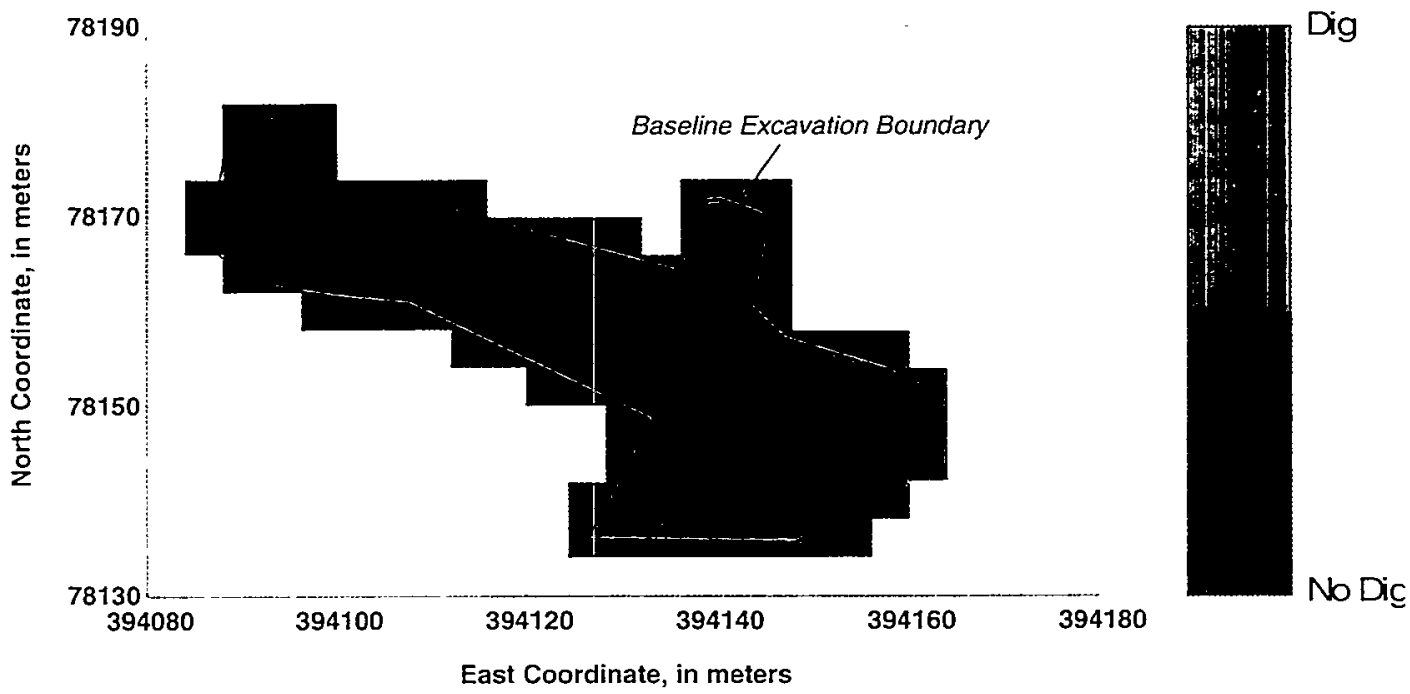

Figure 5. Excavation maps (red = dig) for levels $1-2$ [image (a)], and 3-4 [image (b)] for the $8 \times 8 \times 2$ upscaled models, 95-percent reliability level. 


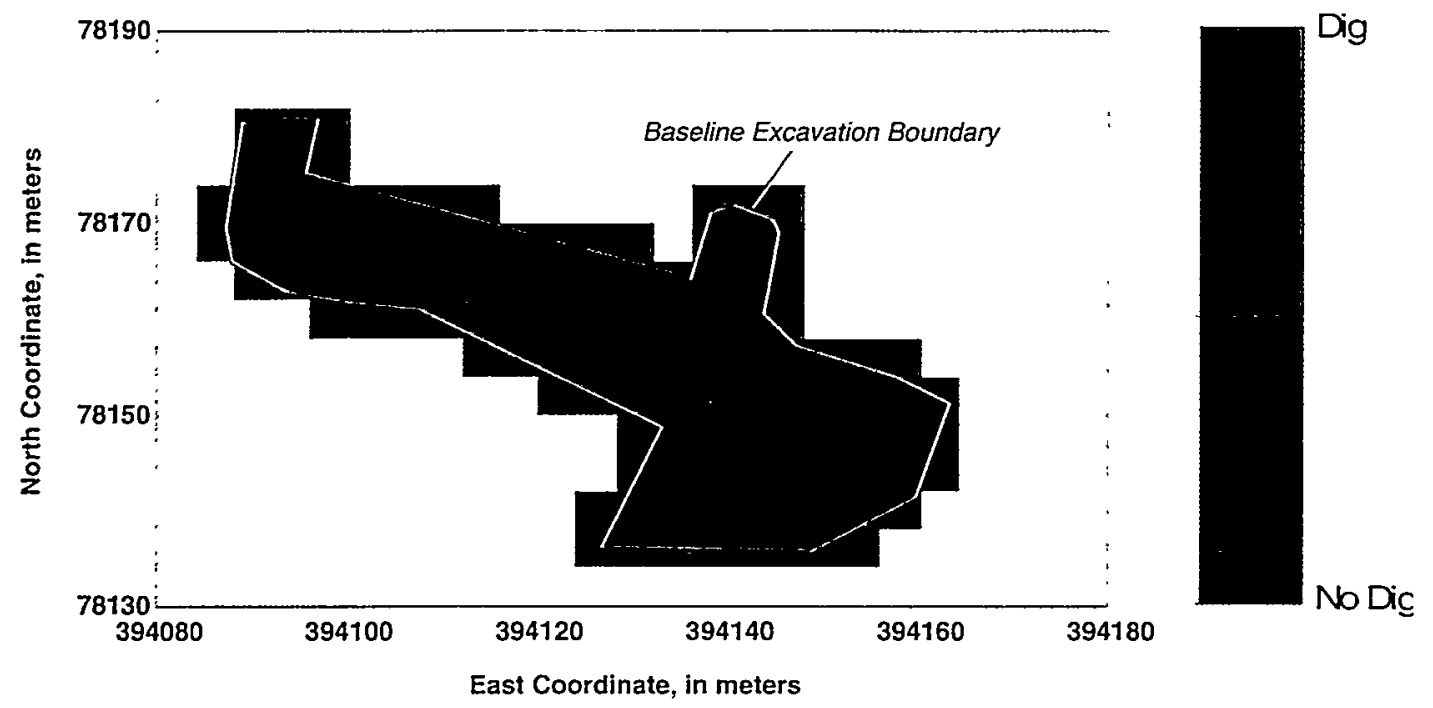

Figure 6. Excavation map (red $=\mathrm{dig}$ ) for levels $1-4$ for the $8 \times 8 \times 4$ upscaled models, 95 -percent reliability level.

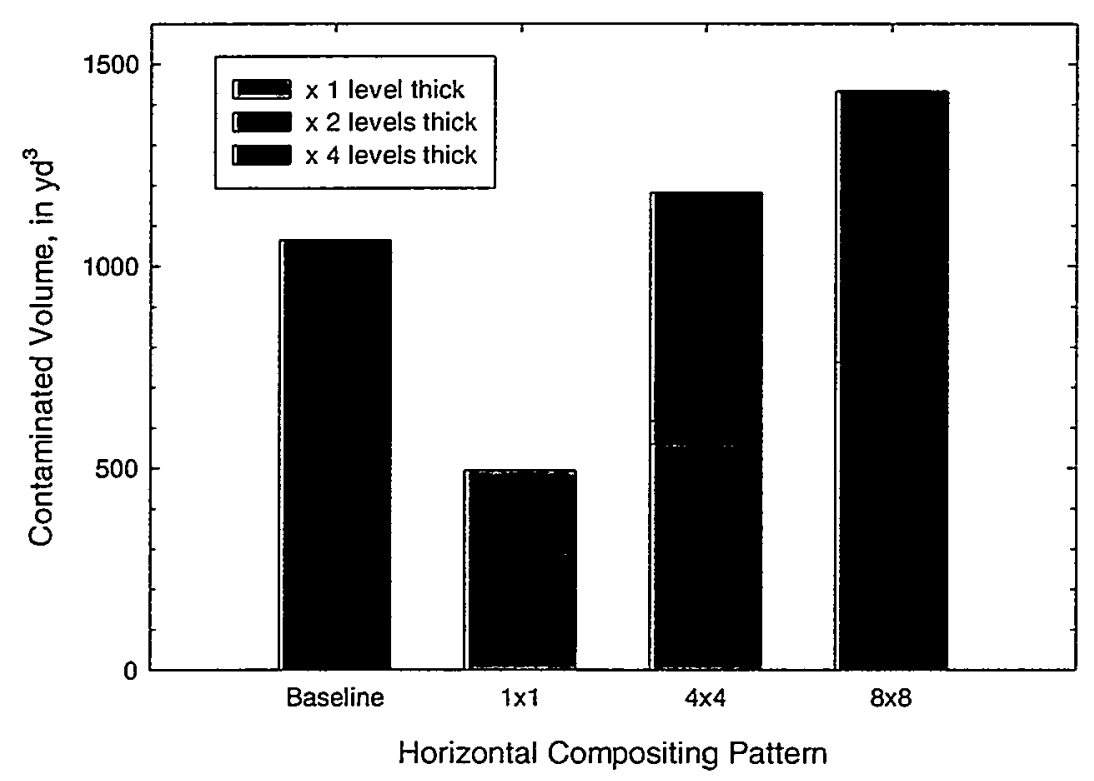

Figure 7. Contaminant volumes at different levels of selective excavation (degrees of upscaling), computed at a threshold ${ }^{137} \mathrm{Cs}$ activity of $23 \mathrm{pCi} / \mathrm{g}$ and at 95 -percent reliability. 
Table 1: Summary of Results for Numerical Upscaling Experiments

[all panel counts and volumes computed at the 95-percent reliability level]

\begin{tabular}{l|r|rrr|rr|}
\hline \multicolumn{1}{|c|}{ Upscaling Scheme: } & $1 \times 1 \times 1$ & $4 \times 4 \times 1$ & $4 \times 4 \times 2$ & $4 \times 4 \times 4$ & $8 \times 8 \times 2$ & $8 \times 8 \times 4$ \\
\hline Individual Panel Volume $\left(\mathrm{yd}^{3}\right)$ & 0.050 & 0.797 & 1.595 & 3.190 & 6.379 & 12.758 \\
Total No. of Panels & 21,364 & 1,552 & 1,552 & 1,552 & 118 & 118 \\
No. Contaminated Panels & 9894 & 703 & 387 & 371 & 117 & 111 \\
Contaminated Volume (yd $\left.{ }^{3}\right)$ & 493 & 561 & 617 & 1,183 & 746 & 1.416 \\
Avg. Activity Excavated (pCi/g) & 81.9 & 79.2 & 65.3 & 40.8 & 63.5 & 40.1 \\
Avg. Activity Remaining (pCi/g) & $<1.0$ & $<1.0$ & $<1.0$ & 4.7 & 5.2 & 5.6 \\
\hline
\end{tabular}

Note that the "averaging" that is contemplated in this set of numerical experiments presumes that mixing of material from within each selective remediation unit (of varying size) is essentially "complete." as represented by the simple arithmetic averaging process used in the numerical algorithm. Actual physical excavation (and subsequent transportation, stockpiling, and processing) of contaminated soils may not produce quite such complete mixing as is implied here. However, if the landscape soils are fairly sandy, internal mixing of the material to be processed by the SGS may be fairly thorough.

Note also that the volumes implicit in the 4-by-4 upscaling schemes (a maximum of 3.2 $\mathrm{yd}^{3}$ ) are fairly small relative to the $10-20 \mathrm{yd}^{3}$ estimates that have been discussed as "practical" excavation/transportation volumes. Even the soil volumes implied by the 8-by-8 upscaling schemes (a maximum of about $13 \mathrm{yd}^{3}$ ) are less than the upper limit of the supposed "practical" quantities.

Given that selective excavation increases costs, the hypothetical excavation schemes outlined in this report must be balanced by the changes in total volume of contaminated soil that is thus excavated and which must be disposed of. High per-cubic-yard disposal costs argue for more selective excavation, transportation, and stockpiling (and for more successful real-time separation using the SGS) than do lower per-yard disposal costs. The concern is that the multiple physical manipulations of the soil materials which lie between the in-situ estimates of contaminated vol ume and the input conveyor of the SGS may work to defeat the potential volume reductions that might otherwise be obtained by using the segmented gate technology. 


\section{DISTRIBUTION:}

Skip Chamberlain

U.S. Department of Energy

Headquarters, Germantown

19901 Germantown Road

Building Cloverleaf, Room 1160

Germantown, MD 20874-1290

U. S. Department of Energy

Albuquerque Operations Office

Pennsylvania \& H Street

Kirtland Air Force Base

Albuquerque, N.M. 87116

Lin Yarborough

Pamela Saxman, Bldg. 384-3

U. S. Department of Energy

Ohio Field Office

1 Mound Road

Miamisburg, $\mathrm{OH} 45342$

Doug Maynor

Oba Vincent

Art Kleinrath

Rick Provencer

James A. Wright

U. S. Department of Energy

Savannah River Site

BIdg. 703A, Rm. B-202

P. O. Box A-Rd. 1

Aiken, SC 29802

Anthony Armstrong

Oak Ridge National Laboratory

P. O. Box 2008, MS 6480

Oak Ridge, TN 37831-6480

Robert Johnson

Argonne National Laboratory

9700 S. Cass Avenue

Argonne, IL 60439
Chris Murray

Applied Geology \& Geochemistry

Pacific Northwest Natl Laboratory

P.O. Box 999, MS K-6-81

Richland, WA 99352

Maureen McGraw

Los Alamos National Laboratory

MS F649, EES-5: Geoanalysis

Los Alamos, NM 87545

Andrew Avel

235, USEPA Facilities

26 West Martin Luther King Drive

Cincinnati, OH 45268

Jeff VanEe

USEPA Natl. Exposure Research Lab

Environmental Sciences, Div/ORD Div

P. O. Box 93478

Las Vegas, NV 89193-3478

Evan Englund

USEPA National Exposure Res. Lab.

Environmental Sciences, Div/ORD Div

P. O. Box 93478

Las Vegas, NV 89193-3478

Tim Fischer

SRF-5J, USEPA Region 5

77 West Jackson Blvd.

Chicago, IL 60604-3507

Southwest District Office

Federal Facilities

401 E. Fifth Street

Dayton, OH 45402-2911

Graham Mitchell, 285-6018

Brian Nickel, 285-6468

Tom Schneider, 285-6466 
John Price

Washington Dept. of Ecology

P. O. Box 47600

Olympia, WA 985047600

Lane Butler

RF Env. Tech. Site, Rocky Flats

Golden, CO 80402-0928

John Lavoi

Babcock \& Wilcox

P. O. Box 66

Miamisburg, OH 45342

Jon Krueger

Babcock \& Wilcox

P. O. Box 66

Miamisburg, OH 45342
George Padilla

Navajo Superfund Program

P. O. Box 2946

Window Rock, NM 86515

Ann Sasahara

Navajo Superfund Program

P. O. Box 2946

Window Rock, NM 86515

Sandia Internal:

MS 0719 Tom Burford, 6131

MS 0719 Ray Patteson, 6131 (40)

MS 0735 Erik Webb, 6115

MS 0716 Paul Kaplan, 6805 (10)

MS 0735 Sean McKenna, 6115

MS 0755 Gary Brown,m 6233

MS 0755 Malcolm Siegel, 6233

MS 0748 Chris Atcitty, 6413

MS 0706 Chris Rautman, 6113 (5)

MS 9018 Central Tech., Files, 8940-2

MS 0899 Technical Library, 9616 (2)

MS 0612 Review and Approval

Desk,9612

For DOE/OSTI, (1) 